\title{
Title
}

\section{Human skeletal muscle organoids model fetal myogenesis and sustain uncommitted PAX7 myogenic progenitors.}

\section{Authors}

Lampros Mavrommatis ${ }^{1,2 *}$, Hyun-Woo Jeong ${ }^{3 *}$, Gemma Gomez-Giro ${ }^{2,4}$, Martin Stehling ${ }^{5}$, Marie-Cécile Kienitz $^{6}$, Olympia E. Psathaki ${ }^{2,7}$, M. Gabriele Bixel ${ }^{3}$, Gabriela Morosan-Puopolo ${ }^{1}$, Daniela Gerovska $^{8}$, Marcos J. Araúzo-Bravo ${ }^{8,9}$, Jens C. Schwamborn ${ }^{4}$, Hans R. Schöler ${ }^{2,10}$, Ralf H. Adams ${ }^{3,10}$, Matthias Vorgerd ${ }^{11,12}$, Beate Brand-Saberi ${ }^{1}$, Holm Zaehres ${ }^{1,2 *}$

1 Ruhr-University Bochum, Medical Faculty, Department of Anatomy and Molecular Embryology, 44801 Bochum, Germany

2 Max Planck Institute for Molecular Biomedicine, Department of Cell and Developmental Biology, 48149 Münster, Germany

3 Max Planck Institute for Molecular Biomedicine, Department of Tissue Morphogenesis, 48149 Münster, Germany

4 Luxembourg Centre for Systems Biomedicine, LCSB, Developmental and Cellular Biology, University of Luxembourg, 4367 Belvaux, Luxembourg

5 Max Planck Institute for Molecular Biomedicine, Flow Cytometry Unit, 48149 Münster, Germany

6 Ruhr-University Bochum, Medical Faculty, Department of Cellular Physiology, 44801 Bochum, Germany

7 Center for Cellular Nanoanalytics Osnabrück, CellNanOs, University of Osnabrück, 49076 Osnabrück, Germany

8 Computational Biology and Systems Biomedicine, Biodonostia Health Research Institute, San Sebastián 20014, Spain 9 IKERBASQUE, Basque Foundation for Science, Bilbao 48013, Spain

10 Westphalian Wilhelms-University Münster, Medical Faculty, 48149 Münster, Germany

11 Heimer Institute for Muscle Research, University Hospital Bergmannsheil, 44789 Bochum, Germany

12 Neurological Clinic Bergmannsheil, Ruhr-University Bochum, 44789 Bochum, Germany

* Correspondence: Lampros Mavrommatis (lampros.mavrommatis@rub.de); Hyun-Woo Jeong

(hyun-woo.jeong@mpi- muenster.mpg.de) for bioinformatics; Holm Zaehres (holm.zaehres@rub.de) 


\begin{abstract}
In vitro culture systems that structurally model human myogenesis and promote PAX7 myogenic progenitor maturation have not been established. Here we report that human skeletal muscle organoids can be differentiated from induced pluripotent stem cell lines to contain paraxial mesoderm and neuromesodermal progenitors and develop into organized structures reassembling neural plate border and dermomyotome. Culture conditions instigate neural lineage arrest and promote fetal hypaxial myogenesis towards limb axial anatomical identity, with generation of sustainable uncommitted PAX7 myogenic progenitors and fibroadipogenic (PDGFRa+) progenitor populations equivalent to those from the second trimester of human gestation. Single cell comparison to human fetal and adult myogenic progenitors reveals distinct molecular signatures for non-dividing myogenic progenitors in activated $\left(\mathrm{CD} 44^{\mathrm{High}} / \mathrm{CD}^{+} 8^{+} / \mathrm{MYOD}^{+}\right)$and dormant

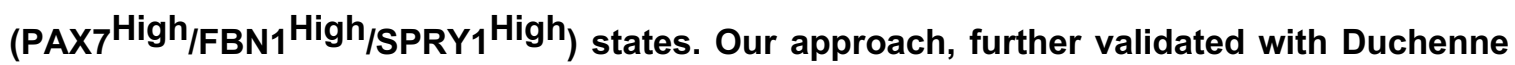
and CRISPR/Cas9 genome-edited Limb-girdle muscular dystrophy (LGMD2A) patient iPSC lines, provides a novel robust 3D in vitro developmental system for investigating muscle tissue morphogenesis and homeostasis.
\end{abstract}




\section{Introduction}

Novel skeletal muscle model systems are required to further elucidate the process of human myogenesis as well as investigate muscular disorders and potential gene, cell or drug therapies. Two-dimensional (2D) culture conditions guide pluripotent stem cell (PSC) differentiation towards skeletal muscle lineage using sequential growth factor applications and/or conditional PAX7 expression (Chal et al., 2015, Xi et al., 2017, Shelton et al., 2014, Borchin et al., 2013, Darabi et al., 2012). Further, surface marker expression can be utilized to isolate myogenic progenitors with in vivo repopulation potential (Magli et al., 2017, Hicks et al., 2018, Al Tanoury et al., 2020). While the few described three-dimensional (3D) differentiation approaches have provided cohorts of terminally differentiated myofibers, focus on potential interactions with the vasculature and nervous system has neglected assessment of the developmental identity or sustainability of myogenic progenitors (Faustino Martins et al., 2020, Maffioletti et al., 2018, Rao et al., 2018). Single cell technologies increasingly provide databases for deciphering myogenic trajectories and expression profiles of myogenic stem and progenitor cells (Xi et al., 2020, Barruet et al., 2020), enabling full evaluation of the ability of PSC differentiation protocols to mimic human development. Translation to model muscular dystrophies and investigate potential interventions in vitro necessitates methods that provide expandable populations of muscle progenitors while promoting self-renewal and preserving a quiescent, non-dividing, state (Quarta et al., 2016, Montarras et al.,2005).

Most vertebrate skeletal muscle progenitors develop from the paraxial mesoderm via transient embryonic developmental structures (somites and dermomyotome) into the skeletal muscle system that spans the whole body. Here, we evaluate human skeletal muscle organoids as a novel system to structurally investigate myogenic differentiation from human induced pluripotent stem cells (iPSCs) in a 3D environment, mimicking pathways described for chicken and mouse (Buckingham and Rigby, 2014). We develop a comprehensive supplementation/reduction protocol to first drive differentiation towards paraxial mesoderm through application of the GSK3 inhibitor CHIR99021, BMP inhibitor LDN193189 and bFGF. Subsequent stimulation with WNT1A, SHH, FGF and HGF is designed to promote derivation of organized structures reassembling neural plate border and dermomyotome. We then aim to arrest neural lineage via FGF removal, while stimulating with HGF to selectively promote propagation of undifferentiated myogenic progenitors and consequent generation of fetal myofibers. Our goal is to provide $\mathrm{PAX} 7^{+}$myogenic progenitors in a non-dividing quiescent state sustainable over weeks after differentiation induction. Single cell analysis will position cells along the quiescent-activation myogenic trajectory discriminating dormant (PAX7+, FBN1+, SPRY11+, CHODL1+) and activated (CD44+, CD98+, MYOD1+, VEGFA+) states. We thus seek to develop and validate a new skeletal muscle organoid system for investigating human myogenesis with translational potential for disease modeling and therapy development. 


\section{Results}

\section{Generation of human fetal skeletal muscle organoids}

Organoid cultures from pluripotent stem cells often require pre-patterning before Matrigel embedding to promote structural development (Lancaster et al., 2013; Spence et al., 2011; Koehler et al., 2017). In our 3D approach, we provided cells with immediate matrix support upon embryoid body formation to preserve cell state transitions. Initial pre- embedding screening indicated high expression of pluripotent markers OCT4, SOX2 and NANOG, moderate expression of neural tube marker PAX6 and low expression of mesodermal markers BRACHYURY and MSGN1 (Figure 1 figure supplement 1A). Upon Matrigel embedding, stimulation with CHIR99021, LDN193189 and bFGF promoted paraxial mesoderm formation through derivation of $\mathrm{BRACHYURY}^{+}$and $\mathrm{TBX}^{+}$ cells (Figures 1A,C - figure supplement 1A). Immunostaining at Day 5 depicted presence of mesodermal (BRACHYURY ${ }^{+}$), paraxial mesodermal $\left(\mathrm{TBX}^{+}\right)$and neuromesodermal $\left(\mathrm{SOX}^{+}{ }^{+}\right.$ BRACHYURY $^{+}$) progenitors (Gouti et al., 2017; Henrique et al., 2015) (Figure 1C). From this stage, we attempted to mimic determination front formation and promote anterior somitic mesoderm (ASM) (Aulehla and Pourquie,2010; Shimozono et al., 2013) by maintaining constant CHIR99021 and LDN193189 levels, reducing bFGF levels to $50 \%$ and simultaneously introducing retinoic acid to the culture. Consequently, distinct $\mathrm{PAX}^{+}$but SOX2${ }^{-}$cells emerged on the organoid surface (Figure 1D), followed by a significant downregulation of PSM markers HES7, TBX6 and MSGN1 (Figures 1E - figure supplement 1A). Concomitantly, we observed significant upregulation of ASM marker MEOX2 and neural crest marker TFAP2A but not of SOX2 or PAX6, excluding a shift towards neural tube formation (Figures 1E,F - figure supplement $1 \mathrm{~A}$ ). Up to this stage, interorganoid sizes showed small variability (Figure 1B). Dermomyotomal fate was promoted by Sonic Hedgehog $(\mathrm{SHH})$ and WNT1A stimulation, while maintaining BMP inhibition avoided lateral mesoderm formation (Figure 1A). Expression profiling at Day 11 depicted presence of neural tube/crest (SOX2, PAX6, TFAP2A, SOX10 upregulation) and mesodermal (UNCX, TBX18, PAX3) lineages and further downregulation of PSM markers (Figures 1E,F - figure supplement 1A). Notably, the dermomyotomal/neural crest marker PAX7 emerged together with markers that define the dorsomedial (EN1) or ventrolateral portion (SIM1) of the dermomyotome (Cheng et al., 2004) (Figures 1D,F - figure supplement 1A).

Consequently, for favoring myogenesis we stimulated organoid culture with FGF and HGF (Charge and Rudnicki, 2004) (Figure 1A). Surprisingly, at Day 17, organoids constituted a mosaic of neural crest and myogenic progenitor cells. Cells with epithelial morphology were TFAP $2 \mathrm{~A}^{+}, \mathrm{SOX}^{+}$, $\mathrm{PAX}^{+}$and $\mathrm{PAX}^{+}$, indicating formation of neural plate border epithelium (Roellig et al., 2017) (Figure 1G). In cell clusters with mesenchymal morphology, we detected specified migrating 
$\mathrm{PAX}^{+} / \mathrm{SOX} 10^{+}$neural crest progenitors and $\mathrm{PAX}^{+}{ }^{+} / \mathrm{SOX}^{-} / \mathrm{SOX} 10^{-}$cells of myogenic origin (Figure 1G). At this stage, myogenic lineages appeared to be primarily represented by PAX3 ${ }^{+}$ $(9.35 \pm 0.07 \%)$ rather than $\mathrm{PAX} 7^{+}$cells, as the $\mathrm{PAX} 7$ expression pattern $\left(15.3 \pm 0.1 \% \mathrm{PAX} 3^{+} / \mathrm{PAX} 7^{+}\right.$, $5.11 \pm 0.13 \% \mathrm{PAX}^{+}$) predominantly overlapped with that of SOX2 and TFAP2A (Figures 1G figure supplement 1B). Morphologically, neural plate boarder and dermomyotomal populations exhibited uneven distribution, and thereby subsequent neural crest and myogenic migration processes introduced organoid size variability (Figure 1B,G). From Day 17 onwards, we omitted FGF stimulation to cease neural crest development and promote delamination/migration of $\mathrm{PAX}^{+} /$ $\mathrm{PAX}^{+} / \mathrm{SOX}^{-} 0^{-}$progenitor cells (Murphy et al., 1994) (Figure 2A). Strikingly, until day 23, we observed committed myogenic populations through detection of fast MyHC myofibers in proximity of $\mathrm{PAX} 7^{+}$but SOX2 $2^{-} / \mathrm{TFAP} 2 \mathrm{~A}^{-} / \mathrm{SOX} 10^{-}$negative cells (Figures $1 \mathrm{H}$ - figure supplement 1C to E). Consistently, expression profiling indicated downregulation of neural tube/crest lineage markers and significant upregulation of muscle precursor migrating markers (Buckingham and Rigby, 2014), such as LBX1, CXCR4 and MEOX2 (Figures 1E, 2A and Figure2 - figure supplement $1 \mathrm{~A})$.

At 8 weeks, organoids showed profound changes in transcription profiling (Figure 2 - figure supplement 1B). Gene ontology enrichment analysis highlighted an ongoing developmental transition with muscle development, muscle contraction and myofibril assembly among the top upregulated gene ontology terms and neurogenesis and nervous system development among the top downregulated terms (Figure 2B). In addition, we detected downregulation of key markers characterizing neural tube and neural crest development (Soldatov et al., 2019), such as PAK3, DLX5, B3GAT1, FOXB1, HES5 and OLIG3 (Figure 2 - figure supplement 1C). Interestingly, we could spatially visualize this process using immunocytochemistry for SOX2, TFAP2A and SOX10 expressing cells that were restricted to the inner portion of the organoid, and probably not susceptible to culture stimulation at 5 weeks (Figures 1H, 2C,D and Figure 2 - figure supplement 1D). This neural / myogenic lineage spatial orientation could be visualized even at Day 84 through presence of $\mathrm{TUJ}^{+}{ }^{+}$neurons confined to inner organoid areas and close to $\mathrm{SOX}{ }^{+}$epithelium, while FastMyHC ${ }^{+}$myofibers occupied exterior areas (Figure 2E). On the other hand, substantial proportions of migratory cells in proximity of FastMyHC ${ }^{+}, \mathrm{MF}^{2} 0^{+}$myofibers expressed PAX7 $(40 \pm 0.3 \%)$ but not SOX2, TFAP2A, SOX10 or MYOD1 (3.55 $\pm 0.32 \%)$ (Figures 2F - figure supplement 1D,E). This behavior is further illustrated by the presence of MYOD $1^{+}$cells confined to organoid periphery (Figure 2D). 
Culture progression led to significant increase in PAX7 ${ }^{+}$and MYOD $1^{+}$cells at 8 weeks $(45.3 \pm 3,4 \%$ and $49.8 \pm 0.62 \%$, respectively) (Figures $2 \mathrm{~F}$ - figure supplement $1 \mathrm{E}$ ), suggesting an interval in which organoid culture predominantly commits to myogenic lineage. Expression profiling at this stage depicted upregulation of markers characteristic for limb migrating myogenic cells, e.g. LBX1, PAX7, SIX1/4, EYA1/4, PITX2, MYF5, TCF4 and MSX1 (Figure 2 - figure supplement 1A). Consequently, HOX gene cluster profiling at 4 weeks correlated HOX A9, B9, C9 upregulation with limb bud site, while upregulation of the HOX 10-13 cluster during 8 to16 weeks attributed later organoid development to a more distal limb axial anatomical identity (Shubin et al., 1997; Xu et al., 2011, Raines et al., 2015)' (Figure 2G).

\section{Lineage representation and developmental identity for skeletal muscle organoids}

Analysis of organoid culture at single cell resolution indicated predominant presence of skeletal muscle lineage ( $n=3945$ cells, $91.26 \%$ of total population), complemented with two smaller cell clusters of mesenchymal'ffibroadipogenic' ( $n=165$ cells, $3.82 \%$ of total population) and neural $(n=213$ cells, $4.93 \%$ of total population) origin (Figures 3 A - figure supplement 1A). Skeletal muscle lineages further separated into distinct sub-clusters: myogenic muscle progenitors in nondividing $\left(\mathrm{PAX} 7^{+} / \mathrm{PAX} 3^{-}\right)$and mitotic states $\left(\mathrm{PAX} 7^{+} / \mathrm{CDK} 1^{+} / \mathrm{KI} 167^{+}\right)$, myoblasts $\left(\mathrm{MYOD} 1^{+}\right)$, myocytes $\left(\mathrm{MYOG}^{+}\right)$and myotubes $\left(\mathrm{MYH}^{+}\right)$(Figures 3A - figure supplement 1A,B). Further, investigation of mesenchymal cluster identity suggested fibroadipogenic potential of a distinct cell population with PDGFRa among the top upregulated genes (Uezumi et al., 2010,2011; Xi et al., 2020) (Figure 3A,F - figure supplement 1A,B). Consistently, we detected upregulation of fibrotic markers. Moreover, adipogenic potential was highlighted through upregulation of PREF-1 and EBF2 (Figure 3F). Occasionally, we detected structures resembling adipocytes from 9 to10 weeks onwards, with adipogenic nature verified by PRDM16 and Oil red O positive staining (Figures 3B,D - figure supplement 1 C,D). A SOX ${ }^{+} /$TUBB $^{+}$positive neural cluster potentially derived from the neural plate border epithelium at younger stages could be located towards organoid interior (Figure $3 C$ - figure supplement $1 E)$.

Myogenesis progression based on $t$-SNE feature and Violin plots of key markers from each stage indicated gradual transitions from myogenic progenitor to myotube subclusters (Figures 3E - figure supplement 1F). MyHC expression profiling at single cell resolution demonstrated predominant presence of embryonic $\left(\mathrm{MYH}^{+}\right)$and perinatal $\left(\mathrm{MYH}^{+}\right)$myofibers, co-expressing $\beta$-Enolase and M-cadherin in vicinity of PAX $7^{+}$cells (Figure $3 \mathbf{G}-\mathbf{J}$ ). Consistently, we detected MCAM expression on muscle subclusters (Figue $\mathbf{3 G}$ ), while bulk RNA seq at 16 weeks highlighted expression of additional MyHC isoforms, e.g. MYH2 ( $\mathrm{Il}_{\mathrm{a}}$ ), MYH4(Ilb) and transcription factor NFIX (Moore et al., 
1993; Barbieri et al., 1990; Alexander et al. 2016; Messina et al., 2010). At more mature stages, we detected adult MYH1 or slow MYH7 isoforms (Figures 3 - figure supplement 1G), presumably due to myofiber stimulation via spontaneous contraction (Video S1, S2). In agreement, differential expression comparison between 8 and 16 week organoids indicated less variance in transcription profiling (Figures 3 - figure supplements 1H, 2A). Consistently, sarcomere organization, ion transport, response to stimulus and synapse structure maintenance were among the upregulated gene ontology terms and mitosis, cell cycle, DNA packaging and nuclear division among the top downregulated terms (Figures 3 - figure supplement 2B-D). Notably, ongoing maturation did not affect pool of progenitor cells, as even at 14 weeks we could report significant increases in PAX7 ${ }^{+}$ $(50,16 \pm 2.19 \%)$ and MYOD ${ }^{+}{ }^{+}(58.53 \pm 0.92 \%)$ cells (Figures $2 \mathrm{~F}$ and Figures 3 - figure supplement 2E,F).

\section{Functionality and maturation of organoid derived myofibers}

Regarding localization and functionality of organoid derived myofibers, immunocytochemistry revealed positive staining for dystrophin and a continuous laminin sheath around individual muscle fibers. Ultrastructure and 2- photon microscopy analysis depicted well developed sarcomeres (Figures 3 - figure supplement 3A-D). Moreover, patch clamp experiments, upon superfusion of cells with acetylcholine (ACh), indicated inward current generations that rapidly declined to a low steady state level (Figures 3K - figure supplement 3E). The I/V-curve of this current component showed almost linear behavior and reversal potential around $0 \mathrm{mV}$ (Figure $3 \mathrm{~L}$ ). These data are in line with previous studies that described currents with analogous properties as characteristic nAChR currents (Jahn et al., 2001; Shao et al., 1998). Application of a fluorescent biosensor for monitoring changes in cytosolic $\mathrm{Ca}^{2+}$ (Twitch2B) revealed $\mathrm{nAChR}$ efficiency in modulating intracellular $\left[\mathrm{Ca}^{2+}\right]$. Summarized FRET recordings (Figures $3 \mathbf{M}$ - figure supplement $3 \mathbf{F}$ ), following application of ACh $(10 \mu \mathrm{M})$, illustrated a rapid increase in FRET ratio that gradually declined in the presence of $\mathrm{ACh}$, probably reflecting desensitization of nAChRs. These results demonstrated that $\mathrm{nAChR}$ in skeletal muscle cells are functional in terms of inducing $\mathrm{Ca}^{2+}$ release from intracellular stores.

\section{Genome editing on LGMD2A patient line using CRISPR/Cas9}

Using our organoid protocol, we successfully derived fetal muscle progenitors and electrophysiologically functional myofibers from hiPSC lines with Duchenne Muscular Dystrophy and Limb Girdle Muscular Dystrophy (LGMD2A) genetic backgrounds (Figure $\mathbf{3}$ - figure supplement 3E,F). For the LGMD2A iPSC patient line, heterozygous for two mutations in neighboring exons (Figure 4A), we developed a new strategy for introducing biallelic modifications 
within the genome using the CRISPR/Cas9 genome editing technology to rescue patient mutations. This approach introduced a stringent selection of successful biallelic events based on fluorescent interrogation and drug administration. Consequently, the selection cassette system comprised two plasmids, one expressing under the constitutively active CAG promoter reverse Tetracycline Activator (rtTA) protein and another under the inducible TRE-CMV promoter tdTomato plus puromycin (Figure 4B). This generated a dependent loop between expression cassettes, ensuring that only upon integration of both plasmids red fluorescence could be detected. In addition, to ensure that both alleles are selection cassette free upon PiggyBac mediated excision removal, it was necessary that both plasmids expressed eGFP protein under a constitutively active promoter (Figure 4B). This strategy allowed us to simultaneously rescue LGMD2A patient mutations by deletion (intron skipping), insertion (EXON 4 deletion mutation) and base exchange (Exon3) in a single step (Figures 4C - figure supplement 1 A-D). Upon organoid differentiation we successfully derived PAX7 myogenic progenitor and FastMyHC myofibers (Figure 5E). Further investigation into LGMD2A lines highlighted differences in mitochondrial proteins such as TOM20, prolonged intracellular $\mathrm{Ca} 2+$ concentration upon activation with $\mathrm{ACh}$ and reduced SERCA2 expression for the patient LGMD2A line (Kramerova et al., 2009; Toral-Ojeda et al., 2016) (Figures 4F,G - figure supplement 1E,F).

\section{Identity and sustainability of organoid derived PAX7 myogenic progenitors}

Skeletal muscle organoids remarkably foster sustainable propagation of $\mathrm{PAX} 7^{+}$progenitors

(Figures $2 \mathrm{~F}, 3 \mathrm{~A}$ ). Initial screening of $\mathrm{PAX} 7^{+}$progenitors indicated expression of several satellite cell markers (Fukada et al., 2007), such as CD82, CAV1, FGFR1, FGFR4, EGFR, M-Cadherin, NCAM, FZD7, CXCR4, ITG $\beta 1$, ITGA7, SCD2 and SCD4 (Figure 5 - figure supplement 1A). Further investigation verified NOTCH signaling activity (HES1, HEYL, HEY1 and NRARP) in the myogenic subcluster, while dormant myogenic progenitors exhibited high expression of SPRY1 and cell cycle inhibitors p57 (CDKN1C), p21 and PMP22 (Xi et al., 2020; Fukada et al., 2007; Bjornson et al., 2012; Shea et al., 2010) (Figure 5 - figure supplements 1B, 2A,D). Moreover, proliferation assays performed at the same stage (14 weeks) demonstrated $4.78 \pm 0.28 \% \mathrm{edU}^{+}$ cells, while substantial proportions of $\mathrm{PAX}^{+}$myogenic progenitors remained quiescent (Figure 5 - figure supplements 1C,D). t-SNE clustering divided myogenic progenitors into three distinct groups with unique molecular signatures: "CD44 high", "FBN1 high" and "CDK1 ${ }^{\text {+" clusters (Figures }}$ 5A - figure supplements 2A). The "CD44high" cluster, further characterized by CD98 upregulation, adopted a molecular signature similar to activated satellite cell state (Porpiglia et al., 2017) (Figures 5A,B - figure supplement 2A,D). In this state, myogenic progenitors expressed VEGFA (Figure 5 - figure supplement 2A,D) as previously described for murine satellite cells 
(Verma et al., 2018). Consistently, the $\mathrm{CD} 44^{+} / \mathrm{PAX} 7^{+}$'activated' myogenic population located at sites more accessible to HGF signaling, e.g. exterior organoid areas and forming bulges (Figure 5B). The "FBN1High" sub-cluster was further characterized by "PAX7 $7^{\text {high / }}$ SPRY1 ${ }^{\text {high }} / \mathrm{CHODL}^{\text {high }} / \mathrm{FBN}_{1}{ }^{\text {high" }}$, expression (Figures $5 \mathrm{~A}$ - figure supplement 2A,D). PAX7 $7^{\text {high }}$ cells within the dormant state co-expressed NOTCH3, JAG1 and LNFG, together with $\mathrm{CHODL}$ markers. Further, we verified presence of $\mathrm{FBN} 1^{+}$microfibrils, which, compared to $\mathrm{CD} 44^{+}$ cells, occupied areas without direct access to activation signals (Figure 4C). Lastly, the "CDK1 ${ }^{+"}$ cluster was the only proliferative population, further expressing markers mediating satellite cell activation and proliferation, such as DEK and EZH2 (Cheung et al., 2012; Juan et al., 2011) (Figures 5A,D - figure supplements 1A, 2A,B).

Pseudotemporal ordering of myogenic progenitors indicated that the "FBN1 ${ }^{H i g h}$ " subcluster was the main progenitor population residing in dormant state, which by downregulating PAX7, FBN1 and CHODL and upregulating CD44, MYOD1, CD98 (SLC3A2) and VEGF generated activated state (Figures 5D - figure supplement 2B). In activated state, myogenic progenitors that upregulate MYOD1 entered mitosis, proliferated and followed a trajectory leading to myogenic commitment (Figures 5D - figure supplement 2B,D). This commitment was further accompanied by PARD3, p38a MAPK and CD9 expression (Porpiglia et al., 2017; Troy et al., 2012) (Figure 5E). Conversely, myogenic progenitors that upregulated NOTCH3, SPRY1 and PAX7 followed a loop trajectory that reinstated dormant stem cell state (Figures 5D - figure supplement 2B,D). Interestingly, the "FBN1 1 high" cluster highly expressed extracellular matrix collagens, e.g. COL4A1, COL4A2, COL5A1, COL5A2, COL5A3 and COL15A1. Notably, such expression declined upon commitment and differentiation (Figures 5D,F - figure supplement 2C).

Organoid derived myogenic progenitor comparison to human fetal and adult progenitor/stem cells

To evaluate developmental identity of the myogenic cluster, we isolated ITG $\beta 1^{+}$/ CXCR $4^{+}$ organoid derived myogenic progenitors via FACS (Garcia et al., 2018) and compared to human fetal muscle progenitors, demonstrating high similarity (Pearson's correlation co-efficiency, rho=0.9), with myogenic markers such as PAX7, MYF5, MYOG and MYOD1 at comparable expression levels (Figure 5 - figure supplement $\mathbf{3 A}$ - F). Differential expression comparison verified expression of extracellular matrix collagens and proteins, such as COL4A1, COL5A1, COL6A1, COL15A1, FBN1 and CHODL, in myogenic progenitors similar to $17^{\text {th }}$ week human fetal tissue (Pearson's correlation co-efficiency, rho=0.97) (Figure 5G). Further, to evaluate myogenic potency in vitro, isolated ITG $\beta 1^{+}$/ CXCR4 ${ }^{+}$organoid derived myogenic progenitor cells were re- 
plated and allowed to differentiate under the same organoid culture protocol, which demonstrated capacity to generate FastMyHC+ and PAX7+ populations within 10 days (Figure 5 - figure supplement 3B,C). Subsequently, comparison to available transcriptomic dataset of human adult satellite cells at single cell resolution, divided myogenic progenitors and adult satellite cells into four clusters with distinct molecular signatures (Figure $\mathbf{5 H}$ ). Interestingly, myogenic progenitors were enriched for extracellular matrix proteins, while satellite cells mainly upregulated genes repressing transcription/translation, such as ZFP36 and TSC22D1, or related to early activation response, such as MYF5, JUN and FOS (Figure 5 - figure supplement 4A,B). In line, organoid derived myogenic progenitors exhibited higher NOTCH signaling activity in comparison to satellite cells, with $\mathrm{NOTCH} 3$ and RBPJ being among enriched markers (Figure $5 \mathbf{J}$ ). In contrast, adult satellite cells exhibited PAX7 $7^{\text {low } / M Y F 5}{ }^{\text {high }}$ expression profiling, presumably due to tissue dissociation, thereby indicating a tendency for activation rather than preservation or reinstatement of quiescency (Machado et al., 2017; Seale et al., 2000) (Figure 5I). Pseudotime ordering showed two distinct clusters, with adult satellite cells downstream from non-dividing myogenic progenitors (Figure 5 figure supplement $4 \mathrm{C}$ ). Consistently, downregulation of genes promoting quiescence like PAX7, NOTCH3 and RBP, and upregulation of activation genes like MYF5, JUN and FOS along the trajectory (Figure 5 - figure supplement 4D) was a further indication that organoid derived myogenic progenitors resided in dormant non-dividing state and that our organoid platform promoted sustainability of myogenic progenitors.

Organoid derived myogenic progenitors exhibited expression profiling similar to that of Stage 4 myogenic progenitors, correlating to $17-18^{\text {th }}$ week human fetal development, as recently reported in the human skeletal muscle atlas (Xi et al., 2020). SPRY1, PLAGL1, POU4F1, TCF4, PAX7, CD82 and CD44 markers, as well as ECM proteins, nuclear factor I family members (NFIA, NFIB, $\mathrm{NFIC)}$ and $\mathrm{NOTCH}$ signaling are specifically upregulated markers. Furthermore, in comparison to 2D culture protocols, our organoid approach preserved myogenic progenitor dormancy without activating MYOD1 and exhibited higher expression of ECM proteins and key markers characterizing Stage 4 fetal myogenic progenitors (Figure 5 - figure supplement 5). ERBB3 and NGFR markers (Hicks et al., 2017) demarcate populations of earlier developmental stages and were not upregulated either in organoid derived or Stage 4 fetal myogenic progenitors (Figure 5 figure supplement 5). In addition, organoid myogenic progenitors and Stage 4 fetal myogenic progenitors both downregulated cycling genes like MKI67, TOP2A, EZH2 and PCNA (Figure 5 figure supplement 5 ). 


\section{Discussion}

Human skeletal muscle organoids offer a new cell culture system to study human myogenesis, in particular fetal myogenic progenitors. We demonstrate that modulation of Matrigel embedded embryonic bodies with WNT, BMP and FGF signaling at early stages leads to paraxial mesoderm formation (Figure 1B). Further, under guided differentiation, we could promote concomitant development of neural and paraxial mesodermal lineages and derive mesodermal populations with somitic and dermomyotomal origin (Figure 1C - F). With WNT1A and SHH stimulation, neural lineage is directed towards dorsal neural tube / crest development which benchmarks the structural recapitulation of neural plate border epithelium (Figure 1G). In vitro neural plate border can be utilized to assess transcriptomic networks and cell fate decision during human neural crest formation.

Delaminating from the dermomyotome, undifferentiated PAX3 progenitor cells reorientate and align in the cranio- caudal axis to form the underlying myotome or completely detach from the dermomyotome and migrate into the surrounding mesenchyme at the limb sites, where they propagate and become committed to skeletal muscle progenitors (Relaix et al., 2005). By stimulating organoid culture at the neural plate border/dermomyotomal stage with bFGF/HGF we could further visualize both migration of myogenic progenitors and migration/specification of neural crest populations (Figures 1A,G, H, 2A). Further, by omitting FGF during organoid development, we could detect a continuous upregulation of genes involved in the myogenic migration process, such as LBX1, PAX3, PAX7 and CXCR4, but not in genes characterizing neural tube or neural crest development, such as SOX10, TFAP2A, PAK3, DLX5, B3GAT1, FOXB1, HES5 and OLIG3. This indicates that organoid culture conditions and specifically stimulation with HGF favored skeletal muscle over neural lineage (Figures 2C-E). Interestingly, we could show that by stimulating organoid culture with SF/HGF, an essential signal for detachment and subsequent migration, but not for specification of the cells at the lateral lip of the dermomyotome (Dietrich et al., 1999), we could preserve the PAX3+/PAX7+ myogenic migratory population in an undifferentiated and uncommitted state (Figure 2D,E). Strikingly, expression profiling based on HOX gene cluster supported this notion, as over time the organoid culture adopted more distal than proximal limb axial anatomical identify (Figure 2F).

Fetal development is characterized by PAX3+ to PAX7+ myogenic progenitor transition (Seale et al., 2000; Relaix et al., 2005), which we were able to demonstrate in our organoid culture. Our data further support organoid culture representing fetal stages as we could detect NFIX upregulation and verify presence of myofibers expressing fetal MyHC isoform as well as NCAM, M-Cad or MCAM in the proximity of PAX7 progenitors (Figure $3 \mathbf{G}$ to $\mathbf{J}$ ). Consequently, transcriptome comparison indicated high similarity to human fetal muscle tissue (17-week, Pearson correlation, rho=0.9) (Figure 5G), as well as expression of several satellite cell markers (Figure $\mathbf{5}$ - figure 
supplement 1A). This was further verified by comparison to a single cell dataset from the human skeletal muscle cell atlas (Figure 5 - figure supplement 4, 5). Interestingly, single cell resolution showed adult satellite cell clusters with organoid derived myogenic progenitors (Figure $\mathbf{5 H}$ ). In addition, pseudotime ordering indicated that organoid derived myogenic progenitors reside developmentally upstream of activated satellite cells, upregulating markers associated with quiescence such as NOTCH signaling and extracellular matrix proteins (Figures 5E,F,J - figure supplement 4C,D). Preservation of myogenic progenitors in a non-dividing state without activating MYOD1 and self-renewal (Figures 5D-F - figure supplement 1C,D) appeared to be responsible for the observed sustainable propagation of PAX7 progenitor cells (Figures 2F, 3A). In comparison to our 3D protocol patterning in described 2D protocols (Shelton et al., 2014, Chal et al. 2015, Xi et al. 2017) is accompanied by upregulation of the committed myogenic marker MYOD1 (Figure 5 - figure supplement 5) which could explain rapid progenitor decline in 2D protocols. Single-cell RNA sequencing profiles an organoid-derived 'uncommitted' Pax7 progenitor population 12 weeks post differentiation (Figure $\mathbf{5} \mathbf{A}, \mathbf{H}$ ).

In addition, we could observe high expression of extracellular matrix proteins and upregulated NOTCH signaling in dormant non-dividing myogenic progenitors (Figure $\mathbf{5 F}, \mathbf{J}$ ). This phenotype is similarly described for human fetal tissue myogenic progenitors (Figure 5G, Pearson correlation, rho $=0.97$, figure supplement 5 ). Studies evaluating engraftment potential of satellite cells and fetal muscle progenitors propose that muscle stem cells in a quiescent non- committed state exhibit enhanced engraftment potential (Hicks et al., 2017; Quarta et al., 2016; Montarras et al., 2005; Tierney et al., 2016). Our data demonstrate that upon activation and commitment dormant myogenic progenitors downregulate extracellular matrix proteins and upregulate expression of morphogens / receptors that make them susceptible to signals, like VEGFA that communicates with vasculature during tissue reconstitution, or CD9, CD44, CD98 participating in cellular activation (Porpiglia et al., 2017) (Figure 5D - figure supplement 2B,D). It would be of interest for future studies to investigate whether increased engraftment can be achieved in 3D protocols (Faustino Martins et al., 2020; ours) versus 2D protocols patterned progenitor cells and to which degree this is attributed to high expression of extracellular matrix proteins. In particular, high Fibrillin1 expression on dormant non-dividing myogenic progenitors could potentially contribute to avoidance of fibrosis by myogenic progenitors through regulation of TGF- $\beta$ signaling (Cohn et al., 2007).

Different phases of human fetal myogenesis have been modelled with $2 \mathrm{D}$ differentiation protocols (Shelton et al., 2014, Chal et al. 2015, Xi et al. 2017). Our 3D differentiation protocol does not go beyond these protocols when it comes to provide maturated physiologically responsive skeletal muscle cells, which we illustrate with the electrophysiological recording of organoid-derived cells of six different origins (DMD and LGMD muscular dystrophy lines and healthy control iPSC-derived) (Figure 3 K,L,M; Figure 3 - figure Supplement 3 E,F). Structural distinctions like the posterior 
paraxial mesoderm at day 5 , specified neural crest dermomytome at day 17 , myogenic progenitor migration at day 23 and neural crest lineage arrest at day 35 (Figure $1 \mathbf{C}-\mathbf{H}$, Figure 2 C) cannot be similarily observed in 2D protocols. In addition, our 3D organoid protocol provides myogenic progenitors in dormant and activated states for at least 14 weeks in culture. We demonstrate that, in contrast to 2D protocols, organoid culture sustains uncommitted MyoD1-negative, Pax7-positive myogenic progenitors as well as fibroadipogenic (PDGFRa+) progenitors, both resembling their fetal counterpart. This supply of muscle progenitors preserved in a quiescent state indicates translative potential of the approach. Future work will elucidate signaling transduction pathways during skeletal muscle organoid development to model and understand human myogenesis in more detail. 


\section{Materials and Methods}

\section{hiPSCs culture}

Human induced pluripotent stem cell (hiPSC) lines, Cord Blood iPSC (CB CD34 ${ }^{+}$, passage $15-$ 35), LGMD2A patient iPSC (passage 5-25), Isogenic LGMD2A Exon 3-4 edited (passage 2-13), Duchenne Muscle Dystrophy iPSC patient line iPSCORE_65_1 (WiCell, cat.no. WB60393, passage 22-30) and DMD_iPS1 (passage 21-30) \& BMD_iPS1 (passage 17-25) (Boston Children's Hospital Stem Cell Core Facility) (Dorn et al., 2015; Park et al., 2008; Panopoulos et al., 2017) were cultured in TESR-E8 (StemCell Technologies) on Matrigel GFR (Corning) coated 6 well plates. CB CD34 ${ }^{+}$and LGMDA2 hiPSC lines were generated using the SFFV promotor - OSKM vector as described in Dorn et al., 2015. LGMD2A patient material was collected at the University Hospital Bergmannsheil after ethical approval from the ethics commission of the Ruhr-University Bochum, Medical Faculty (15-5401, 08/2015).

\section{Human skeletal muscle organoid differentiation protocol}

Prior differentiation, undifferentiated human PSCs, 60-70\% confluent, were enzymatically detached and dissociated into single cells using TrypLE Select (ThermoFisher Scientific). Embryoid bodies

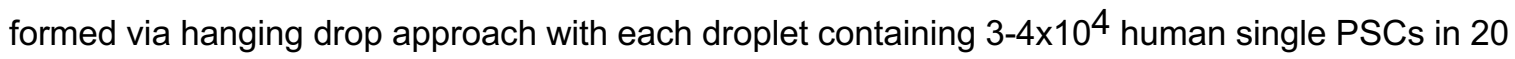
$\mu \mathrm{l}$ were cultured hanging on TESR-E8 supplemented with Polyvinyl Alcohol (PVA) at $4 \mathrm{mg} / \mathrm{ml}$

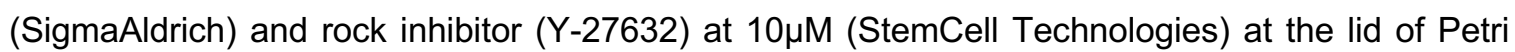
dishes. At the beginning of skeletal muscle organoid differentiation, embryoid bodies at the size of 250-300 $\mu \mathrm{m}$ embedded into Matrigel and cultured in DMEM/F12 basal media (ThermoFisher Scientific) supplemented with Glutamine (ThermoFisher Scientific), Non Essential Amino Acids (ThermoFisher Scientific), 100x ITS-G (ThermoFisher Scientific), (Basal Media) 3 $\mu$ M CHIR99021

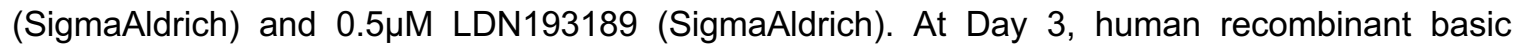
Fibroblast Growth Factor (bFGF) (Peprotech) at 10ng/ $\mu$ l final concentration added to the media. Subsequently, at Day 5 the concentration of bFGF reduced at $5 \mathrm{ng} / \mu \mathrm{l}$ and the media further supplemented with 10nM Retinoic Acid (SigmaAldrich). The differentiation media, at Day 7, supplemented only with human recombinant Sonic hedgehog (hShh) (Peprotech) at $34 \mathrm{ng} / \mathrm{\mu l}$,

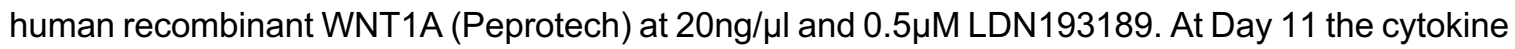
composition of the media changed to $10 \mathrm{ng} / \mathrm{\mu l}$ of bFGF and human recombinant Hepatocyte Growth Factor (HGF) at 10ng/ $\mu$ (Peprotech). From Day 15 onwards, the basal media supplemented with ITS-X (ThermoFisher Scientific) and human recombinant HGF at 10ng/ $\mu$ l. The first 3 days of the differentiation the media changed on a daily basis, from $3^{\text {rd }}$ till $30^{\text {th }}$ every second day, while from Day 30 onwards every third day. We evaluated the organoid approach with 6 hiPSCs lines with 
independent genetic background, with more than 5 independent derivations per line, especially for the control line $\left(\mathrm{CB} C \mathrm{CD} 34^{+}\right)$more than 20 derivation, obtaining always similar results. Per derivation and upon embryoid body matrigel embedding, cultures exhibited high reproducibility. Upon migration and skeletal muscle formation organoids are occupying whole matrigel droplet and through generation of additional bulge reach size of 4-5 mM. Concomitantly, myogenic progenitors fall off the organoid and generate a sheath of myogenic organoids and muscle fibers at the surface of the culture plate. For all the lines, we could demonstrate functional myofibers and PAX7 positive myogenic populations. Myogenic populations from different lines exhibit high similarity, (Pearson correlation, rho $=0.94-0,95$, Figure 5 - figure supplement $\mathbf{3 G}$ ).

\section{CRISPR/Cas9 genome editing of LGMD2A iPSC line}

Genome editing approaches using CRISPR/Cas9 are based on distinguishing successful bi-allelic events through detection of fluorescent protein incorporation (GFP and RFP) into the genome (Arias-Fuenzalida et al., 2017). To these approaches, bi-allelic events can be distinguished by the presence of double GFP / RFP positive cells, while subsequent drug administration does not exclusively select for them. For a more stringent selection process, we developed a system that in addition to fluorescent interrogation, drug administration aids in selecting for cells with successful bi-allelic events.

Selection cassette construction: The selection cassette system was incorporated into plasmids, flanked by $1 \mathrm{~kb}$ in length homology arms. The Upper Homology Arm sequence was corresponding to the wild type sequence of EXON3 $\{130 \operatorname{Trp}(T G G)>C y s(T G C)\}$ of the Calpain 3 locus till the point where by a silent mutation (CTG>CTT) a TTAA sequence corresponding to the Inverted Terminal Repeats (ITRs) of the PiggyBac system, could be generated (Figure 4 - figure supplement 1B,C). This TTAA sequence marked the start for the selection cassette. The selection cassette system itself composed of two plasmids, one expressing under the constitutively active CAG promoter the reverse Tetracycline Activator (rtTA) protein and another under the inducible TRE-CMV promoter the tdTomato plus puromycin. This approach generated a depending loop between the expression cassettes, ensuring that only upon integration of both plasmids red fluorescence could be detected. In addition, to ensure that both alleles are "selection cassettes free" upon PiggyBac mediated excision removal, it was a necessity that both plasmids were expressing the eGFP protein under a constitutively active promoter. The sequence downstream the Inverted Terminal Repeats (ITRs) sequence of the PiggyBac system (TTAA) was corresponding to the lower homology arm of the selection system. To generate the new chimeric EXON3/4 exon without introducing any further alterations, the sequence of the lower homology arm was a chimera between the rest of the EXON3 sequence followed direct by the EXON4 wild type sequence, while skipping the sequence of the intermediate intron. Further, to avoid alterations on the selection cassette introduced by CAS9 
nuclease, we mutated the PAM sequence of the cassette, by introducing another silent mutation (TTC>TTT) (Figure 4B,C). The gRNA sequence introduced into the Cas9 plasmid (Addgene, 58766) was: 5'- TTTGATCATGGGGTATGACT -3'. For performing genome editing of the CAPN3 locus at EXON3 and EXON4 sites, constructs containing selection cassettes together with the Cas9 nuclease were delivered to the cells using Lipofectamine Stem Cell transfection reagent (ThermoFisher Scientific). After transfection, the edited population, was enriched first by Puromycin (SigmaAldrich) selection at concentration of $0.5 \mathrm{mg} / \mathrm{ml}$ followed by sorting for dtTomato- eGFP positive cells (Figure 4 - figure supplement 1B) (BD Biosciences Ariall). At this stage, the genomic integrity of the CAPN3 locus and the presence of the ITRs of the PiggyBac system on genome was evaluated by PCR amplification of the edited areas using GXL Polymerase (Clontech). For the excision of the cassette, cells were transfected with constructs carrying the excision-only mutant (R372A/K375A) of the hyperactive PiggyBac transposase (Li et al., 2013, Yusa et al., 2011) by using Lipofectamine Stem Cell transfection reagent. After transfection, the negative fluorescent cells were selected by FACS sorting followed by genotyping for final validation (Figure 4 - figure supplement $1 \mathrm{C})$.

sgRNA off-target analysis: To evaluate potent mismatches we applied the off-target prediction module from the CCTop- CRISPR/Cas9 target online predictor program (Stemmer et al., 2015) (https://crispr.cos.uni-heidelberg.de), using the default settings for the max. total mismatches, core length, and max. core mismatches. From the output sequences we evaluated the first ten in probability (Table S1) where we could not detect any sequence alteration.

\section{Microarray Karyotype}

Genomic DNA from the patient and genome edited (isogenic) LGMD2A pluripotent stem cell lines purified using DNeasy Blood and Tissue Kit (Qiagen). Samples were further processed at the University of Bonn Life \& Brain Genomics facility using Illumina iScan technology (Figure 4 - figure supplement $1 \mathrm{~A})$.

\section{Immunocytochemistry}

Cryosection Immunochemistry: Organoids from different stages were fixed on $4 \%$ paraformaldehyde overnight at $4^{\circ} \mathrm{C}$ under shakings conditions, dehydrated $(30 \%$ sucrose o/n incubation) and embedded in OCT freezing media. Cryosections were acquired on a Leica CM3050s Cryostat. For the immunostaining process, cryosections were rehydrated with PBS and followed by permeabilization once with $0.1 \%$ Tween-20 in PBS, (rinsed $3 x$ with PBS), and then with $0.1 \%$ Triton-X in PBS (rinsed 3x with PBS). Subsequently, the sections blocked with $1 \%$ BSA / 10\% 
NGS in PBS for $1 \mathrm{hr}$ at room temperature. Primary antibody incubations were performed from 1 to 2 days at $4^{\circ} \mathrm{C}$, where secondary antibody incubations for $2 \mathrm{hr}$ at room temperature.

EdU staining: At 12-week post differentiation, control organoids incubated with $2.5 \mu \mathrm{M}$ BrdU final concentration overnight. To detect EdU, the sections were processed with Click-iT EdU Alexa Fluor 488 cell proliferation kit (Invitrogen) following the manufacturer's instructions. The samples incubated with secondary antibodies after the click reaction for detecting EdU. Primary Antibodies: anti-Brachyury (R\&DSystems, 1:250), anti-TBX6(Abcam, 1:200), anti-PAX3 (DHSB, 1:250), anti- PAX7(DHSB, 1:250), anti-SOX10 (R\&DSystems,1:125), anti-KI67 (ThermoFisher Scientific, clone SolA15, 1:100), anti- TITIN (DHSB, 9D-10, 1:300), anti-MyHC (DHSB, MF20, 1:300), anti-MYOD1 (Santa Cruz Biotechnologies, clone 5.8A, 1:200), anti-PRDM16 (Abcam, ab106410, 1:200), anti-TFAP2A (DHSB, 3B5, 1:100), anti-Dystrophin (Novocastra/Leica Biosystems, clone DY4/6D3, 1:200), anti-Laminin (SigmaAldrich, 1:200), anti-FastMyHC (SigmaAldrich, clone MY-32, 1:300), anti-M-Cadherin (Cell Signaling Technology, 1:200) antiSOX2 (ThermoFisher Scientific, clone Btjce, 1:100), anti-CD44 (eBioscience, clone IM7, 1:100), anti-Fibrillin1 (Invitrogen, clone 11C1.3, 1:100).

Secondary antibodies: Alexa Fluor® 647 AffiniPure Fab Fragment Goat Anti-Mouse IgM, $\mu$ Chain Specific (Jackson Immunoresearch Laboratories, 1:100), Rhodamine RedTM-X (RRX) AffiniPure Goat Anti-Mouse IgG, Fcy Subclass 1 Specific (Jackson Immunoresearch Laboratories,1:100), Alexa Fluor® 488 AffiniPure Goat Anti-Mouse IgG, Fcy subclass 2a specific (Jackson Immunoresearch Laboratories, 1:100), Alexa Fluor 488, Goat anti-Rat IgG $(\mathrm{H}+\mathrm{L})$ Cross- Adsorbed Secondary Antibody, (ThermoFisher Scientific, 1:500), Alexa Fluor 488, Donkey anti-Mouse IgG $(\mathrm{H}+\mathrm{L})$ Cross-Adsorbed Secondary Antibody, (ThermoFisher Scientific, 1:500), Alexa Fluor 647, Donkey anti-Goat IgG $(\mathrm{H}+\mathrm{L})$ Cross-Adsorbed Secondary Antibody, (ThermoFisher Scientific, 1:500), Alexa Fluor 488, Donkey anti-Goat $\lg G(H+L)$ Cross-Adsorbed Secondary Antibody, (ThermoFisher Scientific, 1:500), Alexa Fluor 568, Donkey anti-Rabbit IgG ( $\mathrm{H}+\mathrm{L})$ Cross-Adsorbed Secondary Antibody, (ThermoFisher Scientific, 1:500). Images were acquired on a ZEISS LSM780 inverted confocal microscope.

\section{Oil O Red Staining}

For histological visualization of adipocytes within the organoids, Oil O Red Stain kit (Abcam, ab150678) applied on frozen sections derived from PFA fixated organoids following manufactures recommended protocol. Organoid sections upon staining with Oil O Red were visualized at an Olympus BX61 upright microscope. 


\section{Flow Cytometry}

FACS intracellular staining: Organoids during the $2^{\text {nd }}, 5^{\text {th }}, 9^{\text {th }}$ and $14^{\text {th }}$ week of differentiation were dissociated into single cells by incubating them till dissociating at $37^{\circ} \mathrm{C}$ within papain solution under shaking conditions. Then, the cells pelleted at $400 \mathrm{xg}$ for $5 \mathrm{~min}$ and followed incubation with TryplE Select for $10 \mathrm{~min}$ to ensure dissociation into singe cells. Further, the cells passed through $70 \mu \mathrm{M}$ $\left(2^{\text {nd }}\right.$ week $)-100 \mu \mathrm{M}\left(5^{\text {th }}, 9^{\text {th }}, 14 \mathrm{t}^{\mathrm{h}}\right.$ week $)$ cell strainer to avoid aggregates. For both digesting steps $10 \%$ FBS/DMEM-F12 as digesting deactivation solution applied to the cells. Then, for intracellular flow cytometric staining analysis the Transcription Factor Buffer set (BD Pharmigen) was applied and the cells were analyzed using flow cytometer (BD Biosciences FACS ARIAII).

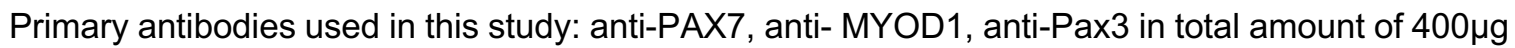
per staining, while as secondaries the Rhodamine RedTM-X (RRX) AffiniPure Goat Anti-Mouse IgG, Fcy Subclass 1 Specific (Jackson Immunoresearch Laboratories), Alexa Fluor $₫ 488$ AffiniPure Goat Anti-Mouse IgG, Fcy subclass 2a specific (Jackson Immunoresearch Laboratories) in 1:50 dilution. As isotype controls, Mouse IgG1 kappa Isotype Control (Invitrogen, clone P3.6.2.8.1), Mouse IgG2a kappa Isotype Control, (Invitrogen, clone eBM2a) were used at $400 \mu g$ total amount per staining.

FACS EdU assay: At 15-week post differentiation, organoids incubated overnight with $5 \mu \mathrm{M}$ EdU final concentration. Next day, organoids were dissociated into single cells by incubation at $37^{\circ} \mathrm{C}$ within papain solution for $1-2 \mathrm{hr}$, followed by incubation with TryplE Select for $10 \mathrm{~min}$ to ensure single cell dissociation. Then, the dissociated cells passed through a $70 \mu \mathrm{m}$ cell culture strainer to remove any remaining aggregates. To detect EdU, the cells were processed with Click- iT EdU Alexa Fluor 488 Flow Cytometry Assay Kit (Invitrogen) according to manufacturer instructions and then analyzed using the 488 channel of a BD Biosciences FACSAria Fusion flow cytometer.

FACS isolation of ITG $\beta 1^{+} / \mathrm{CXCR} 4^{+}$myogenic cell population for RNA sequencing: Organoids from Duchenne and Control iPSC lines and during 15th - 16th week post differentiation dissociated into single cells during incubation with Papain solution till we could observe dissociation upon gentle shaking (1-2hr). To acquire singlets, we filter the cells with through $40 \mu \mathrm{m}$ cell strainer and upon washing with $1 \%$ BSA solution we proceed with surface antigen staining. For surface antigen staining 20 min incubation with the Alexa Fluor 488 anti-human CD29 (Biolegend, clone TS2/16), $\mathrm{PE}$ anti-human CD184[CXCR4] (Biolegend, clone 12G5) were applied together with the corresponding isotype controls: PE Mouse IgG2a, $\mathrm{k}$ Isotype Ctrl antibody (Biolegend, clone MOPC173), 488 Mouse IgG1, $\mathrm{k}$ Isotype Ctrl antibody (Invitrogen, clone P3.6.2.8.1). For removing residual antibodies, the cells were washed twice with $1 \%$ BSA staining solution and processed by BD Biosciences FACSAria Fusion flow cytometer. Briefly before FACS sorting to discriminate between 
dead and alive cells DAPI was added to the samples and then DAPI- / CD29 ${ }^{+} / \mathrm{CXCR}^{+}$cells populations were collected into tubes containing RLT buffer supplemented with b-mercaptoethanol to avoid RNA degradation. FACS gating strategy is further depicted in Figure $\mathbf{5}$ - figure supplement $3 A$.

\section{Bulk RNA sequencing}

RNA extraction: Total RNA was extracted from single organoids or cultured cells by using the RNAeasy Micro Kit (Qiagen) according to the manufacturer's instructions. Subsequently, before library preparation, the RNA integrity was evaluated on an Agilent 2100 Bioanalyzer by using the RNA 6000 Pico kit (Agilent). cDNA library preparation: For 4-week and 8-week organoids cDNA library was prepared by using the whole transcriptome Illumina TruSeq Stranded Total RNA Library Prep Kit Gold (Illumina), followed by evaluation on an Agilent 2100 Bioanalyzer by using the DNA 1000 kit. The resulting mRNA library sequenced as $2 \times 75$ bp paired-end reads on a NextSeq 500 sequencer (Illumina). For 16 -weeks and ITG $\beta 1^{+} /$CXCR4 ${ }^{+}$sorted cells CDNA library was prepared using the whole transcriptome Ovation Solo RNA seq Library Preparation Kit (TECAN, NuGEN), followed by evaluation on an Agilent 2100 Bioanalyzer by using the DNA 1000 Chip. The resulting mRNA library sequenced as 1 X 150 bp single reads on a HiSeq. 3000 sequencer (Illumina).

\section{Bulk RNA seq bioinformatic analysis}

Sequenced reads were aligned to the human reference genome (hg38) with TopHat2 (version 2.1.1), and the aligned reads were used to quantify mRNA expression by using HTSeq-count (version 0.11.2). DESeq2 (Love at al., 2014) was used to identify differentially expressed genes across the samples. ITG $\beta 1^{+}$/ CXCR4 ${ }^{+}$organoid derived myogenic cell populations were compared to already available transcriptomic dataset of human fetal muscle progenitors (GSM2328841-2) (Hicks et al., 2018).

\section{scRNA sequencing}

Sample and cDNA library preparation: Single cells acquired upon incubation for $1 \mathrm{hr}$ with solution containing papain and EDTA. Upon dissociation, we estimated the cell number and viability; then cells resuspended on solution containing $0.5 \%$ BSA in PBS to reach concentration of 390 cells per $\mu \mathrm{l}$. The cDNA library was prepared using the Chromium Single Cell 3' Reagent Kits (v3): Single Cell 3' Library \& Gel Bead Kit v3 (PN-1000075), Single Cell B Chip Kit (PN-1000073) and i7 Multiplex Kit (PN-120262) (10x Genomics) according to the manufacturer's instructions. Then, the cDNA library was run on an Illumina HiSeq 3000 as 150-bp paired-end reads. 


\section{Single cell RNA seq bioinformatic analysis}

Sequencing data were processed with UMI-tools (version 1.0.0), aligned to the human reference genome (hg38) with STAR (version 2.7.1a), and quantified with Subread featureCounts (version 1.6.4). Data normalization and further analysis were performed using Seurat (version 3.1.3, Stuart et al., 2019). For initial quality control of the extracted gene- cell matrices, we filtered cells with parameters low threshold $=500$, high threshold $=6,000$ for number of genes per cell (nFeature_RNA), high threshold $=5$ for percentage of mitochondrial genes (percent.mito) and genes with parameter min.cells $=3$. Filtered matrices were normalized by LogNormalize method with scale factor $=10,000$. Variable genes were found with parameters of selection. method = "vst", nfeatures $=2000$, trimmed for the genes related to cell cycle (KEGG cell cycle, hsa04110) and then used for principal component analysis. Statistically significant principal components were determined by JackStraw method and the first 5 principle components were used for non-linear dimensional reduction (tSNE and UMAP) and clustering analysis with resolution=0.2. Monocle3 (version 0.2.0, Cao et al., 2019) was used for pseudotime trajectory analysis. We imported data matrix of Seurat objects (assays[["RNA"]]@counts) to Monocle R package and then performed dimensionality reduction with PCA method with parameters max_components $=2$ and then cluster_cells, learn_graph and order_cells functions were performed subsequently. Organoidderived myogenic progenitors were compared to already available transcriptomic dataset of adult satellite cells (GSE130646) (Rubenstein et al., 2020).

\section{qPCR expression analysis}

By pooling 3 organoids per sample, total RNA was extracted using the RNAeasy Mini Plus Kit (Qiagen). For first strand cDNA synthesis, the High capacity RNA to cDNA Kit (Applied Biosystems) applied using as template $2 \mu \mathrm{g}$ of total RNA. For setting qPCR reactions, the GoTaq qPCR Master Mix (Promega) was used with input template 4ng cDNA per reaction while the reaction was detected on a CFX 96 Real-Time PCR detection system (BIO-RAD). The relative quantification $(\triangle C T)$ method applied for detecting changes in gene expression of pluripotent, neural tube, neural crest, posterior/anterior somitic; and dermomyotomal markers, between different time points along the differentiation. qPCR primers applied for each marker are listed in Table S2. 


\section{Transmission Electron Microscopy (TEM)}

Skeletal muscle organoids were fixed for $4 \mathrm{~h}$ at room temperature (RT) in $2.5 \%$ glutaraldehyde (SigmaAldrich) in $0.1 \mathrm{M}$ cacodylate buffer pH 7,4 (Sciences Services, Germany), subsequently washed in $0.1 \mathrm{M}$ cacodylate buffer $\mathrm{pH} 7,4$, post- fixed for $2 \mathrm{~h}$ at $\mathrm{RT}$ in $1 \%$ osmium tetroxide (Sciences Services, Germany) in $0.1 \mathrm{M}$ cacodylate buffer $\mathrm{pH} 7,4$, dehydrated stepwise in a graded ethanol series and embedded in Epon 812 (Fluka, Buchs, Switzerland). Ultrathin sections $(70 \mathrm{~nm}$, ultramicrotome EM UC7, Leica, Wetzlar, Germany) were afterwards stained for 30 min in $1 \%$ aqueous uranyl acetate (Leica, Germany) and $20 \mathrm{~min}$ in $3 \%$ lead citrate (Leica, Germany). TEM images were acquired with a $200 \mathrm{kV}$ TEM JEM 2100Plus (Jeol, Japan), transmission electron microscope.

\section{Western blot}

Skeletal muscle organoid proteins were extracted using a Urea containing lysis buffer (7 M Urea, $2 \mathrm{M}$ Thiourea, $2 \%$ CHAPS and $1 \mathrm{M}$ DTT) containing $1 \mathrm{X}$ protease inhibitor cocktail (SigmaAldrich). Protein lysates from individual organoids were loaded in different wells of BoltTM 4-12\% Bis-Tris Plus gels (ThermoFisher Scientific). Samples were resolved following the manufacturer's instructions. Proteins were then transferred to nitrocellulose membranes employing an iBlot2 device (Thermo). Blocking was performed using 2\% milk (Carl Roth) dissolved in PBS for 1 hour at room temperature. Relative amount of outer membrane mitochondrial import receptor TOM20 (Santa Cruz, FL-145 1:1000) and of the sarcoplasmatic / endoplasmatic reticulum ATPase SERCA2 (ThermoFisher Scientific, 2A7-A1, 1:1000) compared to the internal control GAPDH (Abcam, ab9485, 1:1000) was evaluated. Membranes were incubated with SuperSignal West Pico Chemiluminescent Substrate (ThermoFisher Scientific) for visualization.

\section{Second harmonic generation (SHG) imaging using multi-photon microscopy}

A TriM Scope II multi photon system from LaVision BioTec was used to visualize skeletal muscle fiber organization inside organoids and distinct sarcomeres. The microscope setup is a single beam instrument with an upright Olympus BX51 WI microscope stand equipped with highly sensitive nondescanned detectors close to the objective lens. The TriM Scope II is fitted with a Coherent Scientific Chameleon Ultra II Ti:Sapphire laser (tuning range 680-1080 nm) and a Coherent Chameleon Compact OPO (automated wavelength extension from $1000 \mathrm{~nm}$ to $1600 \mathrm{~nm}$ ). A 20x IR objective lens (Olympus XLUMPlanFI 20x/1.0W) with a working distance of $2.0 \mathrm{~mm}$ was used. Muscle fiber SHG signals were detected in forward direction using TiSa light at $850 \mathrm{~nm}$, a 420/40 band pass filter and a blue-sensitive photomultiplier (Hamamatsu H67080-01). 3D-images were acquired and processed with LaVision BioTec ImSpector Software. 


\section{Electrophysiology}

Current measurement: Membrane currents were measured at ambient temperature $\left(22-24^{\circ} \mathrm{C}\right)$ using standard whole- cell patch clamp software ISO2 (MFK, Niedernhausen, Germany). Cells were voltage-clamped at a holding potential of $-90 \mathrm{mV}$, i.e. negative to EnAChR, resulting in inward $\mathrm{Na}^{+}$currents. Every $10 \mathrm{~s}$, voltage ramps (duration $500 \mathrm{~ms}$ ) from $-120 \mathrm{mV}$ to $+60 \mathrm{mV}$ were applied to assess stability of the recording conditions and to generate I/V curves (membrane currents in response to depolarizing voltage ramps are shown as downward deflections). Signals were filtered (corner frequency, $1 \mathrm{KHz}$ ), digitally sampled at $1 \mathrm{KHz}$ and stored on a computer equipped with the hardware/software package ISO2 for voltage control, data acquisition and data analysis. Rapid exposure to a solution containing acetylcholine was performed by means of a custom-made solenoid-operated flow system permitting a change of solution around an individual cell with a half time of about $100 \mathrm{~ms}$. For measurements cells devoid of contact with neighboring cells were selected.

Fluorescence microscopy and imaging: To monitor changes in $\left[\mathrm{Ca} 2^{+}\right] \mathrm{i}$, skeletal muscle cells were transiently transfected with pcDNA3[Twitch-2B] (Addgene, 49531) $(0.25 \mu \mathrm{g}$ per $35 \mathrm{~mm}$ culturedish). Skeletal muscle cells were transfected using either poly-ethyleneimine (PEI) or Lipofectamine (Invitrogen) according to the manufacturer's instructions. Prior to experiments, cells were seeded on sterile, poly-L-lysine-coated glass cover slips and analyzed or $48 \mathrm{~h}$ after transfections. All experiments were performed using single cells at ambient temperature. Fluorescence was recorded buckusing an inverted microscope (Zeiss Axiovert 200, Carl Zeiss AG, Göttingen, Germany) equipped with a Zeiss oil immersion objective (100x/1.4), a Polychrome V illumination source and a photodiode-based dual emission photometry system suitable for CFP/YFP-FRET (FEI Munich GmbH, Germany). For FRET measurements, single cells were excited at $435 \mathrm{~nm}$ wavelength with light pulses of variable duration (20 ms to $50 \mathrm{~ms}$; frequency: 5 $\mathrm{Hz}$ ) to minimize photo- bleaching. Corresponding emitted fluorescence from CFP (F480 or FCFP) or from YFP (F535 or FYFP) was acquired simultaneously and FRET was defined as ratio FYFP/FCFP. Fluorescent signals were recorded and digitized using a commercial hardware/software package (EPC10 amplifier with an integrated D/A board and Patch-master software, HEKA, HEKA Elektronik, Germany). The individual FRET traces were normalized to the initial ratio value before agonist application (FRET/FRET0).

Solutions and chemicals: For FRET measurements an extracellular solution of the following composition was used (mmol/L): $\mathrm{NaCl} 137 ; \mathrm{KCl}$ 5.4; $\mathrm{CaCl} 2$ 2; $\mathrm{MgCl} 2$ 1.0; Hepes/NaOH 10.0, pH 7.4. For whole cell measurements of membrane currents an extracellular solution of the following composition was used (in mmol/L): $\mathrm{NaCl} 120, \mathrm{KCl} 20, \mathrm{CaCl}_{2} 0.5, \mathrm{MgCl} 21.0, \mathrm{HEPES} / \mathrm{NaOH} 10.0$ 
(pH 7.4). The pipette solution contained (in mmol/L): $\mathrm{K}$-aspartate 100, $\mathrm{KCl} 40, \mathrm{NaCl} 5.0, \mathrm{MgCl} 22.0$, Na2ATP 5.0, BAPTA 5.0, GTP 0.025, and HEPES/KOH 20.0, pH 7.4. Standard chemicals were from Merck. EGTA, HEPES, Na2ATP, GTP and acetylcholine chloride, were from SigmaAldrich.

\section{Statistics}

All statistical analysis was conducted using GraphPad Prism6 software. For qPCR analysis we performed one-way ANOVA with Tukey's multiple comparisons test for each marker. For the FACS intracellular staining quantification, we performed one-way ANOVA with Sidak's multiple comparisons test between the different time points. For Western blot quantification we performed Mann-Whitney test between two groups. Significance asterisks represent ${ }^{*} P<0.05,{ }^{* *} P<0.01$, ${ }^{* * *} \mathrm{P}<0.001,{ }^{* * * *} \mathrm{P}<0.0001$, ns: not significant.

\section{Data and code availability}

RNA sequencing datasets produced in this study are deposited in the Gene Expression Omnibus (GEO) under accession code GSE147514. Detailed scripts and parameters used for the study are available from the authors upon reasonable request.

\section{To review GEO accession GSE147514:}

Go to https://www.ncbi.nlm.nih.gov/geo/query/acc.cgi?acc=GSE147514 


\section{ACKNOWLEDGEMENTS}

We are grateful to Dr. Karl Köhrer, Dr. Tobias Lautwein, Dr. Patrick Petzsch and Thorsten Wachtmeister, Genomics \& Transcriptomics Laboratory, Heinrich-Heine-University Düsseldorf for performing single cell and bulk RNAseq experiments with their Illumina HiSeq platform and data provision. We are further grateful to Dr. Kenjiro Adachi, Max Planck Institute Münster for providing the PiggyBac transposase expression vector, Dr. Oliver Griesbeck for the pcDNA3[Twitch-2B] plasmid and Dr. Stephan Hahn, Ruhr-University Bochum for access to equipment from his lab. We thank Dr. Christoph Clemen for contributing experiments, Dr. Johnny Kim, Max Planck Institute Bad Nauheim for critical discussions, Dr. Elisabeth Stevens, English Scientific, Düsseldorf for scientific editing of the manuscript and Pierre Böhme, Bochum for his personal contribution. We thank Ingrid Gelker, Martina Sinn, Max Planck Institute Münster as well as Eva-Maria Konieczny, Rana Houmany, Boris Burr, Ruhr-University Bochum for their technical assistance. Electron microscopy experiments were supported by the Deutsche Forschungsgemeinschaft SFB 944. We thank Dr. George Q. Daley and Dr. Thorsten Schlaeger, Boston Children's Hospital for providing the Duchenne Muscular Dystrophy patient-derived iPS cell lines DMD-iPS1 and DMD-iPS2 in the course of our study. Our study was supported by research grants from FoRUM F873- 16, Medical Faculty, Ruhr University Bochum, from Deutsche Gesellschaft für Muskelkranke e.V (DGM Foundation), Freiburg, the Georg E. und Marianne Kosing-Stiftung, Deutsches Stiftungszentrum, Essen and Deutsche Duchenne Stiftung der action benni \& co e.V., Bochum.

\section{AUTHOR CONTRIBUTIONS}

L.M. conceived and designed experiments and the study, performed experiments, analyzed data, and wrote manuscript, H.W.J. performed bulk RNA seq. experiments, analyzed single cell and bulk RNAseq data, and wrote manuscript, G.G.G contributed to experimental design, analyzed data, and wrote manuscript. M.C.K. designed, performed, analyzed electrophysiology experiments and wrote manuscript. M.S performed and analyzed FACS experiments. O.E.P. performed electron microscopy experiments. M.G.B. performed multi-photon microscopy experiments. D.G., M.J.A.B. performed bioinformatic analysis, G.M.P performed experiments, J.C.S. H.R.S., R.H.A., provided materials and supervised experiments, M.V. provided patient and healthy biopsies and supervised study, B.B.S. provided materials, supervised study and edited manuscript, H.Z. supervised study, experimental design, and wrote manuscript. 


\section{REFERENCES}

Alexander MS, Rozkalne A, Colletta A, Spinazzola JM, Johnson S, Rahimov F, Meng H, Lawlor MW, Estrella E, Kunkel LM, Gussoni E. 2016. CD82 is a marker for prospective isolation of human muscle satellite cells and is linked to muscular dystrophies. Cell Stem Cell 19:800-807. DOI: https://doi.org/10.1016/j.stem.2016.08.006

Al Tanoury Z, Rao J, Tassy O, Gobert B, Gapon S, Garnier JM, Wagner E, Hick A, Hall A, Gussoni E, \& Pourquié O. 2020. Differentiation of the human PAX7-positive myogenic precursors/satellite cell lineage in vitro. Development 147: dev187344. DOI: https://doi.org/10.1242/dev.187344

Arias-Fuenzalida J, Jarazo J, Qing X, Walter J, Gomez-Giro G, Nickels SL, Zaehres H, Schöler HR, Schwamborn JC. 2017. FACS-Assisted CRISPR-Cas9 Genome Editing Facilitates Parkinson's Disease Modeling. Stem Cell Reports 9: 1423-1431. DOI: https://doi.org/10.1016/j.stemcr.2017.08.026

Aulehla A, Pourquie O. 2010. Signaling Gradients during Paraxial Mesoderm Development. Cold Spring Harb Perspect Biol. 2: a000869. DOI: https://doi.org/10.1101/cshperspect.a000869

Baghdadi MB, Castel D, Machado L, Fukada SI, Birk DE, Relaix F, Tajbakhsh S, Mourikis P. 2018. Reciprocal signalling by Notch-Collagen V-CALCR retains muscle stem cells in their niche. Nature 557:714-718. DOI: https://doi.org/10.1038/s41586-018-0144-9

Barbieri G, DeAngelis L, Feo S, Cossu G, Giallongo A. 1990. Differential expression of muscle-specific enolase in embryonic and fetal myogenic cells during mouse development Differentiation 45:179-184. DOI: https://doi.org/10.1111/j.1432-0436.1990.tb00471.x

Barruet E, Garcia SM, Striedinger K, Wu J, Lee S, Byrnes L, Wong A, Xuefeng S, Tamaki S, Brack AS, Pomerantz JH. 2020. Functionally heterogeneous human satellite cells identified by single cell RNA sequencing. Elife. 9:e51576. DOI: https//doi.org/10.7554/eLife.51576.

Bjornson CR, Cheung TH, Liu L, Tripathi PV, Steeper KM, Rando TA. 2012. Notch signaling is necessary to maintain quiescence in adult muscle stem cells. Stem cells 30:232-242. DOI: https://doi.org/10.1002/stem.773

Borchin B, Chen J, Barberi, T. 2013. Derivation and FACS-mediated purification of PAX3+/PAX7+ skeletal muscle precursors from human pluripotent stem cells. Stem Cell Reports 1:620-631. DOI: https://doi.org/10.1016/j.stemcr.2013.10.007

Buckingham M, Rigby PWJ. 2014. Gene Regulatory Networks and Transcriptional Mechanism that Control Myogenesis. Developmental Cell 28:225-238. DOI: https://doi.org/10.1016/j.devcel.2013.12.020 
Cao J, Spielmann M, Qiu X, Huang X, Ibrahim DM, Hill AJ, Zhang F, Mundlos S, Christiansen L, Steemers FJ, Trapnell C, Shendure J. 2019. The single-cell transcriptional landscape of mammalian organogenesis. Nature, 566: 496-502. DOI: https://doi.org/10.1038/s41586-019-0969-x

Chal J, Oginuma M, Al Tanoury Z, Gobert B, Sumara O, Hick A, Bousson F, Zidouni Y, Mursch C, Moncuquet P, Tassy O, Vincent S, Miyanari A, Bera A, Garnier JM, Guevara G, Hestin M, Kennedy L, Hayashi S, Drayton B, Cherrier T, Gayraud-Morel B, Gussoni E, Relaix F, Tajbakhsh S, Pourquié O. 2015. Differentiation of pluripotent stem cells to muscle fiber to model Duchenne muscular dystrophy. Nat Biotechnol. 33:962-969. DOI: https://doi.org/10.1038/nbt.3297

Chargé SB, Rudnicki MA. 2004. Cellular and molecular regulation of muscle regeneration. Physiol. Rev. 84: 209-238. DOI: https://doi.org/10.1152/physrev.00019.2003

Cheng L, Alvares LE, Ahmed MU, El-Hanfy AS, Dietrich S. 2004. The epaxial-hypaxial subdivision of the avian somite. Dev. Biol. 274:348-369. DOI: https://doi.org/10.1016/j.ydbio.2004.07.020

Cheung TH, Quach NL, Charville GW, Liu L, Park L, Edalati A, Yoo B, Hoang P, Rando TA. 2012. Maintenance of muscle stem-cell quiescence by microRNA-489. Nature 482: 524-528. DOI: https://doi.org/10.1038/nature10834

Cohn RD, van Erp C, Habashi JP, Soleimani AA, Klein EC, Lisi MT, Gamradt M, ap Rhys CM, Holm TM, Loeys BL, Ramirez F, Judge DP, Ward CW, Dietz HC. 2007. Angiotensin II type 1 receptor blockade attenuates TGF-beta-induced failure of muscle regeneration in multiple myopathic states. Nat Med, 13:204-210. DOI: https://doi.org/10.1038/nm1536

Darabi R, Arpke RW, Irion S, Dimos JT, Grskovic M, Kyba M, Perlingeiro RC. 2012. Human ES- and iPSderived myogenic progenitors restore DYSTROPHIN and improve contractility upon transplantation in dystrophic mice. Cell Stem Cell, 10:610-619. DOI: https://doi.org/10.1016/j.stem.2012.02.015

Dietrich S, Abou-Rebyeh F, Brohmann H, Bladt F, Sonnenberg-Riethmacher E, Yamaai T, Lumsden A, BrandSaberi B, Birchmeier C. 1999. The role of SF/HGF and c-Met in the development of skeletal muscle. Development 126:1621- 1629.

Dorn I, Klich K, Arauzo-Bravo MJ, Radstaak M, Santourlidis S, Ghanjati F, Radke TF, Psathaki OE, Hargus G, Kramer J, Einhaus M, Kim JB, Kögler G, Wernet P, Schöler HR, Schlenke P, Zaehres H. 2015. Erythroid differentiation of human induced pluripotent stem cells is independent of donor cell type of origin. Haematologica 100: 32-41. DOI: https://doi.org/10.3324/haematol.2014.108068

Faustino Martins JM, Fischer C, Urzi A, Vidal R, Kunz S, Ruffault PL, Kabuss L, Hube I, Gazzerro E, Birchmeier C, Spuler S, Sauer S, Gouti M. 2020. Self-Organizing 3D Human Trunk Neuromuscular Organoids. Cell Stem Cell 26: 172-186. DOI: https://doi.org/10.1016/j.stem.2019.12.007 
Fukada S, Uezumi A, Ikemoto M, Masuda S, Segawa M, Tanimura N, Yamamoto H, Miyagoe-Suzuki Y, Takeda S. 2007. Molecular signature of quiescent satellite cells in adult skeletal muscle. Stem Cells 25: 24482459. DOI: https://doi.org/10.1634/stemcells.2007-0019

Garcia SM, Tamaki S, Lee S, Wong A, Jose A, Dreux J, Kouklis G, Sbitany H, Seth R, Knott PD, Heaton C, Ryan WR, Kim EA, Hansen SL, Hoffman WY, Pomerantz JH. 2018. High-Yield Purification, Preservation, and Serial Transplantation of Human Satellite Cells. Stem Cell Reports. 10:1160-1174. DOI: https//doi.org/ 10.1016/j.stemcr.2018.01.022.

Gouti M, Delile J, Stamataki D, Wymeersch FJ, Huang Y, Kleinjung J, Wilson V, Briscoe J. 2017. A Gene Regulatory Network Balances Neural and Mesoderm Specification during Vertebrate Trunk Development. Dev. Cell 41: 243-261. DOI: https://doi.org/10.1016/j.devcel.2017.04.002

Henrique D, Abranches E, Verrier L, Storey KG. 2015. Neuromesodermal progenitors and the making of the spinal cord. Development 142:2864-2875. DOI: https://doi.org/10.1242/dev.119768

Hicks MR, Hiserodt J, Paras K, Fujiwara W, Eskin A, Jan M, Xi H, Young CS, Evseenko D, Nelson SF, Spencer MJ, Handel BV, Pyle AD. 2018. ERBB3 and NGFR mark a distinct skeletal muscle progenitor cell in human development and hPSCs. Nat Cell Biol. 20:46-57. DOI: https://doi.org/10.1038/s41556-017-0010-2

Jahn K, Mohammadi B, Krampfl K, Abicht A, Lochmüller H, Buffer J. 2001. Deactivation and desensitization of mouse embryonic- and adult- type nicotinic receptor channels currents. Neuroscience Letters 307: 89-92. DOI: https://doi.org/10.1016/s0304-3940(01)01929-2

Juan AH, Derfoul A, Feng X, Ryall JG, Dell'Orso S, Pasut A, Zare H, Simone JM, Rudnicki MA, Sartorelli V. 2011. Polycomb EZH2 controls self-renewal and safeguards the transcriptional identity of skeletal muscle stem cells. Genes \& development 25: 789-794. DOI: https://doi.org/10.1101/gad.2027911

Koehler KR, Nie J, Longworth-Mills E, Liu XP, Lee J, Holt JR, Hashino E. 2017. Generation of inner ear organoids containing functional hair cells from human pluripotent stem cells. Nat Biotechnol. 35:583-589. DOI: https://doi.org/10.1038/nbt.3840

Kramerova I, Kudryashova E, Wu B, Germain S, Vandenborne K, Romain N, Haller RG, Verity MA, Spencer MJ. 2009. Mitochondrial abnormalities, energy deficit and oxidative stress are features of calpain 3 deficiency in skeletal muscle. Human Molecular Genetics 18:3194-3205. DOI: https://doi.org/10.1093/hmg/ddp257

Lancaster MA, Renner M, Martin CA, Wenzel D, Bicknell LS, Hurles ME, Homfray T, Penninger JM, Jackson AP, Knoblich JA. 2013. Cerebral organoids model human brain development and microcephaly. Nature 501:373- 379. DOI: https://doi.org/10.1038/nature12517

Le Douarin NM, Calloni GW, Dupin E. 2008. The stem cells of the neural crest. Cell Cycle 7:1013-1019. DOI: https://doi.org/10.4161/cc.7.8.5641 
Li X, Burnight ER, Cooney AL, Malani N, Brady T, Sander JD, Staber J, Wheelan SJ, Joung JK, McCray PBJr, Bushman FD, Sinn PL, Craig NL. 2013. piggyBac transposase tools for genome engineering. Proc Natl Acad Sci U S A 110: e2279-2287. DOI: https://doi.org/10.1073/pnas.1305987110

Love MI, Huber W, Anders S. 2014. Moderated estimation of fold change and dispersion for RNA-seq data with DESeq2. Genome Biology 15:550. DOI: https://doi.org/10.1186/s13059-014-0550-8

Machado L, Esteves de Lima J, Fabre O, Proux C, Legendre R, Szegedi A, Varet H, Ingerslev LR, Barrès R, Relaix F, Mourikis P. 2017. In Situ fixation redefines quiescence and early activation of skeletal muscle stem cells Cell Rep. 21: 1982-1993. DOI: https://doi.org/10.1016/j.celrep.2017.10.080

Maffioletti SM, Sarcar S, Henderson ABH, Mannhardt I, Pinton L, Moyle LA, Steele-Stallard H, Cappellari O, Wells KE, Ferrari G, Mitchell JS, Tyzack GE, Kotiadis VN, Khedr M, Ragazzi M, Wang W, Duchen MR, Patani R, Zammit PS, Wells DJ, Eschenhagen T, Tedesco FS. 2018. Three-dimensional human iPSC-derived artificial skeletal muscles model muscular dystrophies and enable multilineage tissue engineering. Cell Rep. 23:899-908. DOI: https://doi.org/10.1016/j.celrep.2018.03.091

Magli A, Incitti T, Kiley J, Swanson SA, Darabi R, Rinaldi F, Selvaraj S, Yamamoto A, Tolar J, Yuan C, Stewart R, Thomson JA, Perlingeiro R. 2017. PAX7 Targets, CD54, Integrin $\alpha 9 \beta 1$, and SDC2, Allow Isolation of Human ESC/iPSC- Derived Myogenic Progenitors. Cell Rep. 19:2867-2877. DOI: https://doi.org/10.1016/j.celrep.2017.06.005

Messina G, Biressi S, Monteverde S, Magli A, Cassano M, Perani L, Roncaglia E, Tagliafico E, Starnes L, Campbell CE, Grossi M, Goldhamer DJ, Gronostajski RM, Cossu G. 2010. Nfix regulates fetal-specific transcription in developing skeletal muscle. Cell 140:554-566. DOI: https://doi.org/10.1016/j.cell.2010.01.027

Montarras D, Morgan J, Collins C, Relaix F, Zaffran S, Cumano A, Partridge T, Buckingham M. 2005. Direct isolation of satellite cells for skeletal muscle regeneration. Science 309:2064-2067. DOI: https://doi.org/10.1126/science.1114758

Moore R, Walsh FS. 1993. The cell adhesion molecule M-cadherin is specifically expressed in developing and regenerating, but not denervated skeletal muscle. Development 117:1409-1420.

Mourikis P, Sambasivan R, Castel D, Rocheteau P, Bizzarro V, Tajbakhsh S. 2012. A critical requirement for notch signaling in maintenance of the quiescent skeletal muscle stem cell state. Stem Cells 30: 243-252. DOI: https://doi.org/10.1002/stem.775

Murphy M, Reid K, Ford M, Furness JB, Bartlett PF. 1994. FGF2 regulates proliferation of neural crest cells, with subsequent neuronal differentiation regulated by LIF or related factors. Development 120:3519-3528.

Panopoulos AD, D'Antonio M, Benaglio P, et.al. 2017. iPSCORE: A Resource of 222 iPSC Lines Enabling Functional Characterization of Genetic Variation across a Variety of Cell Types. Stem Cell Reports 8:10861100. DOI: https://doi.org/10.1016/j.stemcr.2017.03.012 
Park IH, Arora N, Huo H, Maherali N, Ahfeldt T, Shimamura A, Lensch MW, Cowan C, Hochedlinger K, Daley GQ. 2008. Disease-specific induced pluripotent stem cells. Cell 134: 877-886. DOI: https://doi.org/10.1016/j.cell.2008.07.041

Porpiglia E, Samusik N, Ho ATV, Cosgrove BD, Mai T, Davis KL, Jager A, Nolan GP, Bendall SC, Fantl WJ, Blau HM. 2017. High-resolution myogenic lineage mapping by single-cell mass cytometry. Nat Cell Biol. 19:558-567. DOI: https://doi.org/10.1038/ncb3507

Quarta M, Brett JO, DiMarco R, De Morree A, Boutet SC, Chacon R, Gibbons MC, Garcia VA, Su J, Shrager JB, Heilshorn S, Rando TA. 2016. An artificial niche preserves the quiescence of muscle stem cells and enhances their therapeutic efficacy. Nat Biotechnol. 34:752-759. DOI: https://doi.org/10.1038/nbt.3576

Raines MA, Magella B, Adam M, Potter SS. 2015. Key pathways regulated by HoxA9,10,11/HoxD9,10,11 during limb development. BMC Developmental Biology 15:28. DOI: https://doi.org/10.1186/s12861-015-00785

Rao L, Qian Y, Khodabukus A, Ribar T, Bursac N. 2018. Engineering human pluripotent stem cells into a functional skeletal muscle tissue. Nat Commun 9:126. DOI: https://doi.org/10.1038/s41467-017-02636-4

Relaix F, Rocancourt D, Mansouri A, Buckingham M. 2005. A Pax3/Pax7-dependent population of skeletal muscle progenitor cells. Nature 435: 948-953. DOI: https://doi.org/10.1038/nature03594

Roellig D, Tan-Cabugao J, Esaian S, Bronner ME. 2017. Dynamic transcriptional signature and cell fate analysis reveals plasticity of individual neural plate border cells. eLife 6:e21620. DOI: https://doi.org/10.7554/eLife.21620

Rubenstein AB, Smith GR, Raue U, Begue G, Minchev K, Ruf-Zamojski F, Nair VD, Wang X, Zhou L, Zaslavsky E, Trappe TA, Trappe S, Sealfon SC. 2020. Single-cell transcriptional profiles in human skeletal muscle. Sci Rep. 10:229. DOI: https://doi.org/10.1038/s41598-019-57110-6

Seale P, Sabourin LA, Girgis-Gabardo A, Mansouri A, Gruss P, Rudnick MA. 2000. Pax7 is required for the specification of myogenic satellite cells. Cell 102:777-786. DOI: https://doi.org/10.1016/s00928674(00)00066-0

Shao Z, Mellor IR, Brierley JM, Harris J, Usherwood PN. 1998. Potentiation and inhibition of nicotinic acetylcholine receptors by spermine in the TE671 human muscle cell line. The Journal of Pharmacology and Experimental Therapeutics 286:1269-1276.

Shea KL, Xiang W, LaPorta VS, Licht JD, Keller C, Basson MA, Brack AS. 2010. Sprouty1 regulates reversible quiescence of a self-renewing adult muscle stem cell pool during regeneration. Cell Stem Cell 6:117-129. DOI: https://doi.org/10.1016/j.stem.2009.12.015 
Shelton M, Metz J, Liu J, Carpenedo RL, Demers SP, Stanford WL, Skerjanc IS. 2014. Derivation and expansion of PAX7-positive muscle progenitors from human and mouse embryonic stem cells. Stem Cell Reports 3:516-529. DOI: https://doi.org/10.1016/j.stemcr.2014.07.001

Sherwood RI, Christensen JL, Conboy IM, Conboy MJ, Rando TA, Weissman IL, Wagers AJ. 2004. Isolation of adult mouse myogenic progenitors: functional heterogeneity of cells within and engrafting skeletal muscle. Cell 119:543-554. DOI: https://doi.org/10.1016/j.cell.2004.10.021

Shimozono S, limura T, Kitaguchi T, Higashijima S, Miyawaki A. 2013. Visualization of an endogenous retinoic acid gradient across embryonic development. Nature 496:363-366. DOI: https://doi.org/10.1038/nature12037

Shubin N, Tabin C, Carroll S. 1997. Fossils, genes and the evolution of animal limbs. Nature 388:639-648. DOI: https://doi.org/10.1038/41710

Soldatov R, Kaucka M, Kastriti ME, Petersen J, Chontorotzea T, Englmaier L, Akkuratova N, Yang Y, Häring M, Dyachuk V, Bock C, Farlik M, Piacentino ML, Boismoreau F, Hilscher MM, Yokota C, Qian X, Nilsson M, Bronner ME, Croci L, Hsiao WY, Guertin DA, Brunet JF, Consalez GG, Ernfors P, Fried K, Kharchenko PV, Adameyko I. 2019. Spatiotemporal structure of cell fate decisions in murine neural crest. Science 364:eaas9536. DOI: https://doi.org/10.1126/science.aas9536

Southard-Smith EM, Kos L, Pavan WJ. 1998. Sox10 mutation disrupts neural crest development in Dom Hirschsprung mouse model. Nat. Genet. 18:60-64. DOI: https://doi.org/10.1038/ng0198-60

Spence JR, Mayhew CN, Rankin SA, Kuhar MF, Vallance JE, Tolle K, Hoskins EE, Kalinichenko VV, Wells SI, Zorn AM, Shroyer NF, Wells JM. 2011. Directed differentiation of human pluripotent stem cells into intestinal tissue in vitro. Nature 470:105-109. DOI: https://doi.org/10.1038/nature09691

Stemmer M, Thumberger T, del Sol Keyer M, Wittbrodt J, Mateo JL. 2015. CCTop: an intuitive, flexible and reliable CRISPR/Cas9 target prediction tool. PLoS One 10:e0124633. DOI: https://doi.org/10.1371/journal.pone.0124633

Stuart T, Butler A, Hoffman P, Hafemeister C, Papalexi E, Mauck WM, Hao Y, Stoeckius M, Smibert P, Satija R. 2019. Comprehensive Integration of Single-Cell Data. Cell 177:1888-1902. DOI: https://doi.org/10.1016/j.cell.2019.05.031

Tierney MT, Gromova A, Sesillo FB, Sala D, Spenlé C, Orend G, Sacco A. 2016. Autonomous Extracellular Matrix Remodeling Controls a Progressive Adaptation in Muscle Stem Cell Regenerative Capacity during Development. Cell Rep. 14:1940-1952. DOI: https://doi.org/10.1016/j.celrep.2016.01.072

Toral-Ojeda I, Aldanondo G, Lasa-Elgarresta J, Lasa-Fernández H, Fernández-Torrón R, López de Munain A, Vallejo- Illarramendi A. 2016. Calpain 3 deficiency affects SERCA expression and function in the skeletal muscle. Expert reviews in molecular medicine, 18:e7. DOI: https://doi.org/10.1017/erm.2016.9 
Troy A, Cadwallader AB, Fedorov Y, Tyner K, Tanaka KK, Olwin BB. 2012. Coordination of satellite cell activation and self-renewal by Par-complex-dependent asymmetric activation of p38a/ $\beta$ MAPK. Cell Stem Cell 11: 541-553. DOI: https://doi.org/10.1016/j.stem.2012.05.025

Uezumi A, Fukada S, Yamamoto N, Takeda S, Tsuchida K. 2010. Mesenchymal progenitors distinct from satellite cells contribute to ectopic fat cell formation in skeletal muscle. Nat. Cell Biol. 12:143-152. DOI: https://doi.org/10.1038/ncb2014

Uezumi A, Ito T, Morikawa D, Shimizu N, Yoneda T, Segawa M, Yamaguchi M, Ogawa R, Matev MM, Miyagoe-Suzuki Y, Takeda S, Tsujikawa K, Tsuchida K, Yamamoto H, Fukada S. 2011. Fibrosis and adipogenesis originate from a common mesenchymal progenitor in skeletal muscle. J Cell Sci. 124:36543664. DOI: https://doi.org/10.1242/jcs.086629

Verma M, Asakura Y, Murakonda BSR, Pengo T, Latroche C, Chazaud B, McLoon LK, Asakura A. 2018. Muscle satellite cell cross-talk with a vascular niche maintains quiescence via VEGF and Notch signaling. Cell Stem Cell 23:530-543. DOI: https://doi.org/10.1016/j.stem.2018.09.007

Xi H, Fujiwara W, Gonzalez K, Jan M, Liebscher S, Van Handel B, Schenke-Layland K, Pyle, AD. 2017. In Vivo Human Somitogenesis Guides Somite Development from hPSCs. Cell Rep. 18:1573-1585. DOI: https://doi.org/10.1016/j.celrep.2017.01.040

Xi H, Langerman J, Sabri S, Chien P, Young CS, Younesi S, Hicks M, Gonzalez K, Fujiwara W, Marzi J, Liebscher S, Spencer M, Van Handel B, Evseenko D, Schenke-Layland K, Plath K, Pyle AD. 2020. A Human Skeletal Muscle Atlas Identifies the Trajectories of Stem and Progenitor Cells across Development and from Human Pluripotent Stem Cells. Cell Stem Cell, 27:158-176. DOI: https://doi.org/10.1016/j.stem.2020.04.017

Xu B, Wellik DM. 2011. Axial Hox9 activity establishes the posterior field in the developing forelimb. Proc Natl Acad Sci U S A.108:4888-4891. DOI: https://doi.org/10.1073/pnas.1018161108

Yusa K, Zhou L, Li MA, Bradley A, Craig NL. 2011. A hyperactive piggyBac transposase for mammalian applications. Proc Natl Acad Sci U S A 108:1531-1536. DOI: https://doi.org/10.1073/pnas.1008322108 
bioRxiv preprint doi: https://doi.org/10.1101/2020.09.14.295832; this version posted January 8, 2021. The copyright holder for this preprint (which was not certified by peer review) is the author/funder, who has granted bioRxiv a license to display the preprint in perpetuity. It is made available under aCC-BY-NC-ND 4.0 International license.

\section{FIGURES AND TABLES}




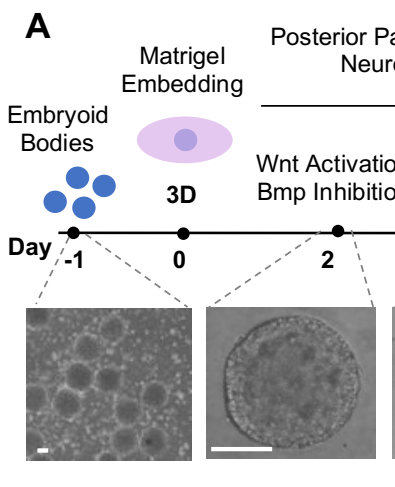

C

\section{Neuromesoderm / Posterior paraxial mesoderm \\ Day 5}

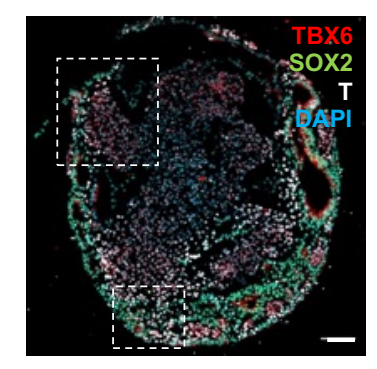

G
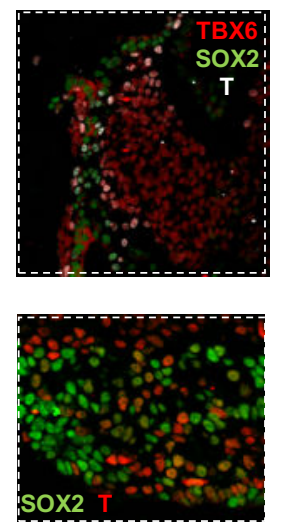

D

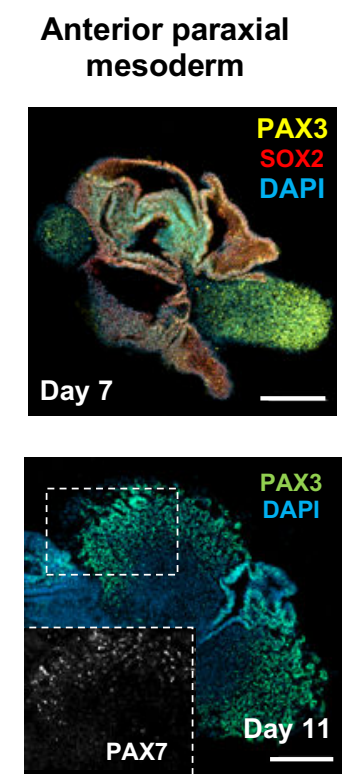

E

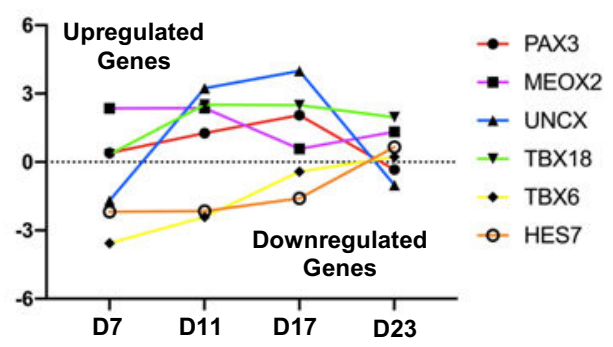

F

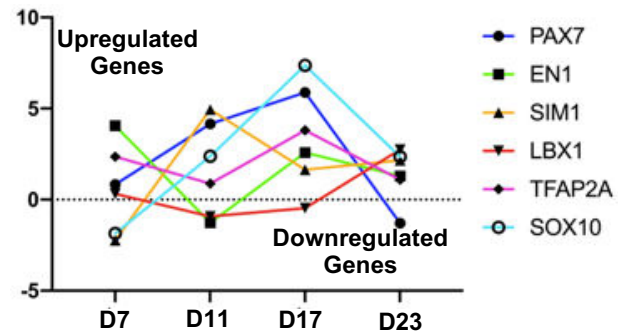

H
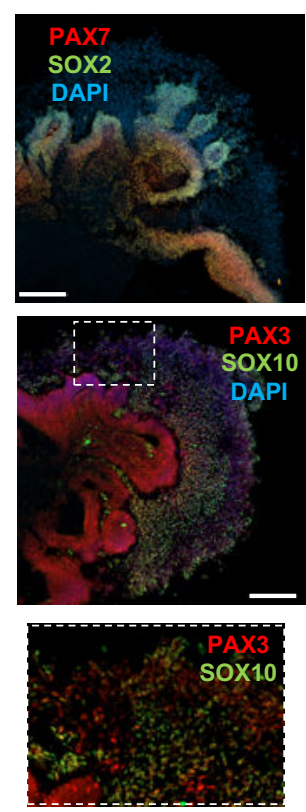
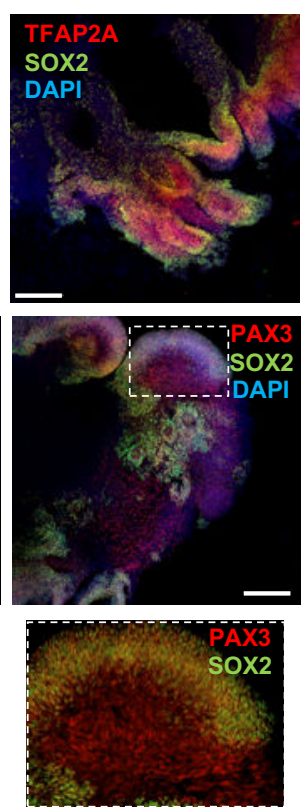
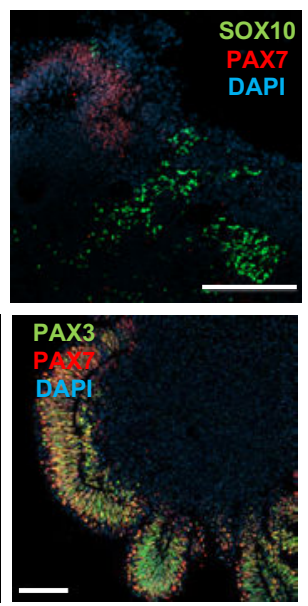

.

DAPI
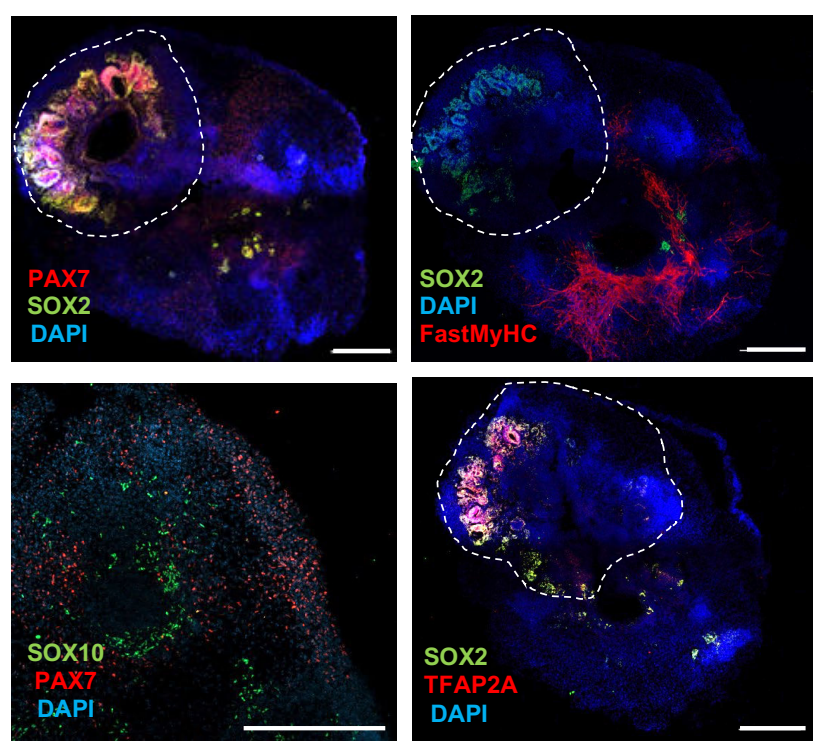
Figure 1. Skeletal muscle organoid protocol and correlation to fetal development. (A) Brightfield images of myogenic development stages, with corresponding cytokines/growth factors protocol applications (B) Graph depicting organoid development in size (Day 0, $n=51$; Day 3, $n=$ 46; Day 5, $n=48$; Day 7, $n=50$; Day 11, $n=50$; Day 17, $n=33$; for each timepoint organoids from 3 independent derivations were measured) (C) Representative mesodermal $\mathrm{T}^{+}$, neuromesodermal $\mathrm{T}^{+}$, SOX $2^{+}$and paraxial mesodermal TBX6 ${ }^{+}$organoid expression (in live DAPI ${ }^{-}$cells) at Day 5 (D) Representative organoid $\mathrm{PAX}^{+}$, mesodermal SOX2${ }^{-}$and neural SOX2 ${ }^{+}$expression at Day 7 ; PAX3/PAX7 coexpression at Day 11 (E) Graph depicting qPCR values for anterior PAX3/UNCX/MEOX2/TBX18 and posterior TBX6/HES7 somitic mesodermal markers (F) Graph depicting qPCR values for epaxial and hypaxial dermomyotomal PAX7/EN1/SIM1/ LBX1 and neural crest TFAP2A/SOX10 markers (G) Representative organoid neural plate border epithelial $\mathrm{PAX}^{+} / \mathrm{PAX}^{+} / \mathrm{SOX}^{+} / \mathrm{TFAP}^{+} \mathrm{A}^{+}$, paraxial mesodermal $\mathrm{PAX} 3^{+} / \mathrm{SOX}^{-}$and delaminating specified neural crest progenitor $\mathrm{PAX}^{+} / \mathrm{SOX} 0^{+}$expression at Day $17(\mathbf{H})$ Representative organoid myogenic FastMyHC ${ }^{+}, \mathrm{PAX}^{+}$and neural SOX2 ${ }^{+} / \mathrm{TFAP}_{2 \mathrm{~A}^{+}} / \mathrm{SOX} 10^{+}$expression at Day 23. Dashed line represents location of embryoid body embedded into Matrigel. Statistics: Values at each timepoint represent difference in mean relative expression for each gene (D7= Day 5 - Day 7, D11= Day 7 - Day 11, D17= Day 11 - Day 17, D23= Day 17 - Day 23) as derived by performing ordinary one-way ANOVA and Tukey's multiple comparison tests (E,F). Scale bars: $200 \mu \mathrm{m}$ (G), $100 \mu \mathrm{m}(\mathrm{A}, \mathrm{D}, \mathrm{H}), 50 \mu \mathrm{m}$ (C). $\mathrm{X}^{+}$organoid expression (in live $\mathrm{DAPI}^{-}$cells) at Day 5 (D) Representative organoid $\mathrm{PAX}^{+}$, mesodermal $\mathrm{SOX}^{-}$and neural $\mathrm{SOX}^{+}$expression at Day 7 ; PAX3/PAX7 coexpression at Day 11 (E) Graph depicting qPCR values for anterior PAX3/UNCX/MEOX2/TBX18 and posterior TBX6/HES7 somitic mesodermal markers (F) Graph depicting qPCR values for epaxial and hypaxial dermomyotomal PAX7/EN1/SIM1/ LBX1 and neural crest TFAP2A/SOX10 markers (G) Representative organoid neural plate border epithelial $\mathrm{PAX}^{+} / \mathrm{PAX}^{+}{ }^{+} / \mathrm{SOX}^{+} / \mathrm{TFAP}^{+} \mathrm{A}^{+}$, paraxial mesodermal $\mathrm{PAX} 3^{+} / \mathrm{SOX}^{-}$and delaminating specified neural crest progenitor $\mathrm{PAX}^{+} / \mathrm{SOX} 0^{+}$expression at Day 17 (H) Representative organoid myogenic FastMyHC ${ }^{+}, \mathrm{PAX}^{+}$and neural SOX2 ${ }^{+} / \mathrm{TFAP}_{2 \mathrm{~A}^{+}} / \mathrm{SOX} 10^{+}$expression at Day 23. Dashed line represents location of embryoid body embedded into Matrigel. Statistics: Values at each timepoint represent difference in mean relative expression for each gene (D7= Day 5 - Day 7, D11= Day 7 - Day 11, D17= Day 11 - Day 17, D23= Day 17 - Day 23) as derived by performing ordinary one-way ANOVA and Tukey's multiple comparison tests (E,F). Scale bars: $200 \mu \mathrm{m}(\mathbf{G})$, $100 \mu \mathrm{m}(\mathbf{A}, \mathbf{D}, \mathrm{H}), 50 \mu \mathrm{m}$ (C). 
bioRxiv preprint doi: https://doi.org/10.1101/2020.09.14.295832; this version posted January 8, 2021. The copyright holder for this preprint (which was not certified by peer review) is the author/funder, who has granted bioRxiv a license to display the preprint in perpetuity. It is made

A

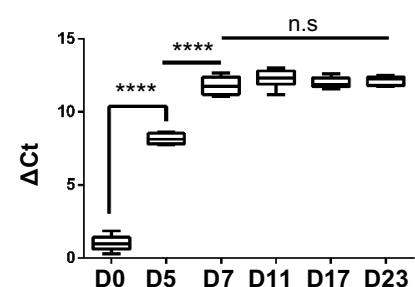
available under aCC-BY-NC-ND 4.0 International license.
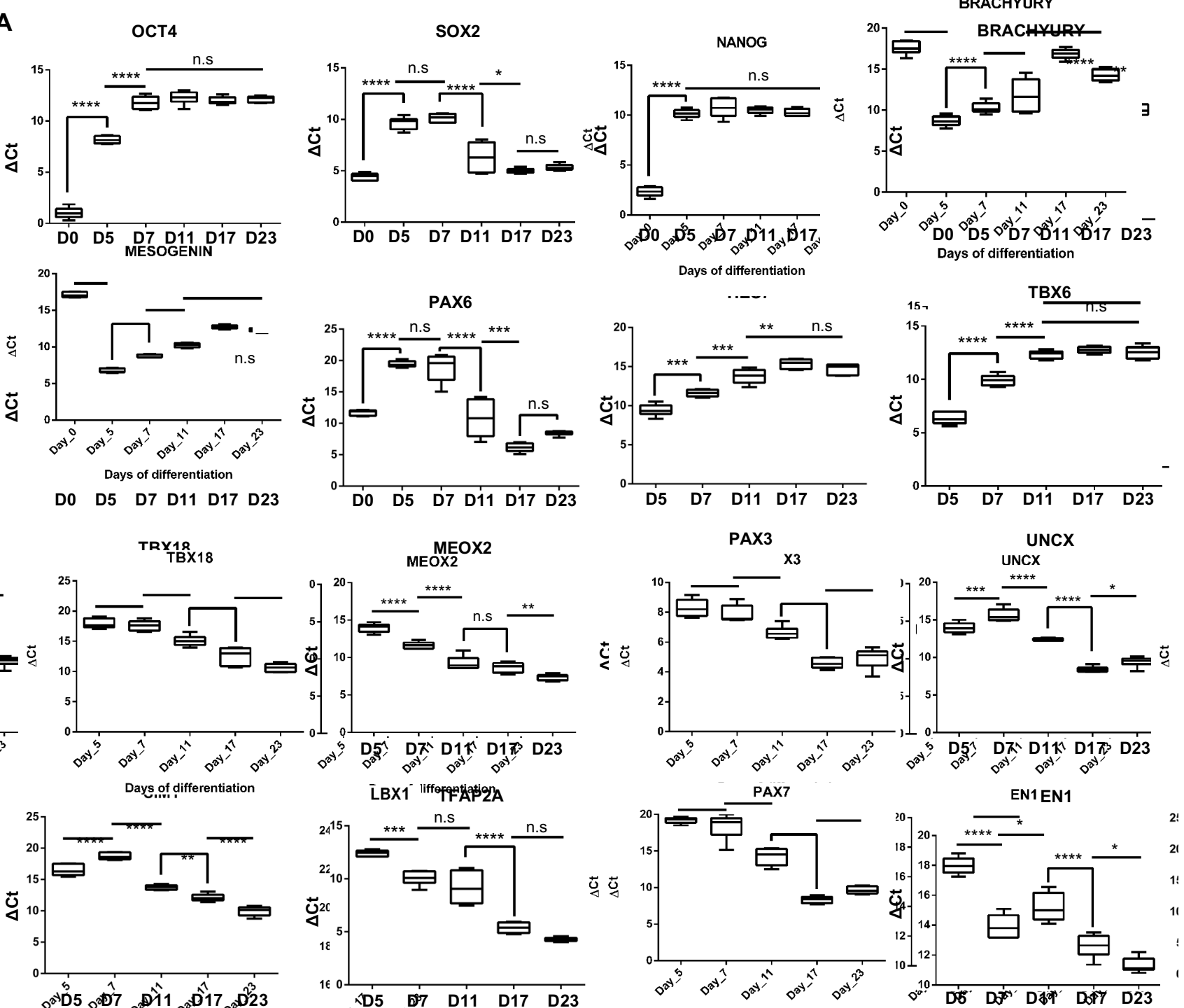

BRACHYURY
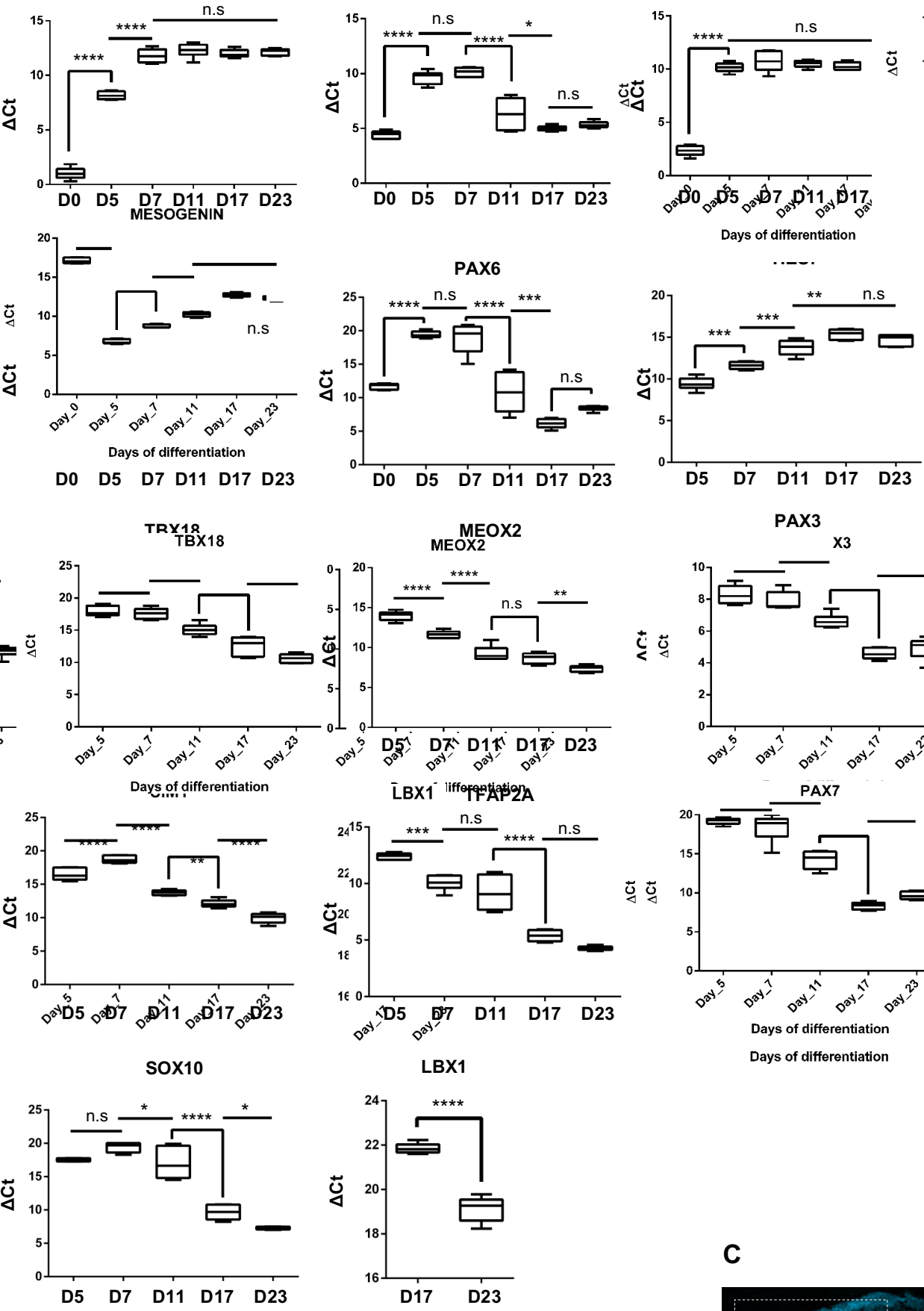

B

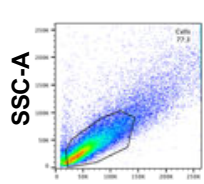

FSC-A

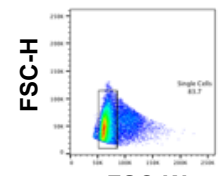

FSC-W Day 10

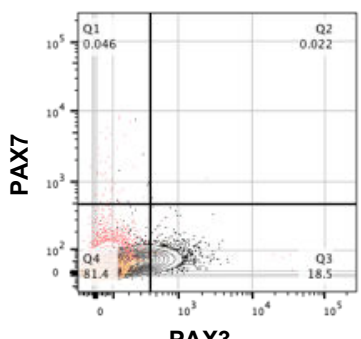

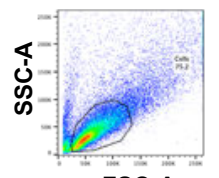
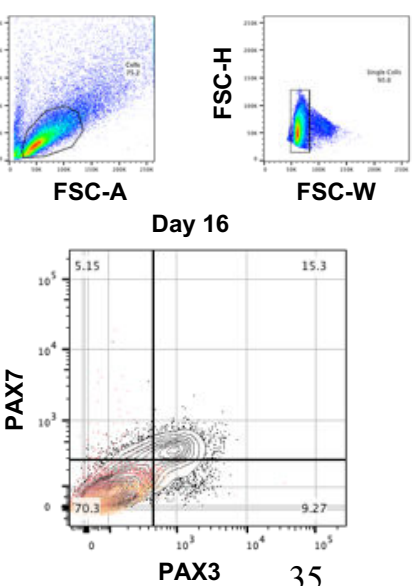

C

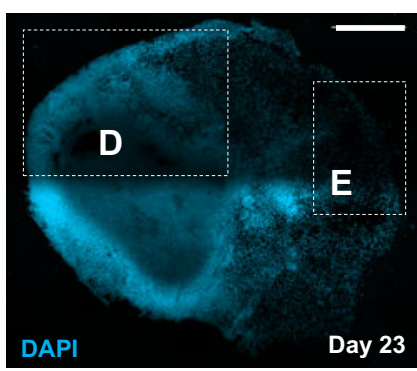

E
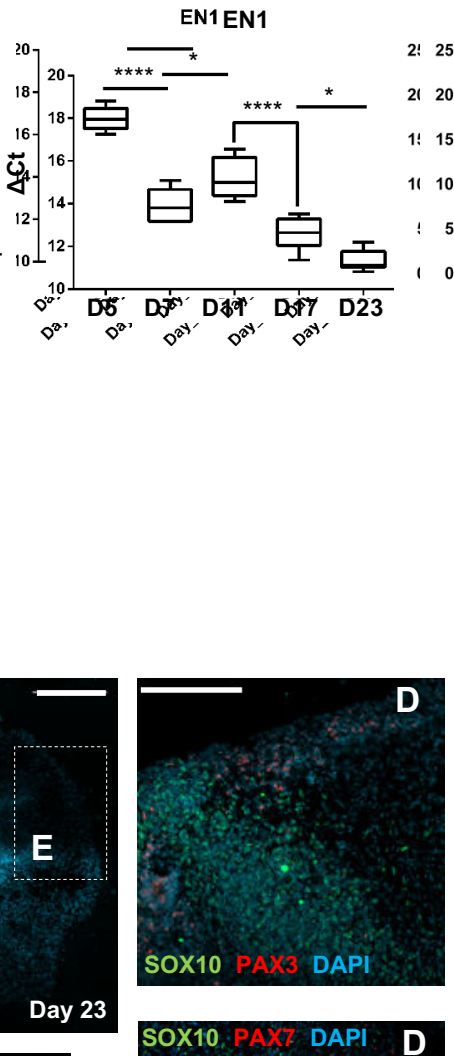

D

E

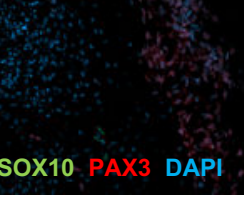


Figure 1 - figure supplement 1. Lineage representation and organoid culture progression at early stages of differentiation protocol. (A) qPCR analysis depicting relative expression of pluripotent (OCT4, SOX2, NANOG), mesodermal / posterior somitic (BRACHYURY,MESOGENIN,TBX6,HES7), anterior somitic (PAX3,UNCX,TBX18,MEOX2), dermomyotomal (PAX7, SIM1, EN1, LBX1) and neural tube / crest markers (SOX2, PAX6, TFAP2A, SOX10) (B) Gating strategies and FACS intracellular quantification of PAX3 and PAX7 markers at Day 10 and 16 (C) Tile scan overview at Day 23 showing neural crest SOX $10^{+}$ populations close to neural plate border epithelium (D) and SOX $10^{-} / \mathrm{PAX}^{+}$populations at more outer locations (E). For each replicate we pooled 6 organoids, $n=6$; gene expression normalized to housekeeping gene. Statistics: ${ }^{*} \mathrm{P}<0.05$, ${ }^{* *} \mathrm{P}<0.01$, ${ }^{* * *} \mathrm{P}<0.001$, ${ }^{* * * *} \mathrm{P}<0.0001$, ns: not significant. FACS plots, yellow: unstained population, red: isotype control, gray: $\mathrm{PAX} 7^{+}$or $\mathrm{PAX} 3^{+}$ population. Scale bars, 500uM (C), 200uM (D, E). 
bioRxiv preprint doi: https://doi.org/10.1101/2020.09.14.295832; this version posted January 8, 2021. The copyright holder for this preprint (which was not certified by peer review) is the author/funder, who has granted bioRxiv a license to display the preprint in perpetuity. It is made available under aCC-BY-NC-ND 4.0 International license.

A

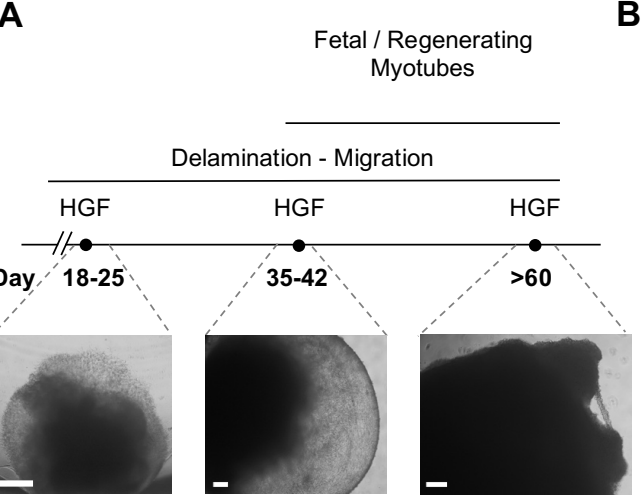

C

Migration of Myogenic Progenitors Neural Plate Boarder and Neural Crest Lineage arrest Day 35
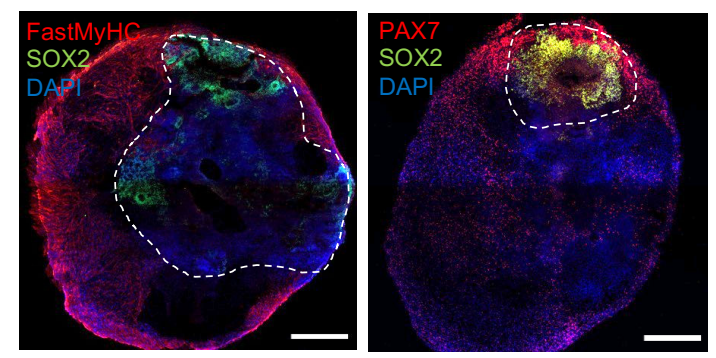

D
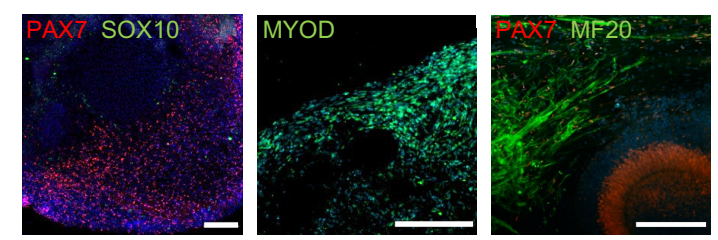

E
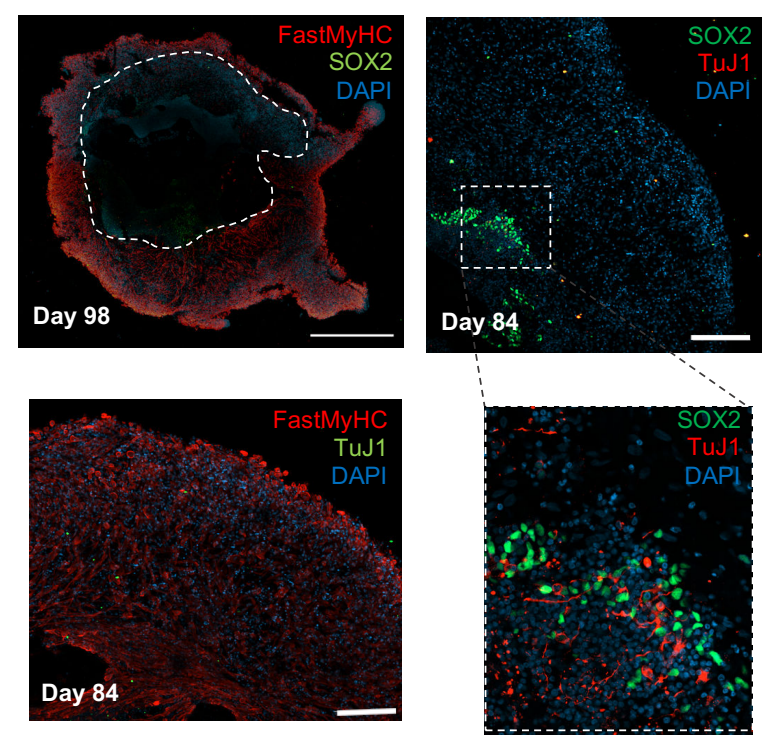

\section{Top Up-regulated Enriched GO Terms}

Muscle structure development Muscle contraction Muscle system process

Anatomical structure development Anatomical structure morphogenesis

Developmental process

System development

Animal organ development

Multicellular organism development Extracellular matrix organization

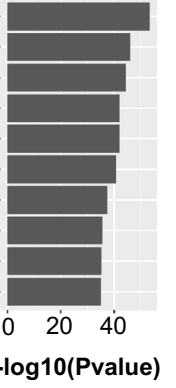

\section{Top Down-regulated Enriched GO Terms}

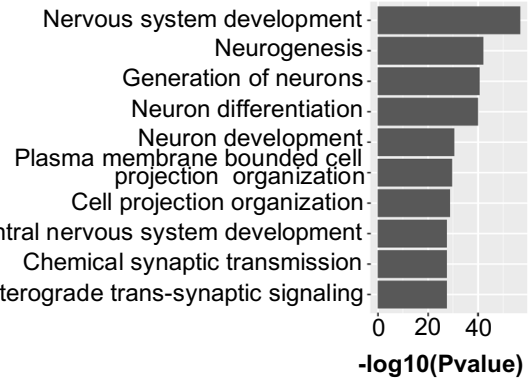

$\mathbf{F}$

PAX7

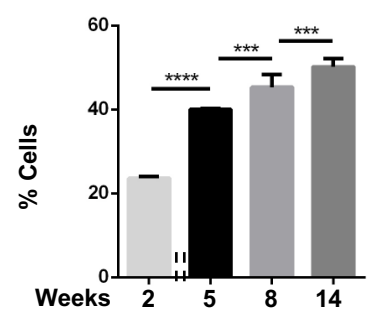

MYOD1

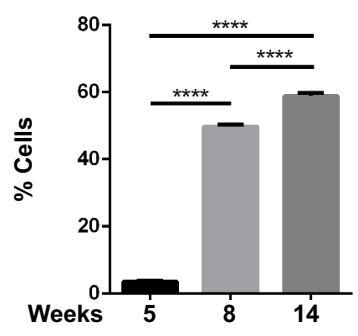

G
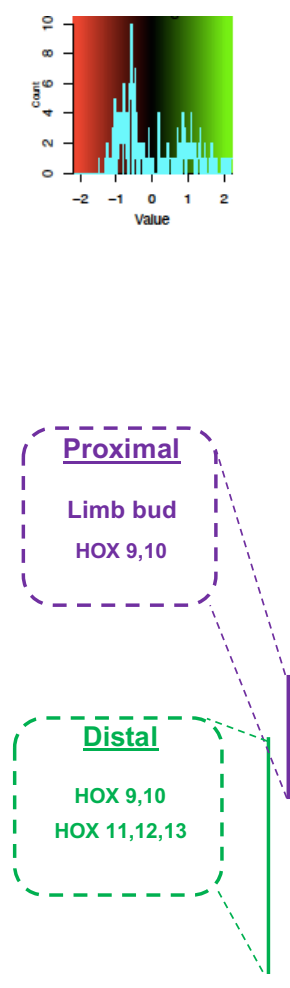
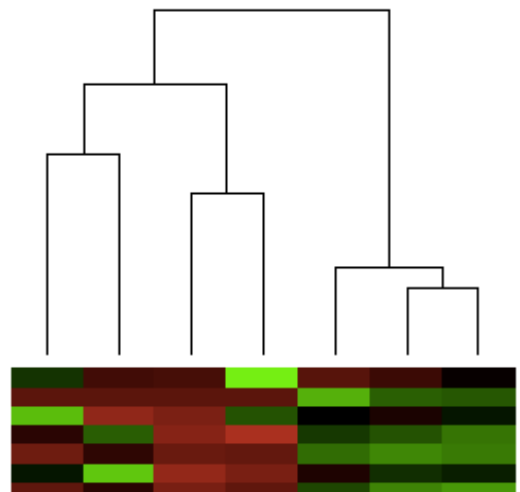

HOXB1

HOXD1

HOXA2

HOXB2
HOXA3

HOXD3

HOXA4

HOXB4

HOXC4

HOXD4
HOXA5

HOXBS
HOXC5

HOXAG

HOXBG

HOXC6

HOXA7

HOXB7

HOXB8
HOXC8

HOXCC
HOXDB

HOXA9

HOXB9

HOXC9

HOXD9

HOXA10
HOXC10

HOXA11

HOXC11

HOXD1

HOXC12

HOXD12
HOXA13

HOXB13

$\mathrm{HOXC13}$
$\mathrm{HOXD} 13$

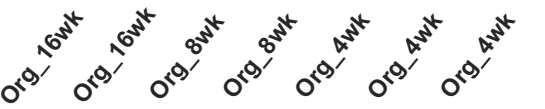


Figure 2. Neural lineage development during skeletal muscle organoid progression. (A) Stepwise brightfield images depicting delamination / migration of progenitor population during organoid culture progression and corresponding myofiber formation (B) Gene ontology enrichment analysis comparing 4 and $8 \mathrm{w}$ organoids attributes muscle identity at $8 \mathrm{w}$ post differentiation and highlights muscle system development and neural lineage arrest among the top upregulated and downregulated gene ontology terms, respectively (C-E) Organoid overview at Day 35 indicates predominant expression of $\mathrm{FastMyHC}^{+}$and $\mathrm{PAX}^{+}$myogenic populations, while $\mathrm{SOX}^{+}{ }^{+}$neural populations demarcate SOX2 neural plate border epithelium location as observed at earlier stages (Day 16) (C); PAX7 cells are of myogenic origin $\left(\mathrm{PAX}^{+} / \mathrm{SOX} 10^{-}\right), \mathrm{MF}^{+} 0^{+}$myotubes are in their proximity and $\mathrm{MYOD} 1^{+}$cells appear at organoid periphery (D); $\mathrm{TUJ}^{+}{ }^{+}$neurons are restricted to inner organoid areas and close to SOX ${ }^{+}$epithelium, while FastMyHC ${ }^{+}$myofibers occupy exterior organoid areas(E) (F) Histographs based on FACS intracellular quantification depicting percentage of $\mathrm{PAX} 7^{+}$or $\mathrm{MYOD} 1^{+}$cells through differentiation protocol. For each replicate we pooled 10 organoids, $\mathrm{n}=10$ Statistics: ${ }^{*} \mathrm{P}<0.05$, ${ }^{* *} \mathrm{P}<0.01$, ${ }^{* * *} \mathrm{P}<0.001$, ${ }^{* * * *} \mathrm{P}<0.0001$, ns: not significant (G) Heatmap of HOX gene cluster emphasizes organoid culture limb axial anatomical identity, by depicting transition from an initial limb bud (HOX 9-10) towards a more distal identity (HOX 11-13)

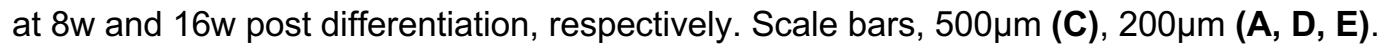


bioRxiv preprint doi: https://doi.org/10.1101/2020.09.14.295832; this version posted January 8, 2021. The copyright holder for this preprint (which was not certified by peer review) is the author/funder, who has granted bioRxiv a license to display the preprint in perpetuity. It is made available under aCC-BY-NC-ND 4.0 International license.

A
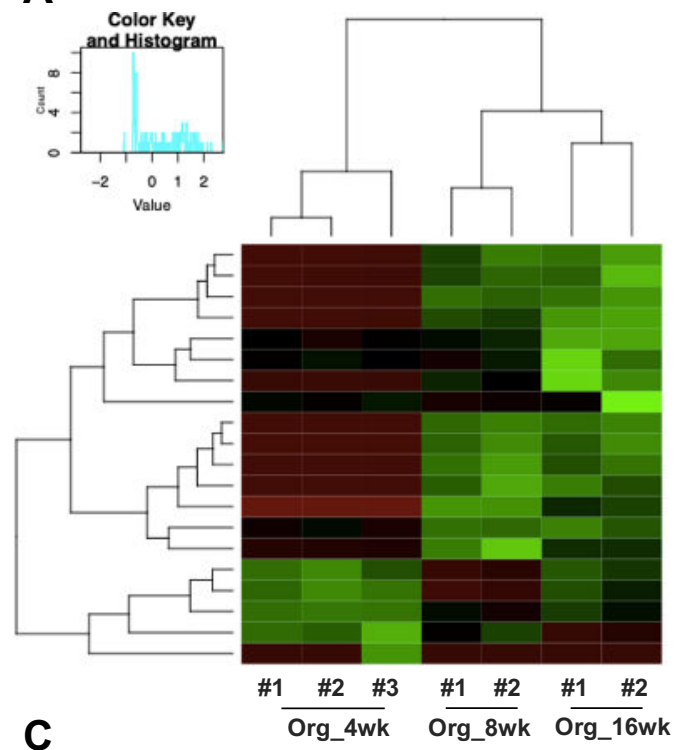

C
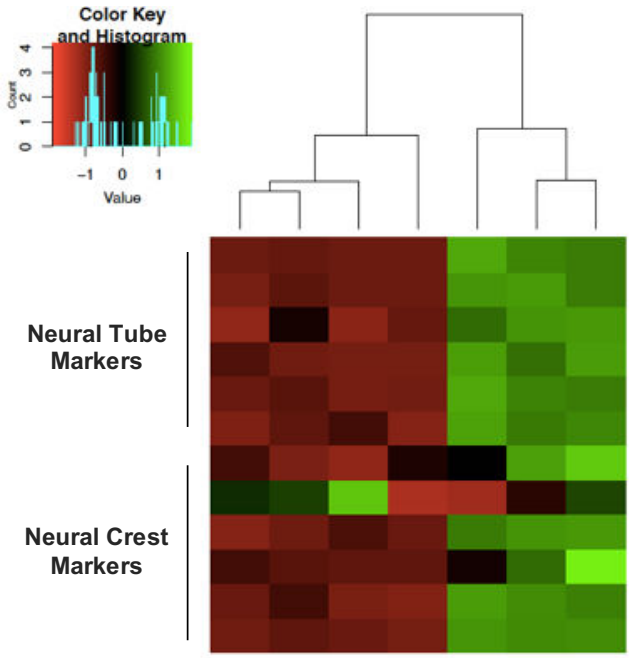

\#1 $\quad$ \#2 $\quad$ \#1 $\quad$ \#2 \#1 \#2 \#3

$\overline{\text { Org_8wk }} \overline{\text { Org_16 }} w \mathrm{Org} \overline{\text { Orgwk }}$
B

Org_8wk vs Org_4wk

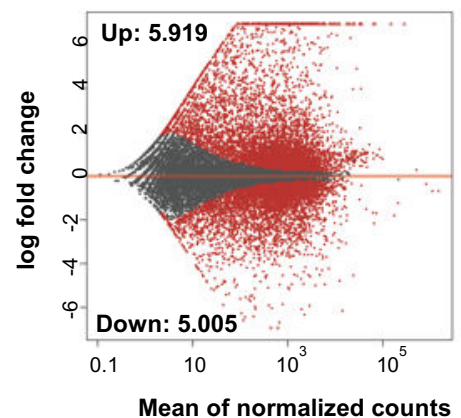

Delamination / Migration - Myogenic

\section{D}

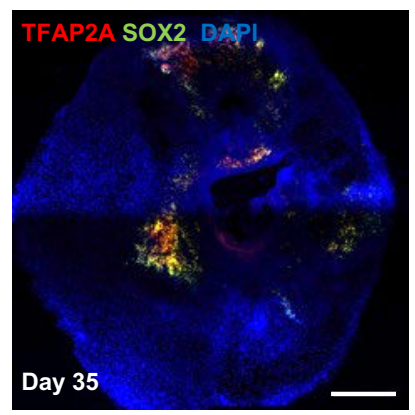

E

FSC-A

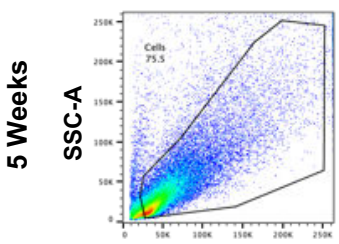

FSC-A

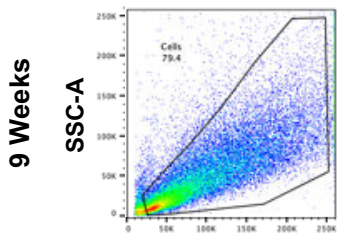

FSC-A
FSC-W

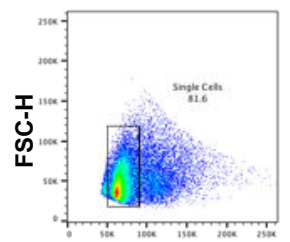

FSC-W

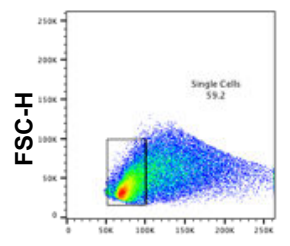

FSC-W
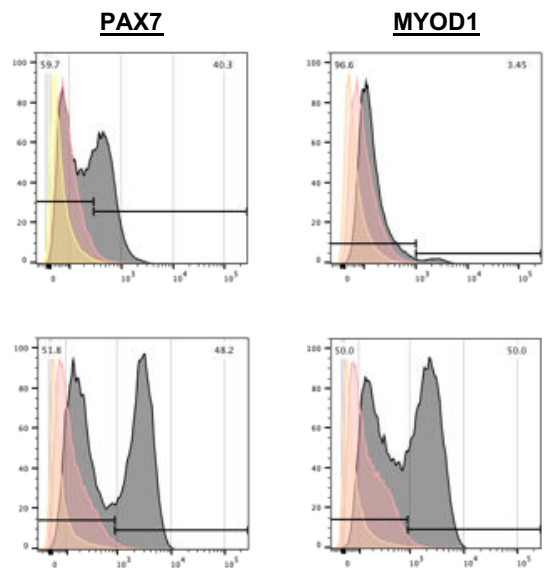

Rhodamine Red-X 
Figure 2 - figure supplement 1 . Myogenic versus neural fate during organoid development. (A) Heatmap of limb myogenic progenitor markers emphasizes upregulation through organoid protocol development (B) Differential expression comparison highlights upregulated $(n=5.919)$ and downregulated ( $n=5.005$ ) genes between 8 vs 4 w organoids. (Padj $<0.001)$ (C) Heatmap of neural tube and neural crest markers during 4,8 and $16 \mathrm{w}$ post differentiation highlights neural lineage arrest from $4 \mathrm{w}$ onwards (D) Organoid overview at Day 35 indicates presence of MF $20^{+}$myofibers in proximity of $\mathrm{PAX} 7^{+}$cells and delamination migration of mainly myogenic origin since SOX2 and TFAP2A expression is restricted towards inner organoid areas (E) Gating strategy applied to quantify MYOD ${ }^{+}$(committed state) and $\mathrm{PAX}^{+}$(progenitor state) populations at 5 and $8 \mathrm{w}$ post differentiation. Yellow histogram: unstained population, red: isotype control, gray: $\mathrm{PAX}^{+}$or MYOD $^{+}$population. Scale bars, $500 u M(D)$. 
bioRxiv preprint doi: https://doi.org/10.1101/2020.09.14.295832; this version posted January 8, 2021. The copyright holder for this preprint (which was not certified by peer review) is the author/funder, who has granted bioRxiv a license to display the preprint in perpetuity. It is made available under aCC-BY-NC-ND 4.0 International license.

A

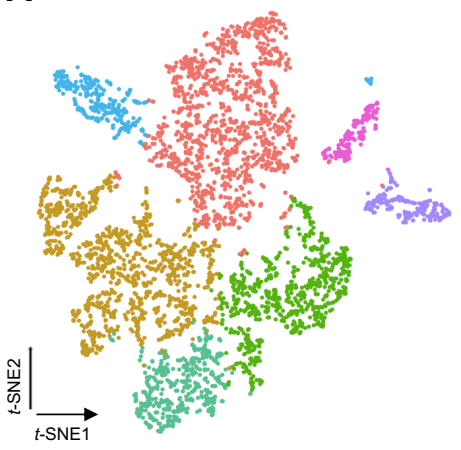

E

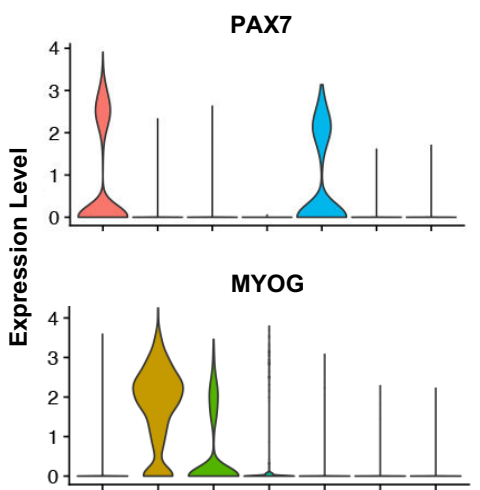

G

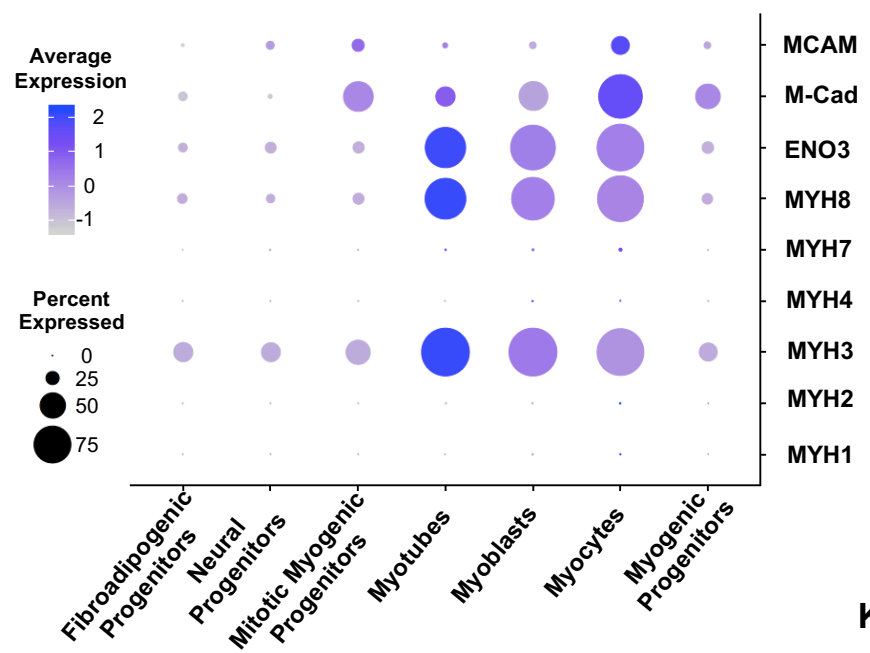

H
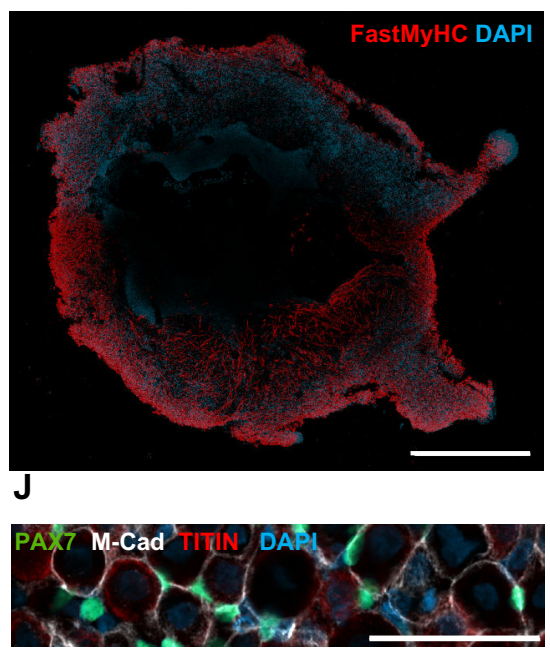

B

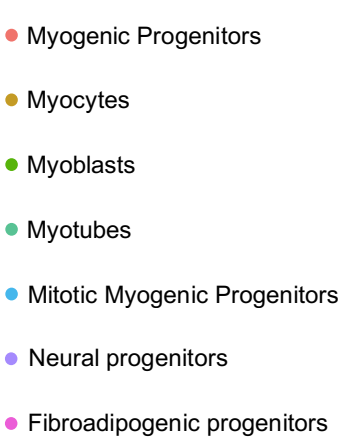

MYOD1
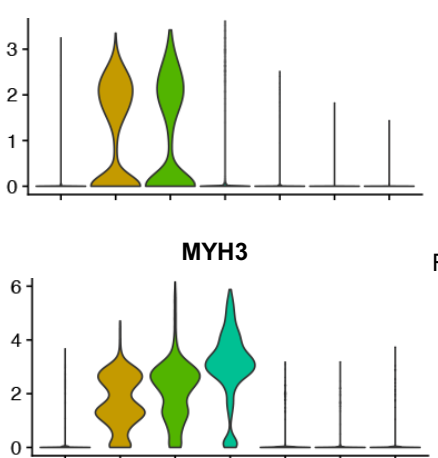

I
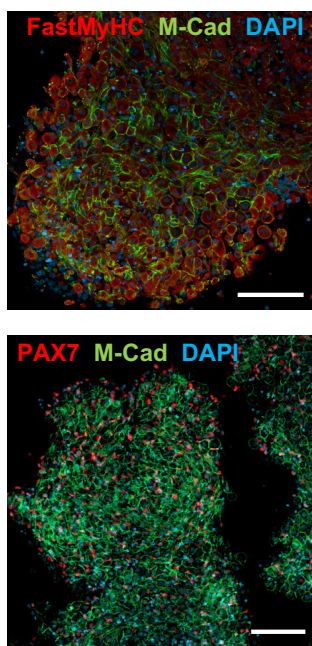

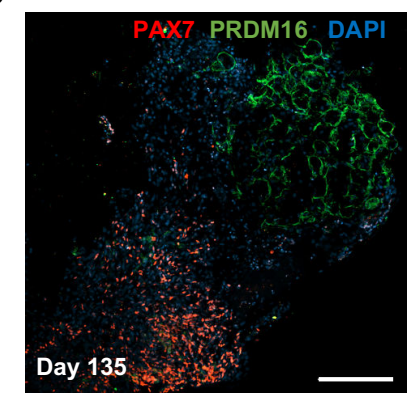

C

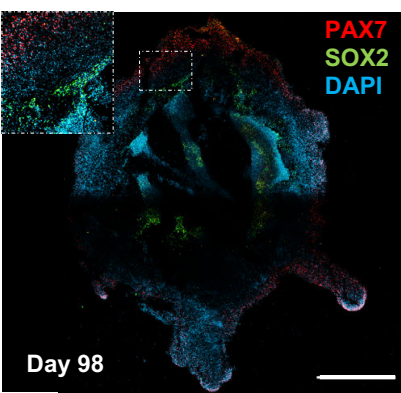

D

Oil O Red

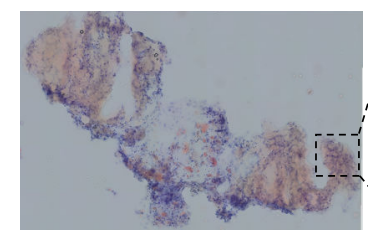

$\mathbf{F}$

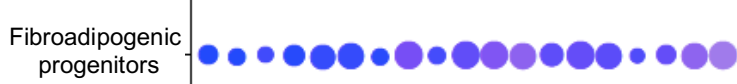
progenitors

Neura

Mitotic

Myogenic

Progenitors

Myotubes

Myoblasts

Myocytes

Myogenic

Progenitors

.

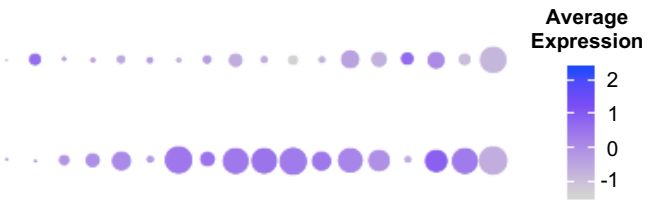

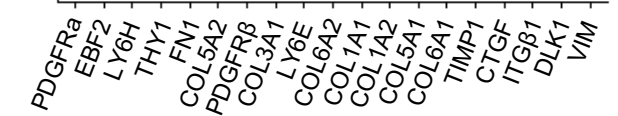
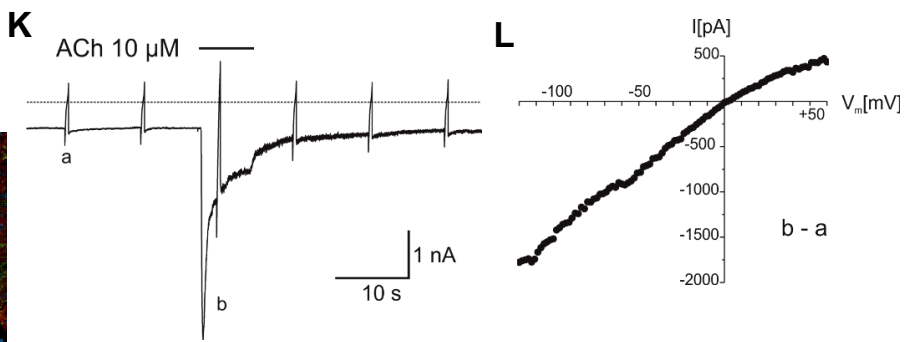

M

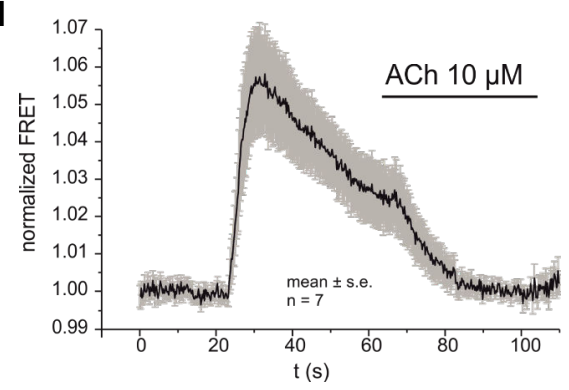


Figure 3. Skeletal muscle organoid characterization at single cell resolution. (A) t-SNE visualization of color-coded clustering ( $n=4.323$ cells) at $12 \mathrm{w}$ post differentiation highlights predominant presence of skeletal muscle lineage, represented by clusters corresponding to myogenic progenitors ( $n=1625$ cells, $37 \%$ of total population) in non-dividing ( $n=1317$ cells) and mitotic ( $n=308$ cells) state, myoblasts ( $n=731$ cells), myocytes $(n=1147$ cells) and myotubes $(n=442$ ). Additionally, mesenchymal and neural lineages are represented by 2 smaller clusters of fibroadipogenic ( $n=165$ cells) and neural ( $n=213$ cells) progenitors, respectively (B) Immunocytochemistry at Day 135 indicates derivation of PRDM16 ${ }^{+}$adipocyte clusters distinct from $\mathrm{PAX7}^{+}$myogenic progenitors (C) Organoid overview at Day 98 depicts expression of PAX7 ${ }^{+}$ myogenic populations and highlights SOX2+ neural populations towards organoid interior (D) Positive areas with Oil O Red staining indicate derivation of adipocytes in organoid culture at Day 135 (E) Violin plots of key markers PAX7, MYOD1, MYOG, MYH3 from each stage as in 3A depict relative expression levels and emphasize gradual transition from myogenic progenitor to myotube subcluster (F) Dot plot showing expression of representative genes related to adipogenesis and fibrogenesis across the 7 main clusters. Circle area represents percentage of gene ${ }^{+}$cells in a cluster, color reflects average expression level (gray, low expression; blue, high expression) (G) Dot plot showing expression of representative genes related to fetal myogenesis across the 7 main clusters. Circle area represents percentage of gene ${ }^{+}$cells in a cluster, color reflects average expression level (gray, low expression; blue, high expression). (H-J) Representative organoid overview at Day 98 indicates predominant expression of Fast MyHC fetal myofibers $\mathbf{( H , J )}$, positive for M-Cadherin and in $\mathrm{PAX7}^{+}$cells proximity $(\mathbf{I}, \mathbf{J})(\mathbf{K})$ Representative recording $(n=6)$ of acetylcholine (ACh)-induced changes in holding current in a single skeletal muscle cell. ACh (10 $\mu \mathrm{M}$ ) was applied as indicated by the bar. Holding potential $-90 \mathrm{mV}$. Downward deflections represent membrane currents in response to depolarizing voltage ramps (duration $500 \mathrm{~ms}$ ) from $-120 \mathrm{mV}$ to $+60 \mathrm{mV}$. Dashed line indicates zero current level. (L) I/N curve of nAChR currents obtained by subtraction of voltage ramp-induced changes of current in presence and absence of ACh (10-5 $\mathrm{mol} / \mathrm{L}$ ), corresponding lower-case letters $\mathrm{b}$ - a (M) Summarized FRET-recordings from skeletal muscle cells transfected with Twitch2B to monitor the increase in [Ca2+]i during ACh application

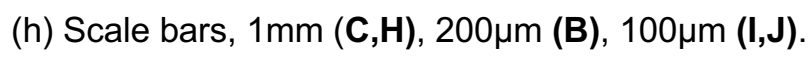


bioRxiv preprint doi: https://doi.org/10.1101/2020.09.14.295832; this version posted January 8, 2021. The copyright holder for this preprint (which was not certified by peer review) is the author/funder, who has granted bioRxiv a license to display the preprint in perpetuity. It is made

A

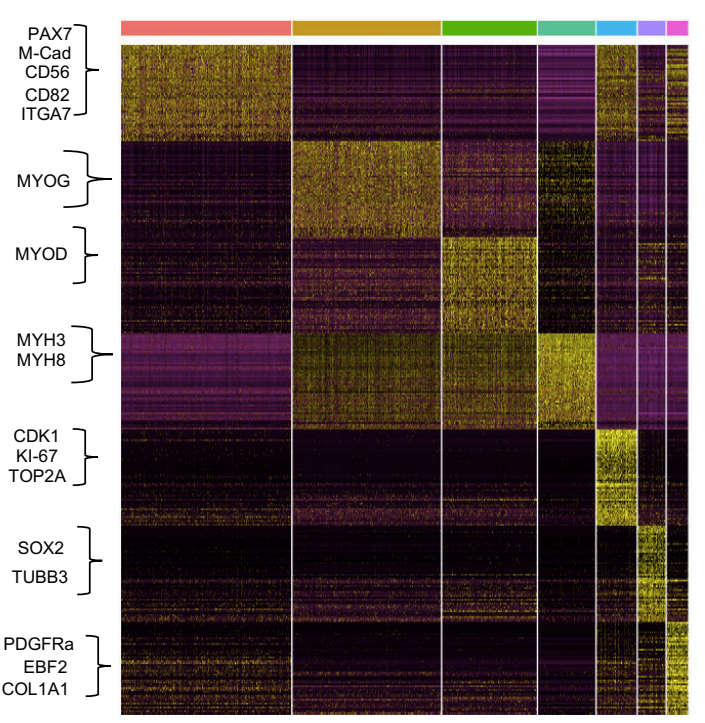

C

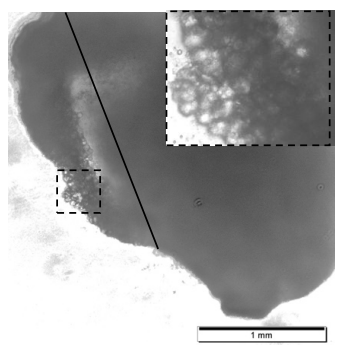

D available under aCC-BY-NC-ND 4.0 International license. allicense. 
Figure 3 - figure supplement 1 . Single cell RNA seq expression profiling and lineage representation in organoid culture at $12 \mathrm{w}$. (A) Gene signatures of $t$-SNE described clusters based on relative expression levels of the 50 most significant markers for each of the 7 clusters (B) $t$-SNE plot of myogenic and fibroadipogenic markers (C) Brightfield image at Day 135 highlights presence of structures reassembling adipocytes (D) Immunocytochemistry at Day 135 emphasizes derivation of $\mathrm{PRDM}_{16}{ }^{+}$cells in FastMyHC ${ }^{+}$myofibers proximity (E) Organoid overview at Day 98 highlights muscle system development at outer and neural lineage representation at more inner sites (F) $t$-SNE plot of key markers PAX7, MYOD1, MYOG, MYH from each stage depict relative expression levels and emphasize gradual transition from myogenic progenitor to myotube subcluster (G) Heatmap of embryonic or fetal myogenic markers depicts a fetal environment during 8 to16 w post differentiation $(\mathrm{H})$ Two-dimensional principal component analysis based on gene expression profiling between samples separates skeletal muscle organoid cluster from pluripotent and highlights greater difference in variance between 4 and 8-16w subgroups in comparison to 8 and 16 w subgroup. w.p.d.: weeks post differentiation. Scale bars, $1 \mathrm{mM}$ (D), 200uM (E, F). 
bioRxiv preprint doi: https://doi.org/10.1101/2020.09.14.295832; this version posted January 8, 2021. The copyright holder for this preprint (which was not certified by peer review) is the author/funder, who has granted bioRxiv a license to display the preprint in perpetuity. It is made available under aCC-BY-NC-ND 4.0 International license.

A

Org_16wk vs Org_8wk

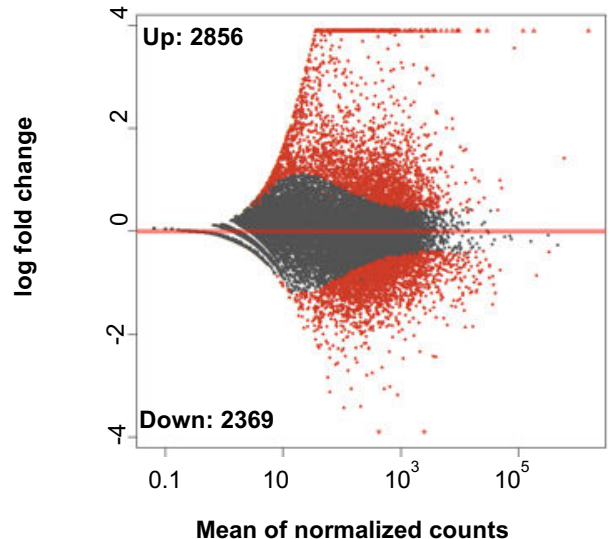

C

Top Down-regulated Enriched GO Terms

Cellular component organization Cellular component organization

Organelle organization

DNA packaging

Nucleosome assembly

Chromatin assembly

Cellular component biogenesis

Mitotic nuclear division

Mitotic cell cycle

Mitotic cell cycle process

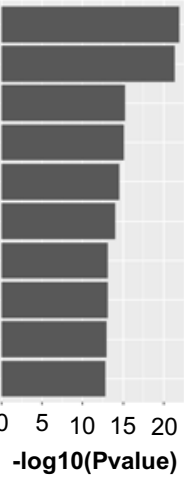

B

\section{Top Up-regulated Enriched GO Terms}

Positive regulation of RNA metabolic process Positive regulation of nucleic acid-templated transcription

Positive regulation of RNA biosynthetic process

Positive regulation of transcription, DNA templated

Developmental process Positive regulation of nucleobase containing compound metabolic process

Regulation of ion transport Positive regulation of gene expression Positive regulation of transcription by RNA pol. II Anatomical structure development

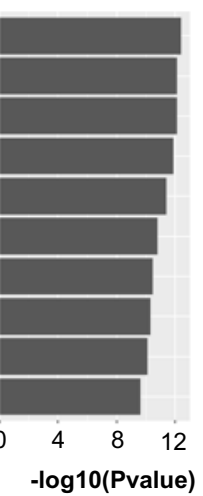

D

Up-regulated Enriched GO Terms

Muscle structure development Ion transmembrane transport Cation transport Regulation of cation transmembrane transport Muscle system process Striated muscle cell differentiation Cellular response to chemical stimulus Sarcomere organization Striated muscle contraction

Muscle organ development Maintenance of synapse structure Response to stimulus regulating muscle adaptation Neuromuscular synaptic transmission Regulation of ryanodine-sensitive calcium-release channel activity

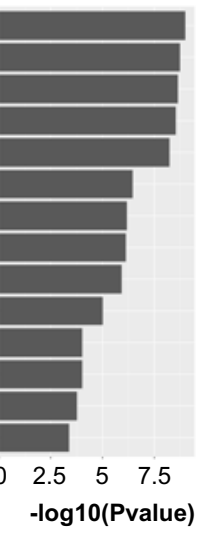

E

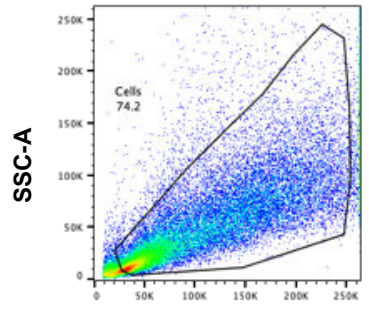

FSC-A

PAX7

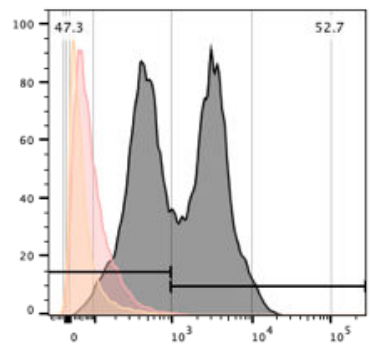

14 Weeks

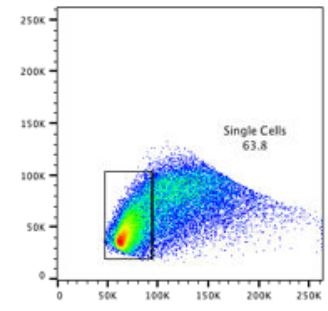

FSC-W

MYOD1

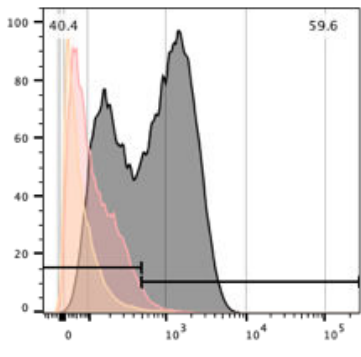

$\mathbf{F}$
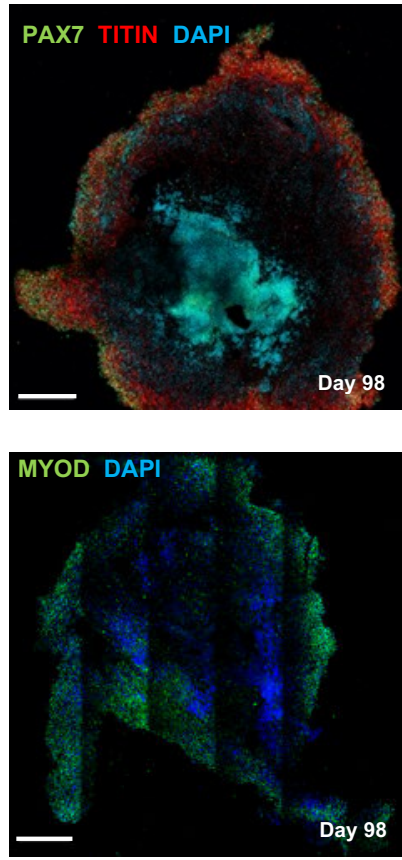

Rhodamine Red-X 
Figure 3 - figure supplement 2. Skeletal muscle organoid culture maturation and identity. (A) Differential expression comparison highlights upregulated $(n=2.856)$ and downregulated ( $n=2.369)$ genes between 16 and 8 w organoids (Padj<0.001) (B-C) Gene ontology enrichment analysis at $16 \mathrm{w}$ depicts top statistically significant upregulated (B) and downregulated (C) gene ontology (GO) terms; (D) statistically significant upregulated GO terms further highlight skeletal muscle maturation (E) Gating strategy applied to quantify MYOD $1^{+}$(committed state) and PAX7 ${ }^{+}$ (progenitor state) population at $14 \mathrm{w}$ post differentiation $(\mathbf{F})$ Organoid overview at Day 98 depicts high proportion of $\mathrm{PAX7}^{+} / \mathrm{MYOD}^{+}$cells towards outer areas. Yellow histogram: unstained population, Red histogram: Isotype Control, Gray Histogram: $\mathrm{PAX}^{+}$or $\mathrm{MYOD}^{+}$population. Scale bars, 500uM (F) 
bioRxiv preprint doi: https://doi.org/10.1101/2020.09.14.295832; this version posted January 8, 2021. The copyright holder for this preprint (which was not certified by peer review) is the author/funder, who has granted bioRxiv a license to display the preprint in perpetuity. It is made available under aCC-BY-NC-ND 4.0 International license.

A

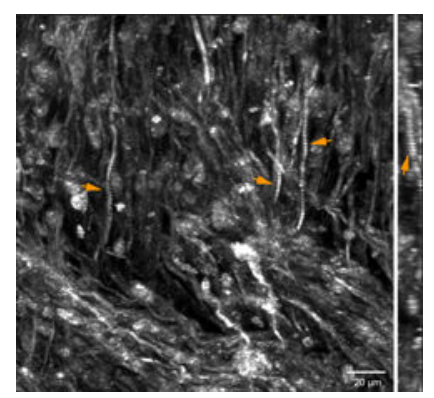

B

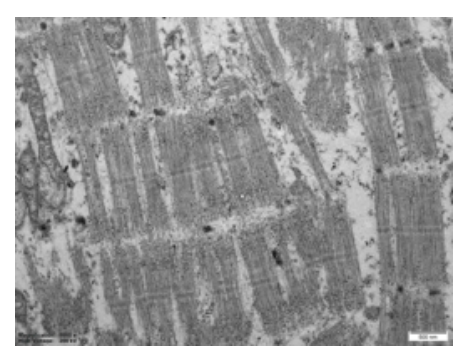

C

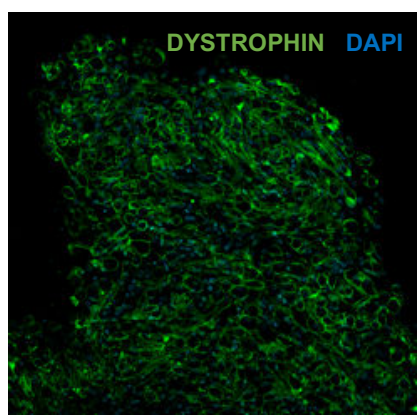

D

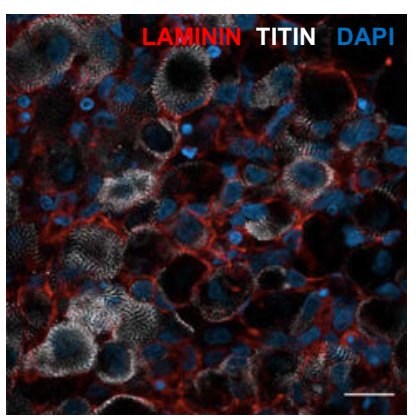

E

LGMD2A patient

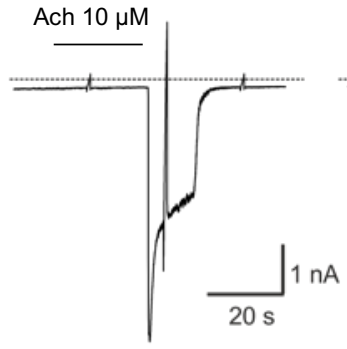

DMD_IPS1

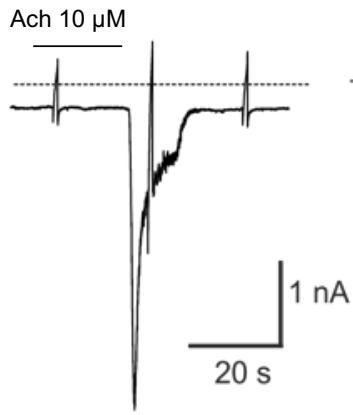

BMD_IPS1

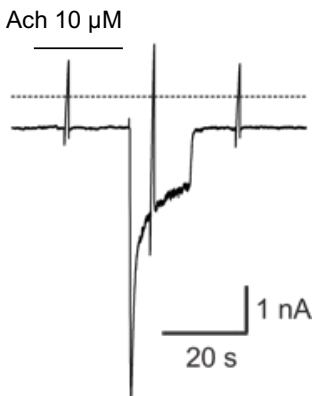

$\mathbf{F}$
LGMD2A patient

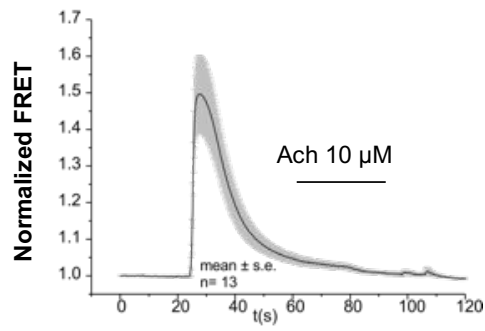

DMD_IPS1

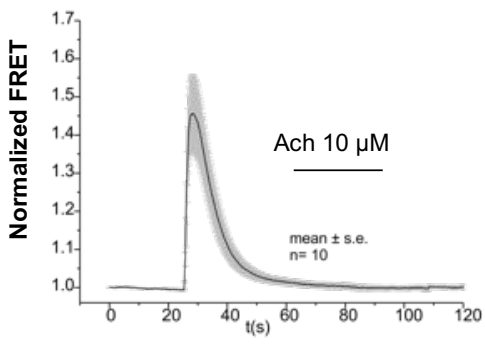

BMD_IPS1

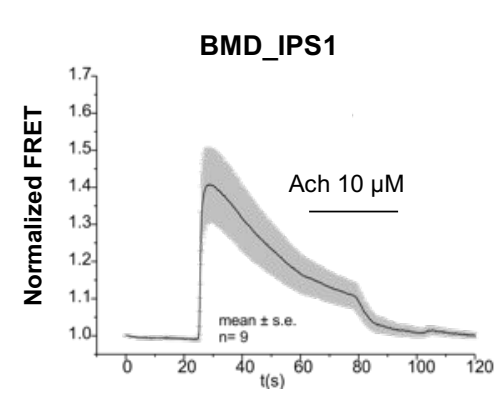

LGMD2A Isogenic

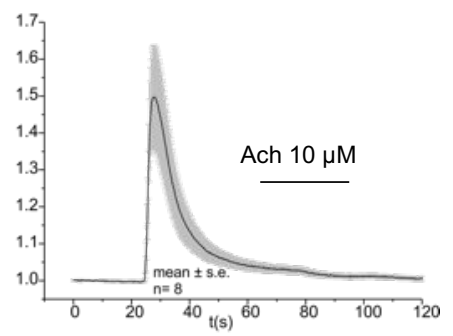

DMD_IPSCORE_65_1

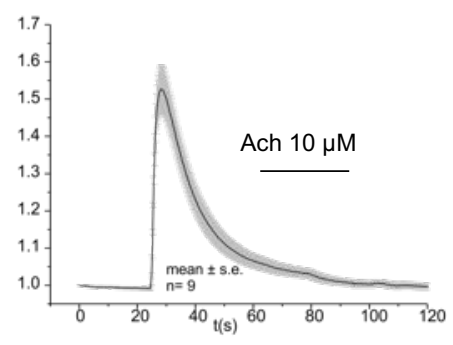


Figure 3 - figure supplement 3. Functional properties of organoid derived skeletal muscle myofibers. (A) Second Harmonic Generation imaging (SHG) from areas with dense fiber network reveals myofibril formation with distinct sarcomeres ( $z$ plane of stack right) (B) Electron microscopy depicts myofibrils with well-developed sarcomeres (C,D) Skeletal muscle organoid derived myofibers expressed LAMININ and DYSTROPHIN (E) Representative recording of acetylcholine (Ach)-induced changes in holding current in a single skeletal muscle cell from organoid derived skeletal muscle cells from iPSC lines with Duchenne (DMD_IPS1, DMD_IPSCORE_65_1), Becker (BMD_IPS1) or LGMD2A genetic background. ACh $(10 \mu \mathrm{M})$ was applied as indicated by the bar. Holding potential $-90 \mathrm{mV}$. Downward deflections represent membrane currents in response to depolarizing voltage ramps (duration $500 \mathrm{~ms}$ ) from $-120 \mathrm{mV}$ to $+60 \mathrm{mV}$. Dashed line indicates zero current level. (F) Summarized FRET-recordings from organoid derived skeletal muscle cells from iPSC lines with Duchenne (DMD_IPS1, DMD_IPSCORE_65_1), Becker (BMD_IPS1) or LGMD2A genetic background; transfected with Twitch2B to monitor the increase in [Ca2+]i during ACh application. Scale Bars, 100uM (C,D), 20uM in (A), 500nM (B) 
bioRxiv preprint doi: https://doi.org/10.1101/2020.09.14.295832; this version posted January 8, 2021. The copyright holder for this preprint (which was not certified by peer review) is the author/funder, who has granted bioRxiv a license to display the preprint in perpetuity. It is made

A TGC (LGMD2A) > TGG (WT)
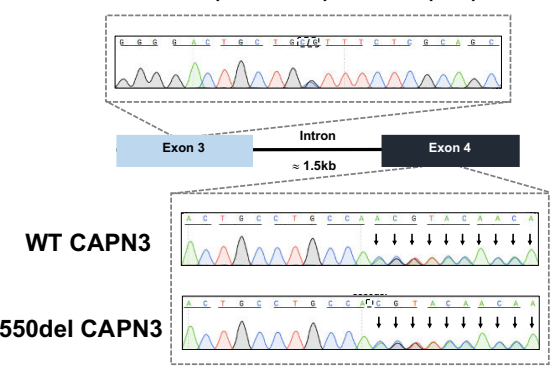

OCT4 DAPI
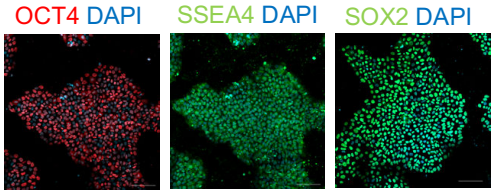

C
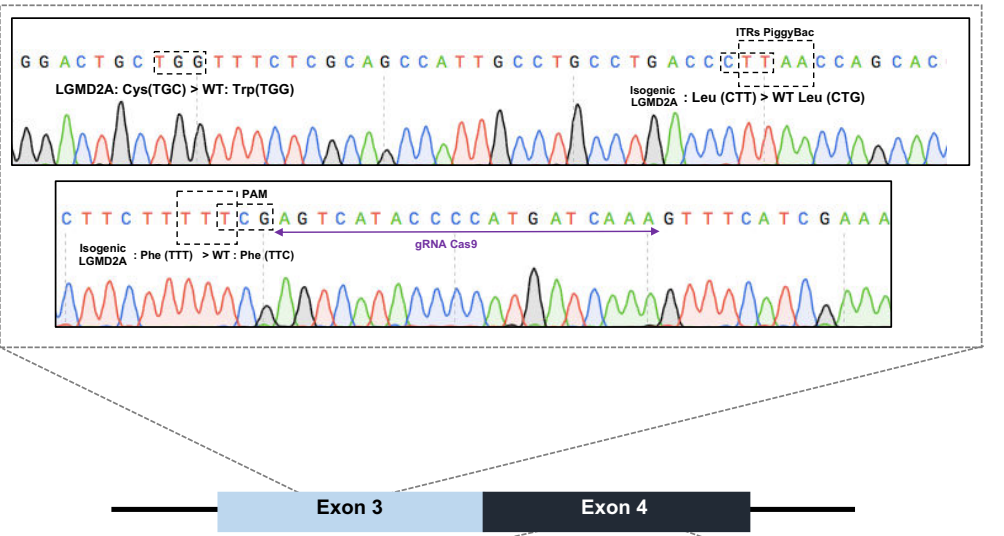

F
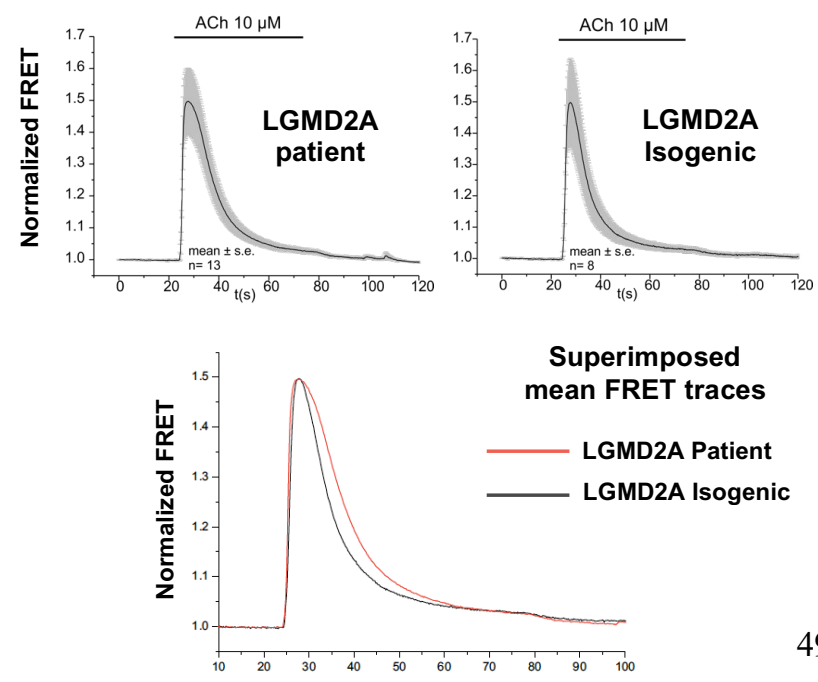

$t(s)$

B

G

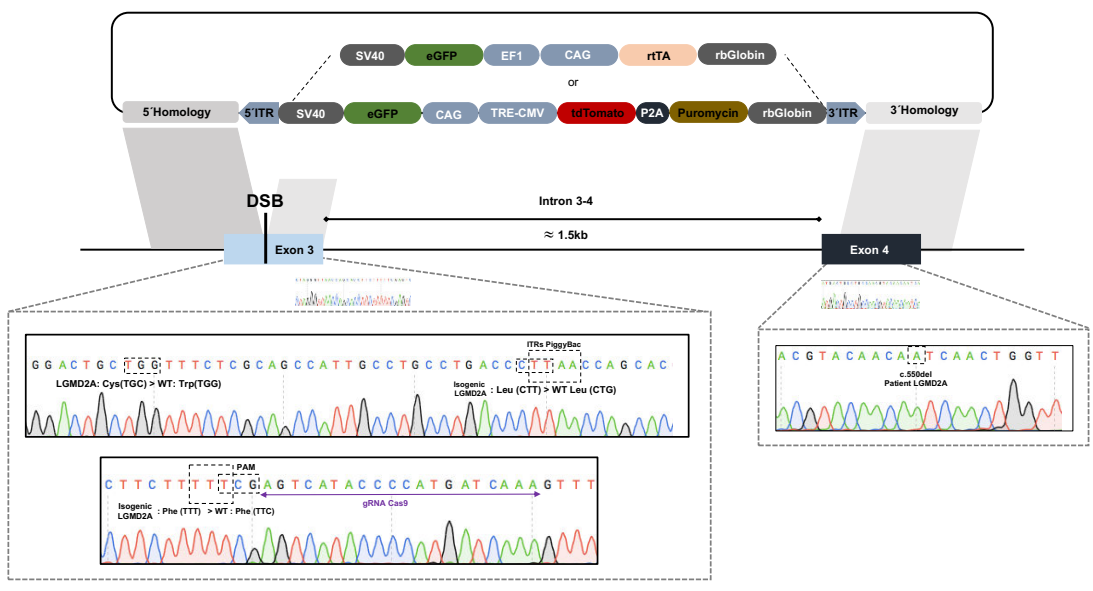

D

SOX2 DAPI

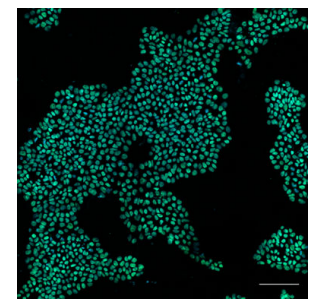

OCT4 DAPI

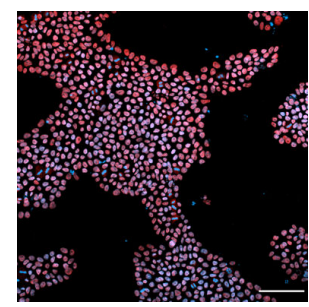

E

Isogenic LGMD2A
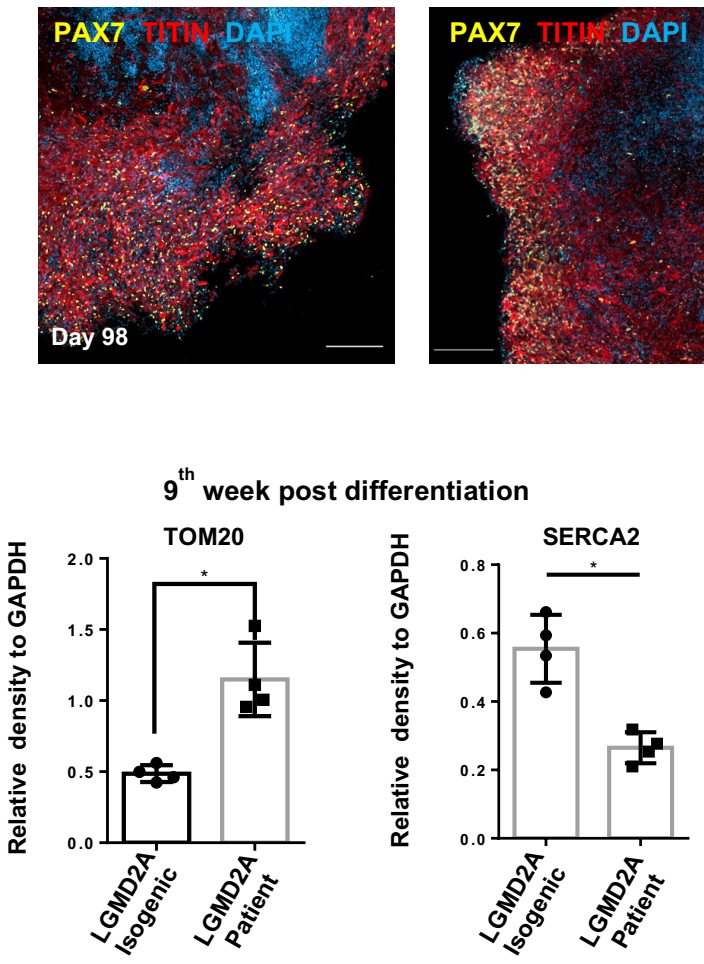
Figure 4. Generation of functional isogenic LGMD2A hiPSC line using CRISPR/Cas9 genome editing technology. (A) Graph illustrating genetic alterations on EXON3 and EXON4 of Calpain 3 locus for patient LGMD2A line together with immunocytochemistry displaying pluripotent state before genome editing (B) Graph depicting genome editing strategy for introducing controlled biallelic modification (C) Scheme displaying new EXON3/4 CAPN3 conformation together with pyrograms emphasizing all silent introduced mutations TTT:TTC (Phe), CTG:CTT (Leu), EXON3 to EXON4 transition, as well as rescues in EXON3: 130Cys(TGC-LGMD2A)>Trp(TGG-WT) and EXON4: c.550delA (D) Immunocytochemistry displaying pluripotent state of isogenic LGMD2A line after genome editing (E) Immunocytochemistry highlighting derivation of $\mathrm{PAX7} 7^{+}$fetal myogenic progenitor and TITIN ${ }^{+}$myofiber population during skeletal muscle organoid development for patient and isogenic LGMD2A hiPSC lines (F) Summarized FRET-recordings from organoid derived skeletal myotubes from iPSC lines with patient and isogenic LGMD2A genetic background; transfected with Twitch2B to monitor increase in intracellular $\left[\mathrm{Ca}^{2+}\right]$ during acetylcholine $(\mathrm{ACh})$ application. Superimposed FRET traces for patient and isogenic LGMD2A derived skeletal myotubes indicated prolonged intracellular $\left[\mathrm{Ca}^{2+}\right]$ upon $A C h$ activation for patient LGMD2A line (G) Relative quantification of TOM20 and SERCA2 levels from western blots. Data points represent individual organoids ( $n=4$ from independent derivations). Comparison between patient and isogenic LGMD2A cell lines was performed with a Mann-Whitney test $\left({ }^{*} p=0.0286\right)$. Scale bars, 200uM $(E)$, 100uM (A,D). 
bioRxiv preprint doi: https://doi.org/10.1101/2020.09.14.295832; this version posted January 8, 2021. The copyright holder for this preprint (which was not certified by peer review) is the author/funder, who has granted bioRxiv a license to display the preprint in perpetuity. It is made

A LGMD2A Patient

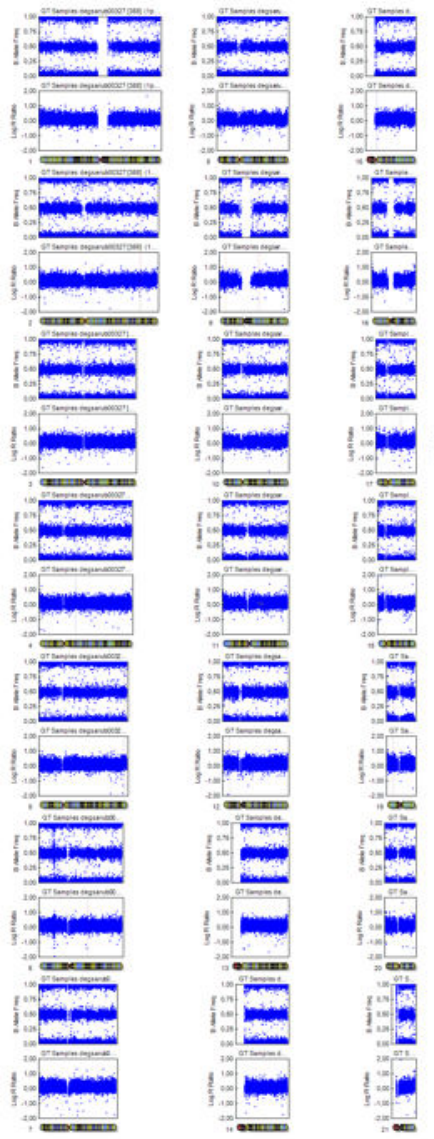

Isogenic LGMD2A

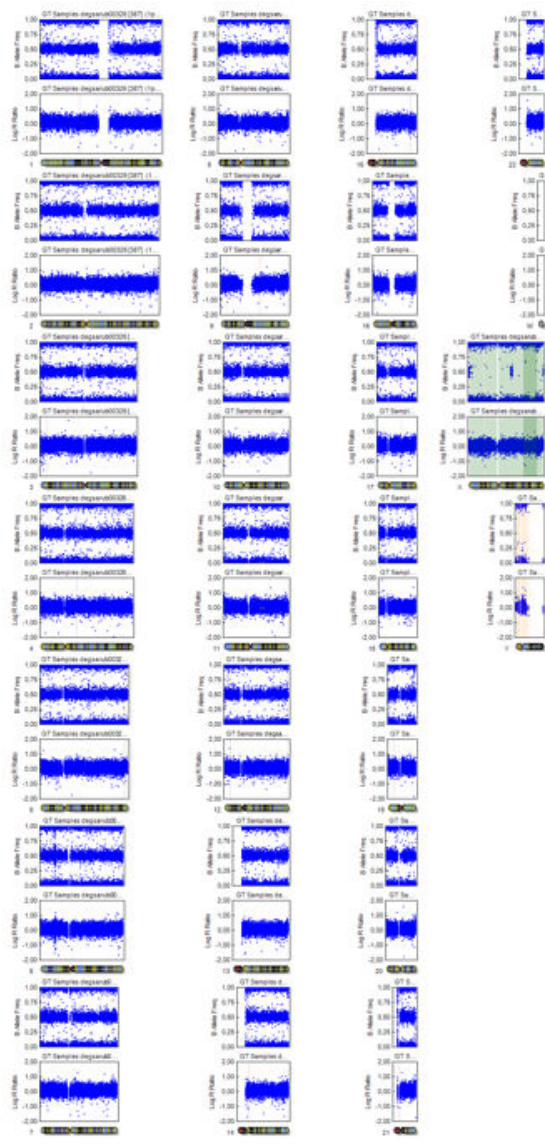

B

C
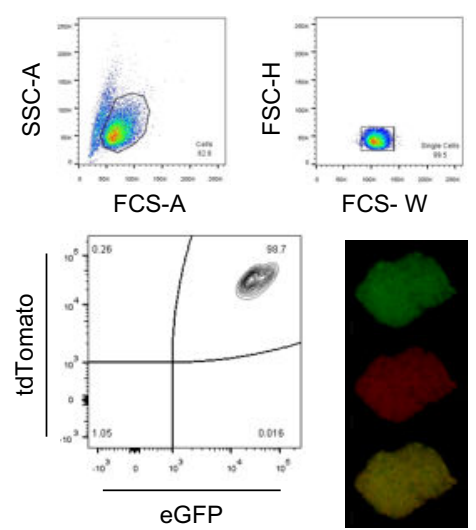

D

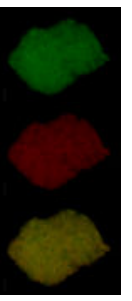

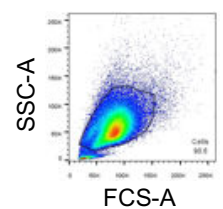
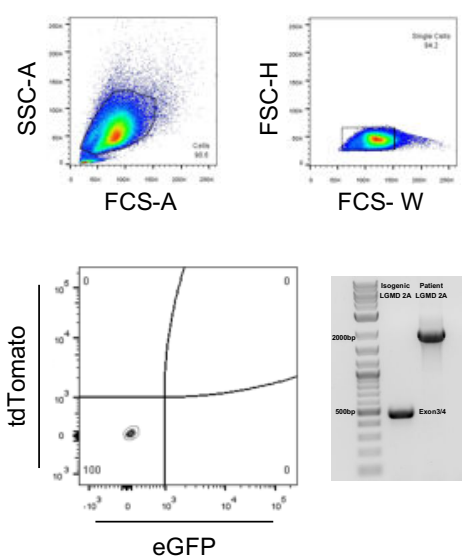

。

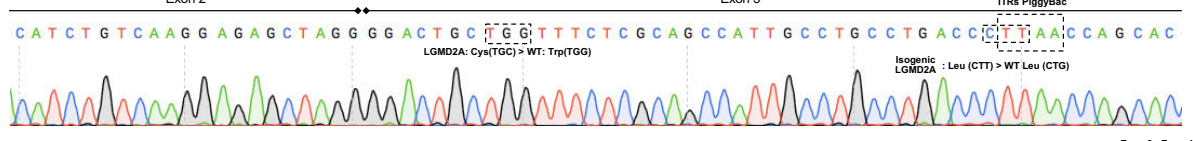

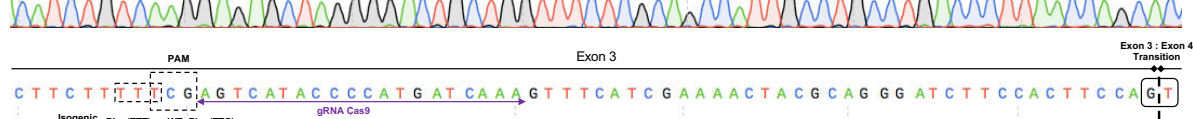

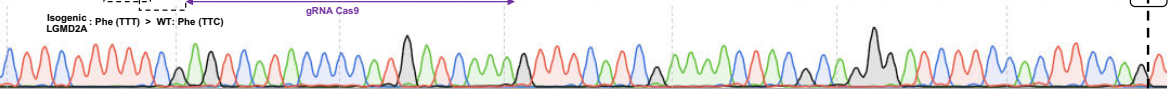
Exon 4

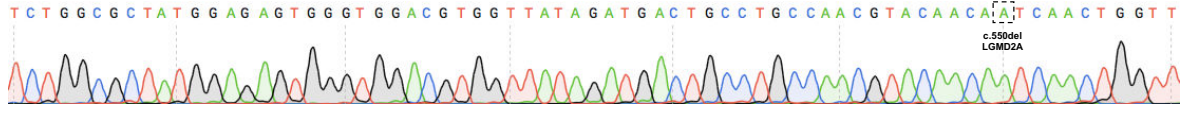

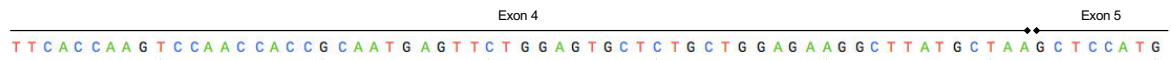

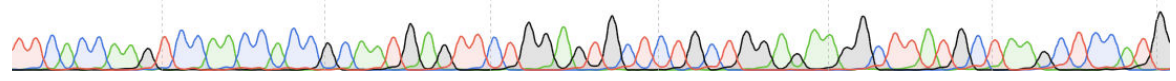

E

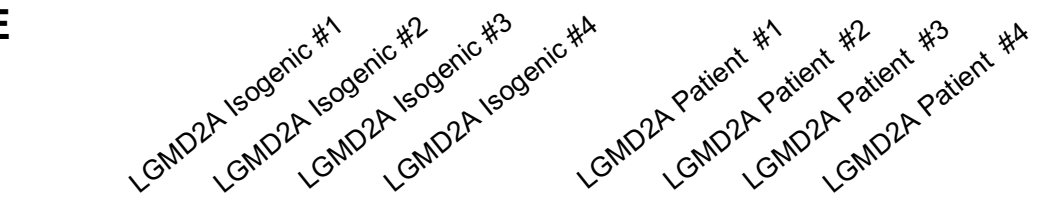

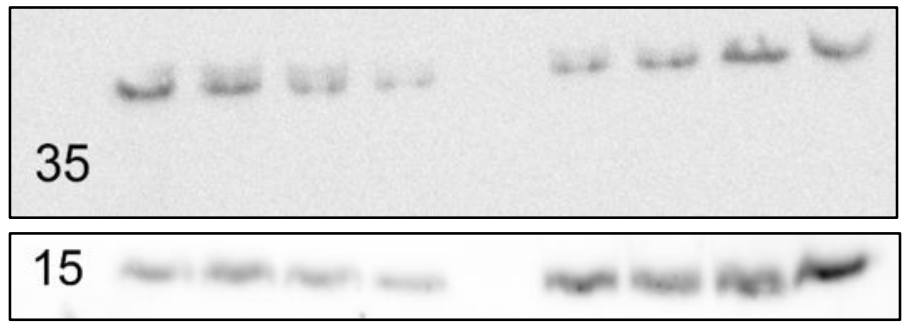
GAPDH (expected size 36KDa) Exposure time $100 \mathrm{~ms}$

$\mathbf{F}$

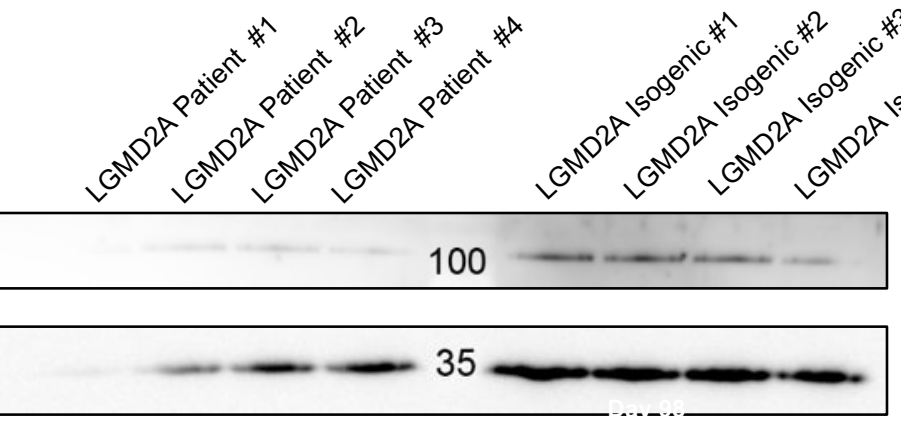

TOM20

(expected size 16KDa) Exposure time 5min 
Figure 4 - figure supplement 1. Evaluation of isogenic LGMD2A hiPSC line integrity and functionality. (A) Karyograms from patient and isogenic LGMD2A lines indicating no genomic alterations occurred during genome editing (B) FACS plots displaying gating strategy for cell enrichment incorporated selection cassettes; immunofluorescence of an iPSC colony after sorting for tdTomato ${ }^{+} /$eGFP $^{+}$population (C) Gating strategy to distinguish / acquire cells with traceless removal of selection cassette (tdTomato ${ }^{-} /$eGFP- $^{-}$population), PCR verification of traceless cassette excision at CAPN3 locus and chimeric Exon3/4 generation (D) cDNA from isogenic LGMD2A skeletal muscle organoids highlights intron skipping had no effect on CAPN3 mRNA sequence (E-F) Representative western blot staining for TOM20 (E) and SERCA2 (F) showing increases in LGMD2A patient derived organoids. 
bioRxiv preprint doi: https://doi.org/10.1101/2020.09.14.295832; this version posted January 8, 2021. The copyright holder for this preprint (which was not certified by peer review) is the author/funder, who has granted bioRxiv a license to display the preprint in perpetuity. It is made available under aCC-BY-NC-ND 4.0 International license.

A

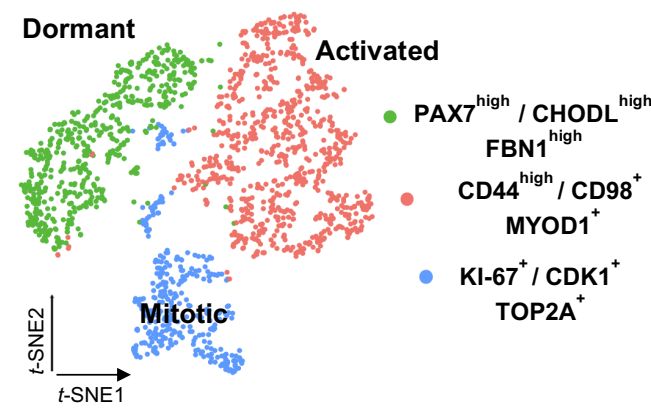

B
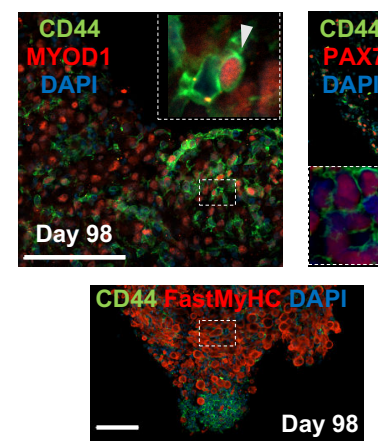

C
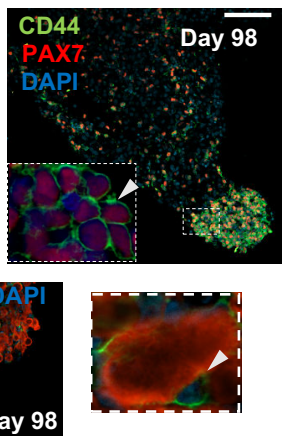

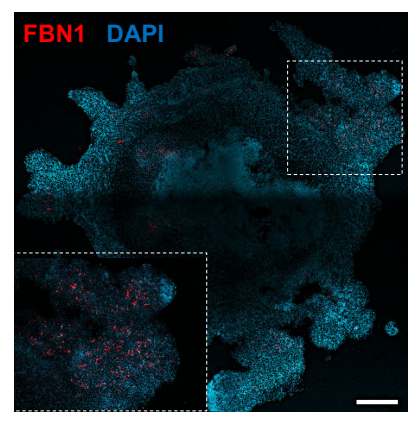

D

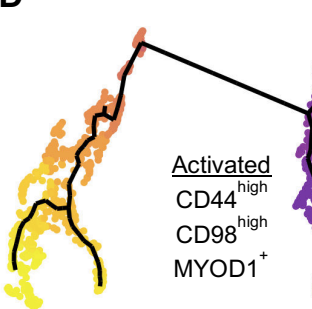

Myoblasts

$\stackrel{\text { UMAP1 }}{\longrightarrow}$

G

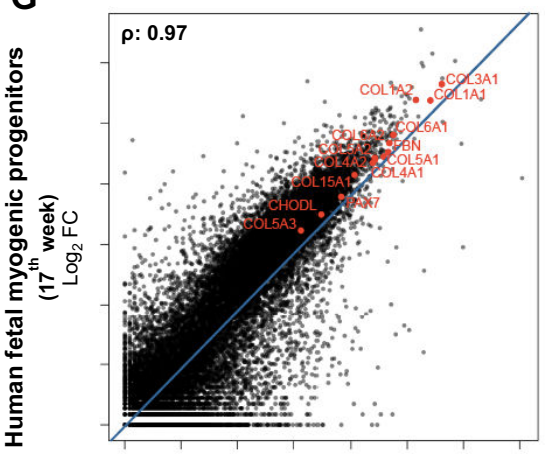

$\log _{2} \mathrm{FC}$

H
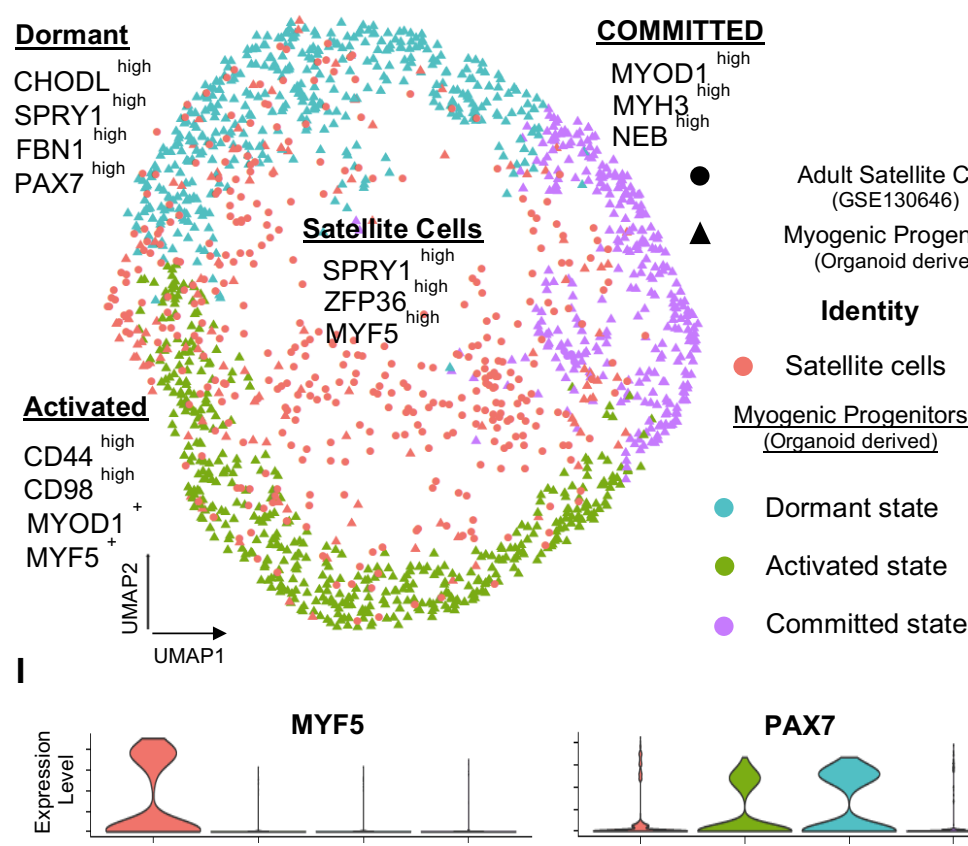

Progenitors

$\underline{\text { Quiescent }}$ FBN $1^{\text {high }}$ SPRY $1^{\text {nigh }}$ CHODL ${ }^{\text {high }}$

F
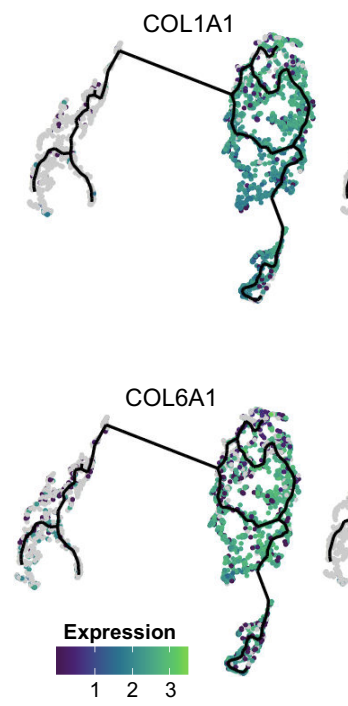

Myogenic
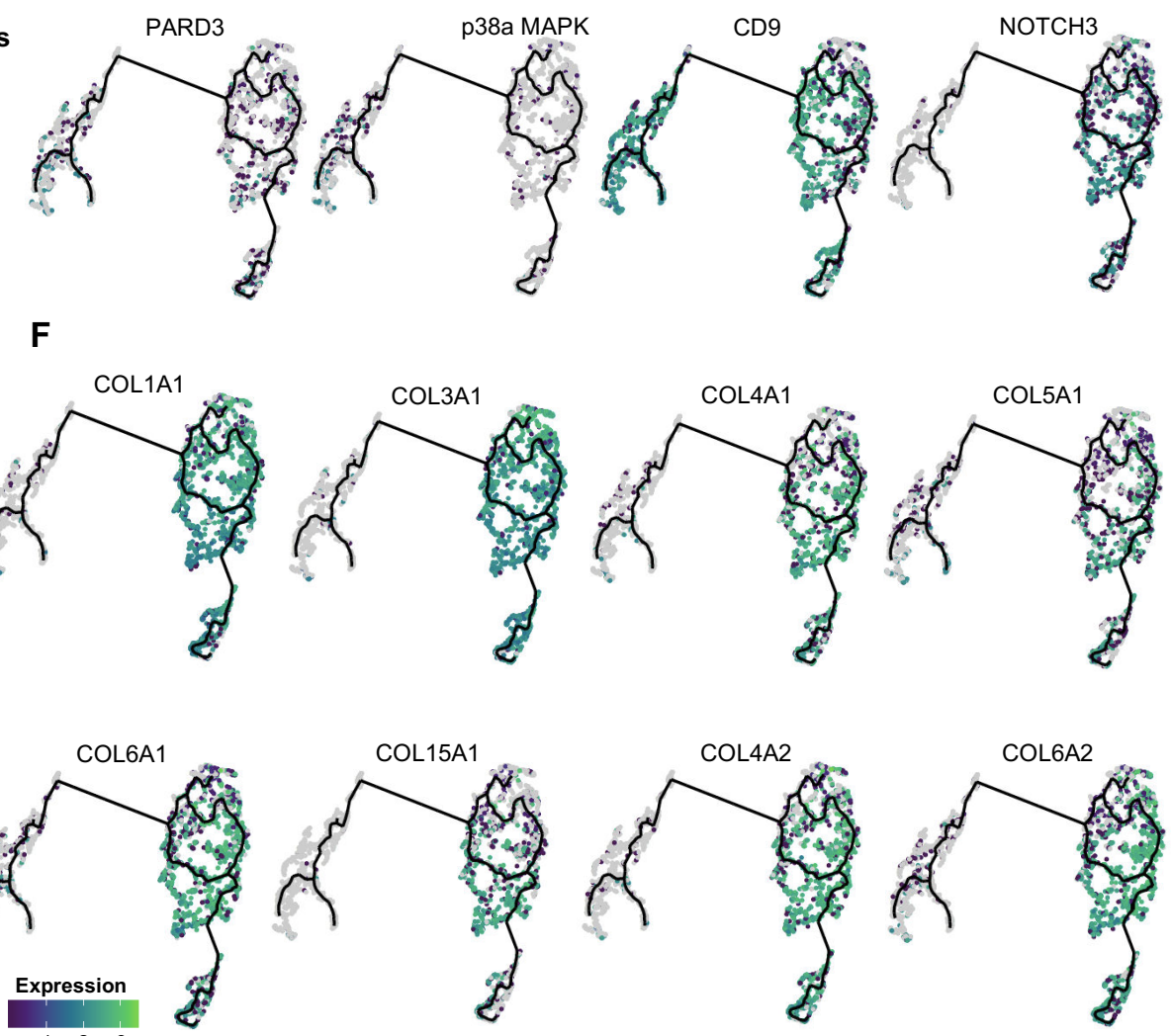

J

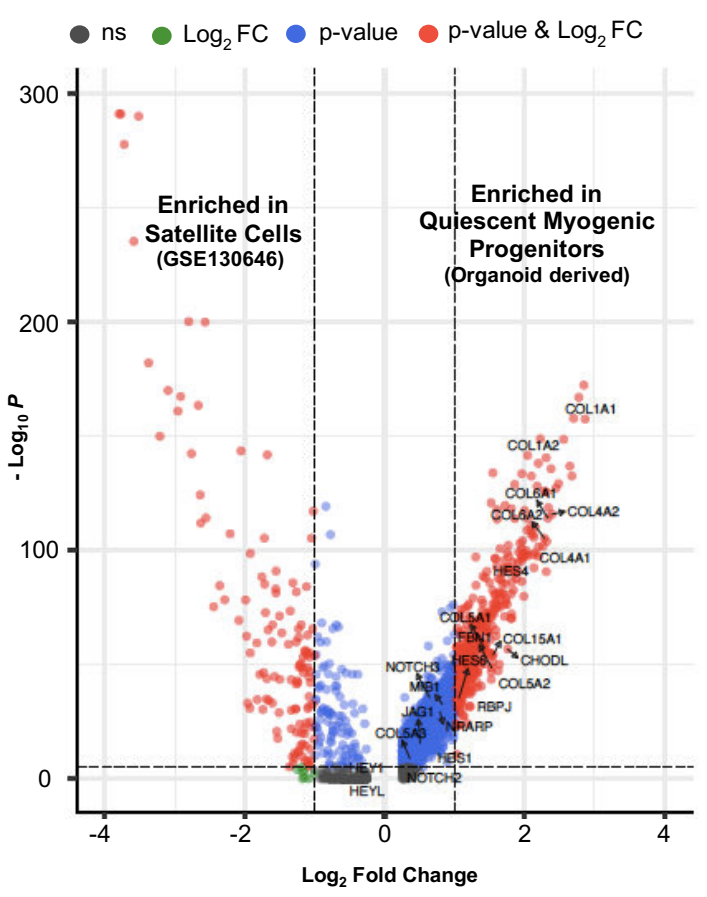


Figure 5. Myogenic progenitor identity and comparison to progenitors derived from fetal and adult muscle tissue. (A) t-SNE plot visualization of color-coded clustering indicates myogenic progenitor sub-cluster with distinct molecular signatures: "dormant" PAX7 high/ $\mathrm{CHODL}^{\text {high}} / \mathrm{FBN1}$ high, "activated" $\mathrm{CD} 44^{\text {high }} /{\mathrm{CD} 98^{+}}^{+} \mathrm{MYOD}^{+}$and "mitotic" $\mathrm{KI}-$ $67^{+} / \mathrm{CDK} 1^{+} / \mathrm{TOP} 2 \mathrm{~A}$ (B) Organoid overviews at Day 98 illustrate CD44 and PAX7 expressing cells at developing sites, which are more accessible to HGF activation signal, specificity of CD44 on $\mathrm{MYOD}^{+} / \mathrm{PAX7}^{+}$progenitor expressing cells (arrows) and absence from $\mathrm{FastMyHC}^{+}$positive myofibers is highlighted (C) $\mathrm{FBN}_{1}{ }^{+}$microfibrils are located towards organoid interior (D) Pseudotime ordering for myogenic progenitors and myoblast corresponding clusters highlights distinct developmental trajectories promoting myogenic commitment and self-renewal (E,F) UMAP feature plots depicting relative expression of genes regulating asymmetric divisions and selfrenewal (PARD3, p38a/b MAPK, NOTCH3; E) and extracellular matrix collagens (COL3A1, COL4A1, COL5A1, COL5A1, COL6A1, COL15A1; F) (G) Correlation coefficient plot for Log2 fold change (Log2 FC) values for isolated myogenic progenitors from human fetal tissue (17w) and FACS sorted CXCR4 ${ }^{+} / \mathrm{ITG} 1^{+}$organoid derived myogenic progenitors (16w). PAX7, COL1A1, COL3A1, COL4A1, COL5A1, COL15A1, FBN1 and CHODL and further extracellular matrix related genes are highlighted on the plot. Pearson's correlation coefficient, rho $=0.9$ for global expression comparison and rho $=0.97$ for selected genes $(\mathbf{H})$ UMAP color-based clustering divides non-dividing myogenic progenitors and adult satellite cells into 4 clusters with distinct molecular signatures: satellite cells characterized by SPRY $1^{\text {high }} /$ ZFP36 ${ }^{\text {high }} /$ MYF5 ${ }^{\text {high }}$ expression, co-clustered with dormant SPRY1 ${ }^{\text {high }} / \mathrm{FBN} 1^{\text {high }} / \mathrm{CHODL}^{\text {high }} / \mathrm{PAX} 7^{\text {high }}$, activated $\mathrm{CD} 44^{\text {high }} / \mathrm{CD} 98^{\text {high }} /$

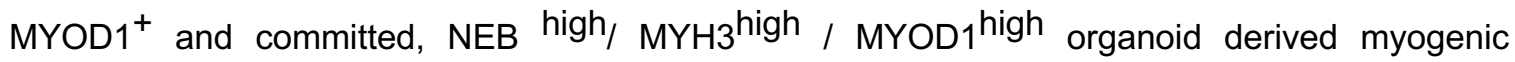
progenitors. Dots correspond to adult satellite cells from GSE130646 database, triangles correspond to organoid derived myogenic progenitors (I) Violin plots depicting relative expression levels of markers specific for quiescent PAX7 or activated MYF5 muscle stem cell state across adult satellite cells (GSE130646) and organoid derived myogenic progenitors subclusters (J) Enhanced Volcano plot from comparing transcript levels between all adult satellite cells (GSE130646) and organoid derived myogenic progenitors. Log2 fold-change in normalized gene expression versus -Log10 adjusted p-value is plotted. Differentially expressed genes: blue, adjusted $p$-value $<0.001$; green, adjusted $p$-value $>0.001$ and log2 fold-change $>1$; , red, log2 foldchange $>1$ and adjusted $p$ value $<0.001$; gray, no significance. Scale Bars, 500uM (C), 100uM (B). 
bioRxiv preprint doi: https://doi.org/10.1101/2020.09.14.295832; this version posted January 8, 2021. The copyright holder for this preprint (which was not certified by peer review) is the author/funder, who has granted bioRxiv a license to display the preprint in perpetuity. It is made available under aCC-BY-NC-ND 4.0 International license.

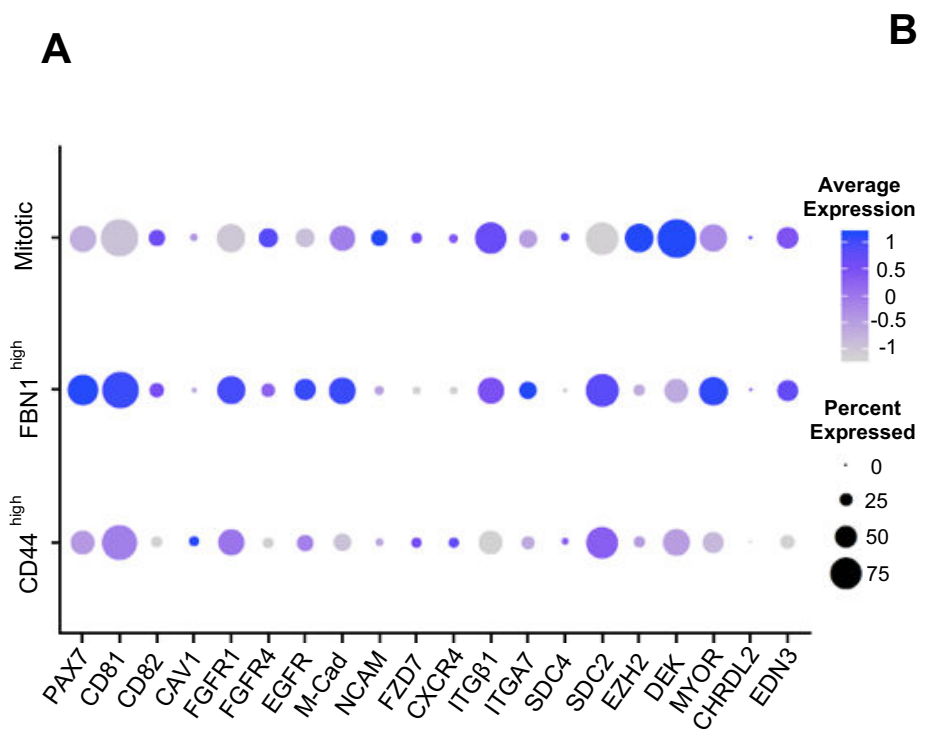

C
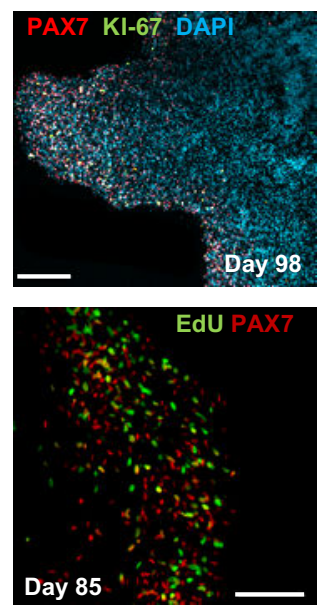

B

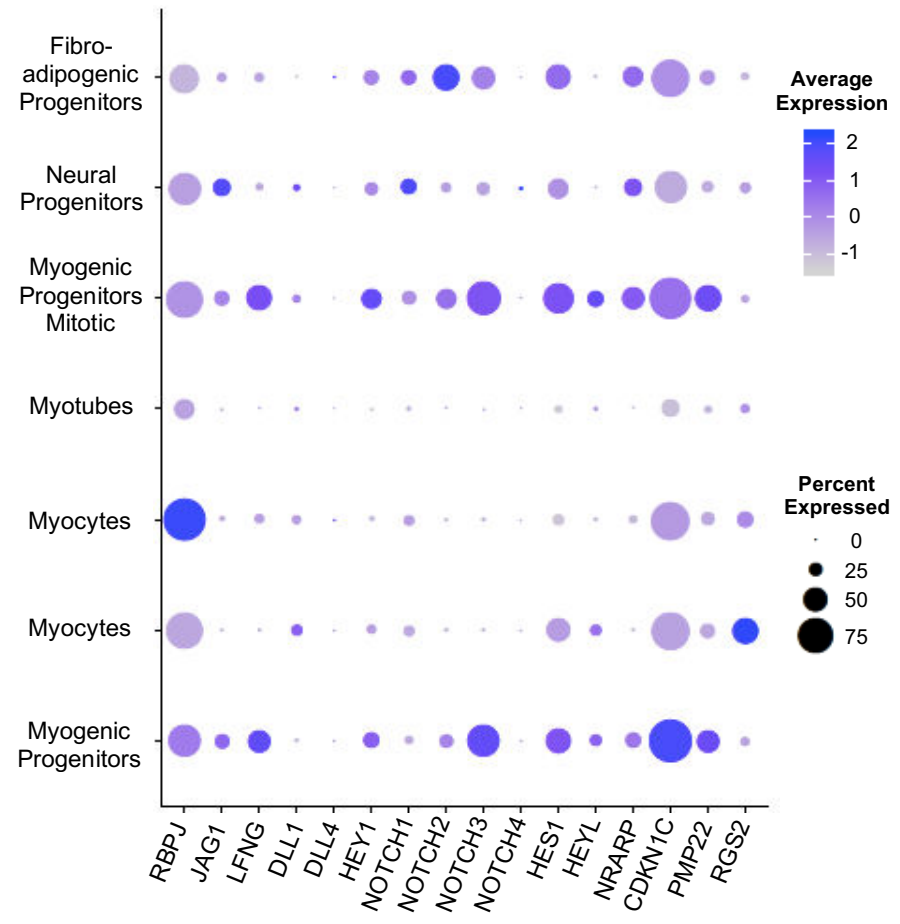

\section{D}
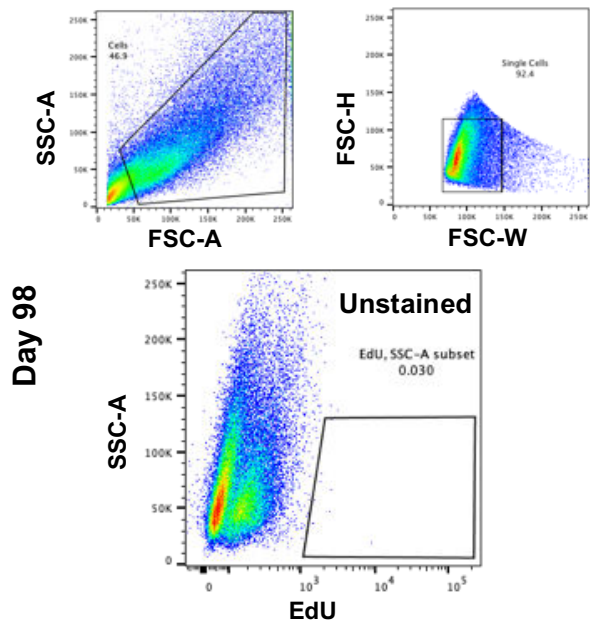

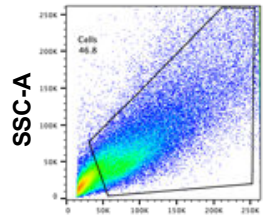

FSC-A

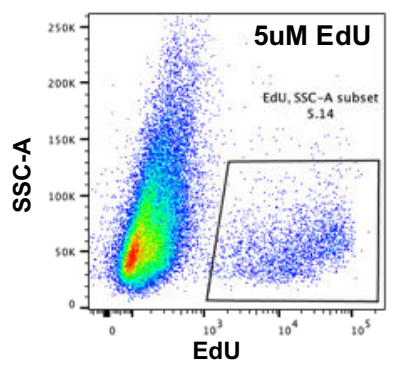

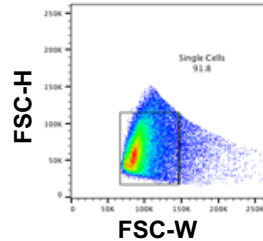

FSC-W

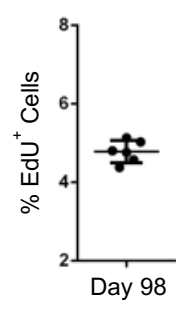


Figure 5 - figure supplement 1 . Subclustering of myogenic progenitors and NOTCH signaling. (A) Dot plot showing expression of representative genes related to satellite cell identity across the 7 main clusters. (B) Dot plot showing expression of representative genes related to NOTCH signaling are identified as regulators of satellite cell quiescence across the 7 main clusters (C) Organoid overview at Day 98 indicates PAX7 myogenic progenitors that are $\mathrm{Ki}^{-67} / \mathrm{EdU}^{-}$(D) Gating strategy applied to quantify EdU+ proliferating cells in organoid culture at Day 98 (14 weeks); histograph depicting percentage of $\mathrm{EdU}^{+}$cells; Dot plot, circle area represents percentage of gene ${ }^{+}$cells in a cluster, color reflects average expression level (gray, low expression; blue, high expression). Scale Bars, 100uM in (C). 
bioRxiv preprint doi: https://doi.org/10.1101/2020.09.14.295832; this version posted January 8, 2021. The copyright holder for this preprint (which was not certified by peer review) is the author/funder, who has granted bioRxiv a license to display the preprint in perpetuity. It is made available under aCC-BY-NC-ND 4.0 International license.

A

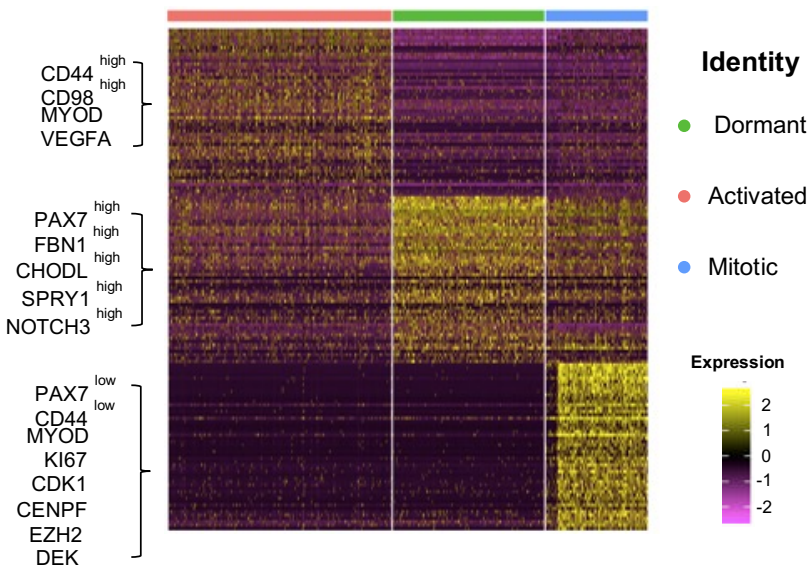

B

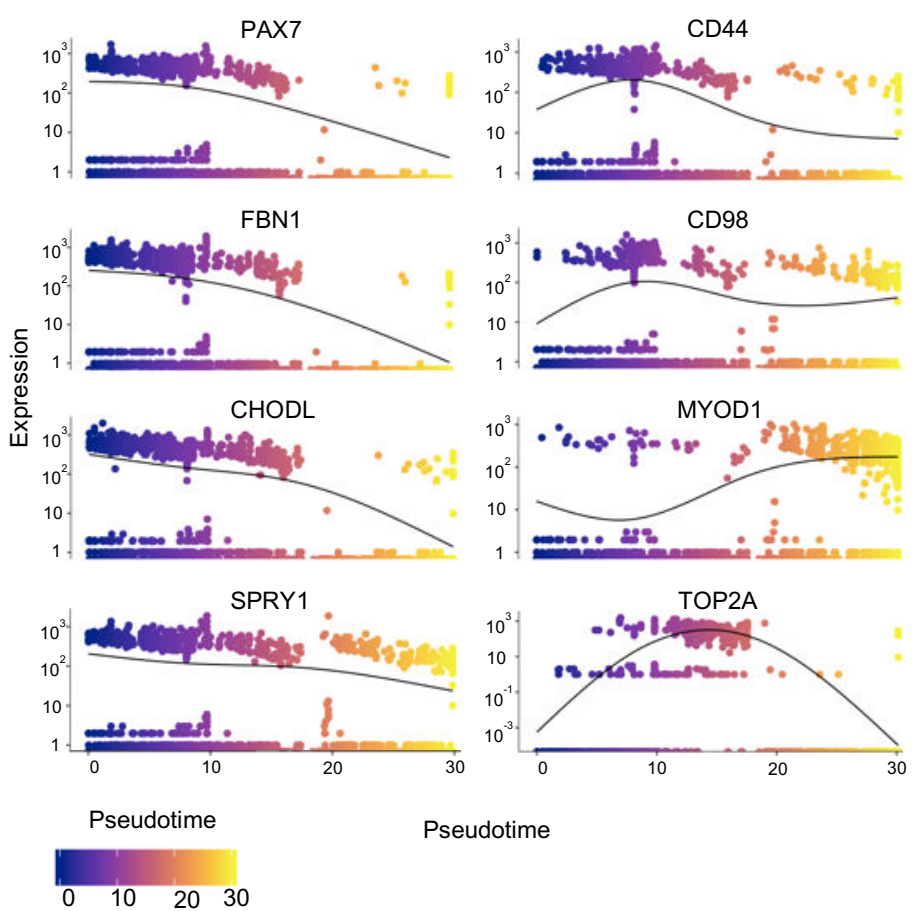

C
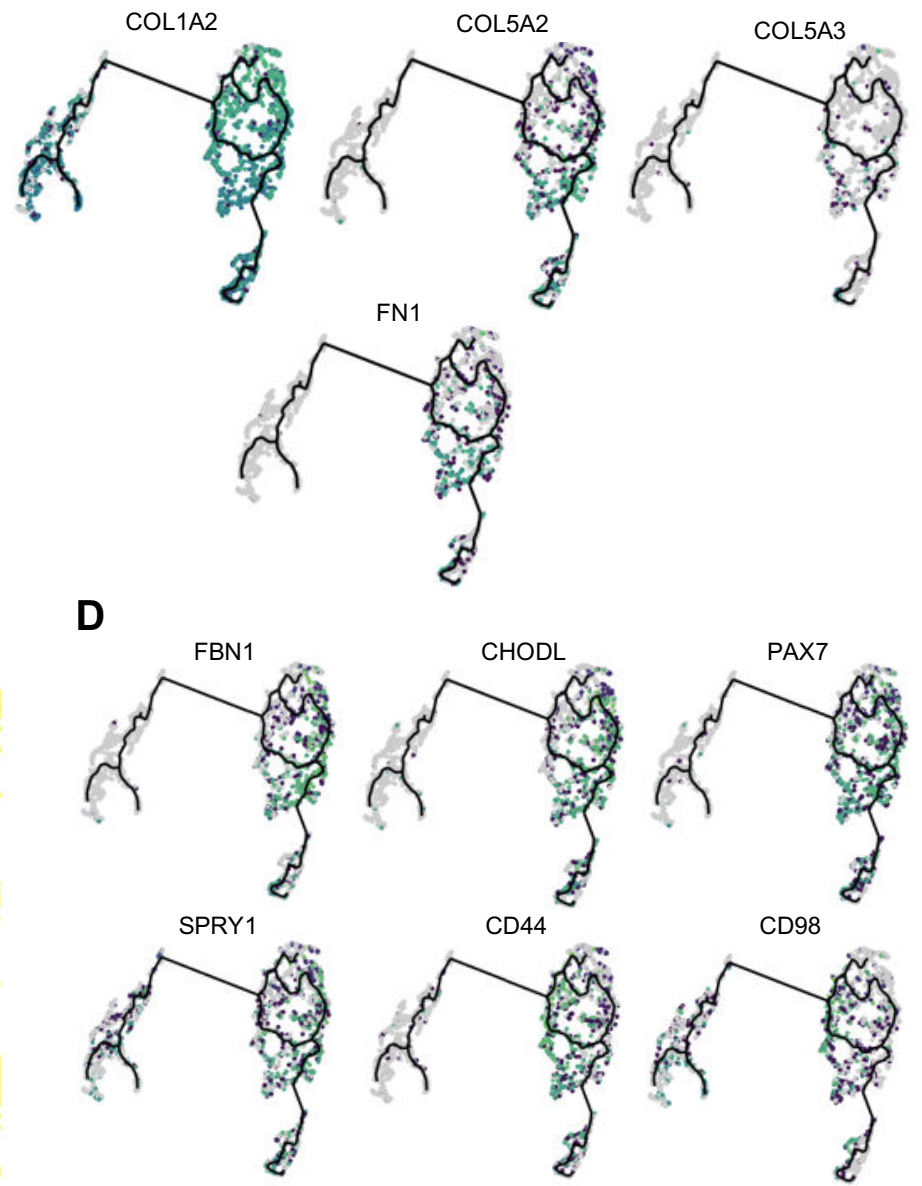

MYOD1 TEGFA TOP2A

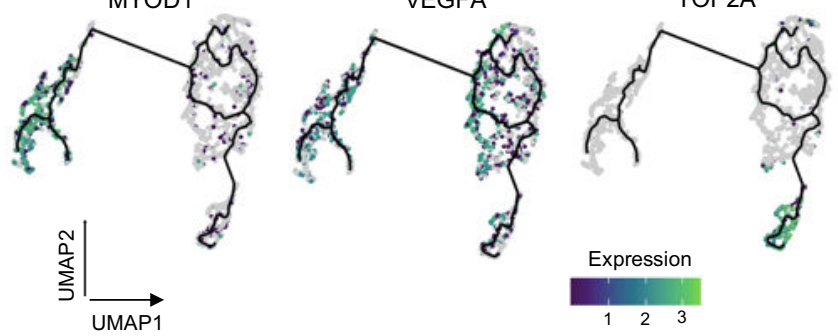


Figure 5 - Figure supplement 2. Pseudotime ordering of myogenic progenitor reveals distinct states and cell fate decisions. (A) Gene signatures of $t$-SNE described clusters based on relative expression levels of the 50 most significant markers for each of the 3 clusters (B) Expression of selected genes along pseudotime. Group of genes selected for myogenic progenitors: PAX7, SPRY1, CHODL (dormant state), CD44, CD98, MYOD1 (activated state), TOP2A (mitotic state), and for myoblasts: MYOD1 (C) Cells along the myogenic progenitors trajectory colored by expression of extracellular matrix proteins COL1A2, COL4A2, COL5A2, COL5A3, COL6A2, FN1 (D) Cells along the myogenic progenitors trajectory colored by expression of selected transcriptional regulators that define dormant (PAX7, FBN1, CHODL, SPRY1), activated (CD44, CD98, MYOD1, VEGFA) and mitotic (TOP2A) state of myogenic progenitor and myoblast (MYOD1) clusters. 
bioRxiv preprint doi: https://doi.org/10.1101/2020.09.14.295832; this version posted January 8, 2021. The copyright holder for this preprint (which was not certified by peer review) is the author/funder, who has granted bioRxiv a license to display the preprint in perpetuity. It is made available under aCC-BY-NC-ND 4.0 International license.

A

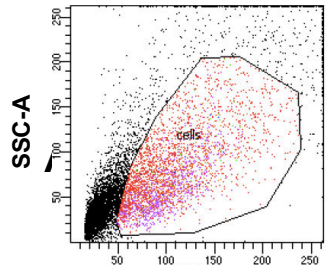

FSC-A

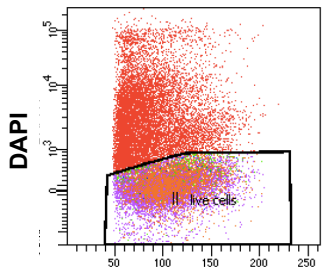

FSC-A

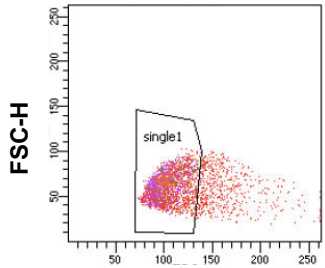

FSC-W

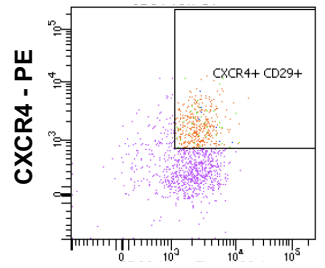

CD29 - Alexa Fluor 488

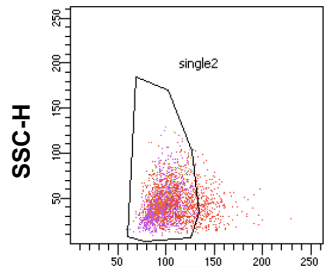

SSC-W

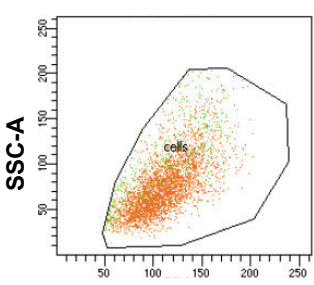

FSC-A

B

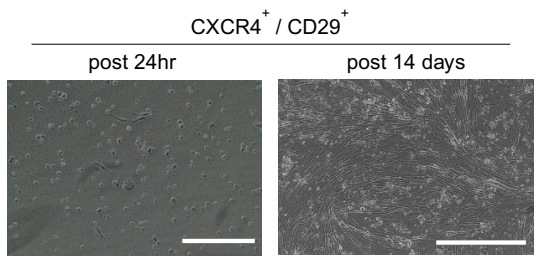

C

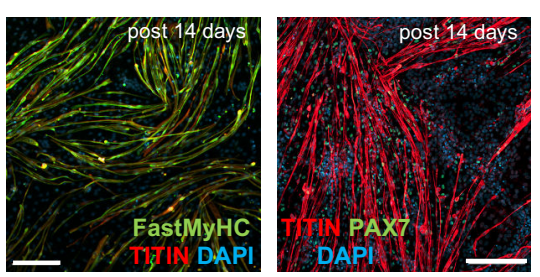

$\mathbf{E}$
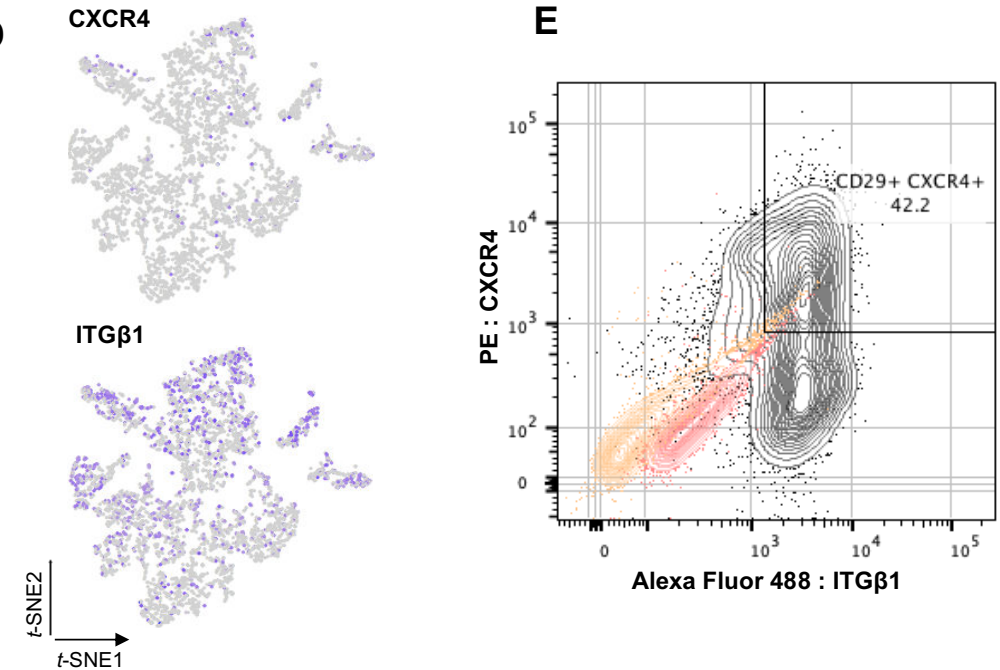

G

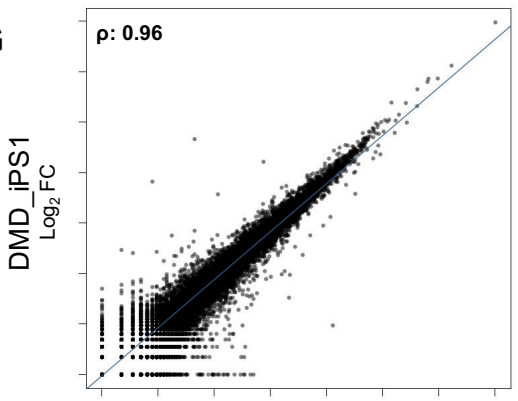

$\log _{2}$ FC

BMD_iPS1
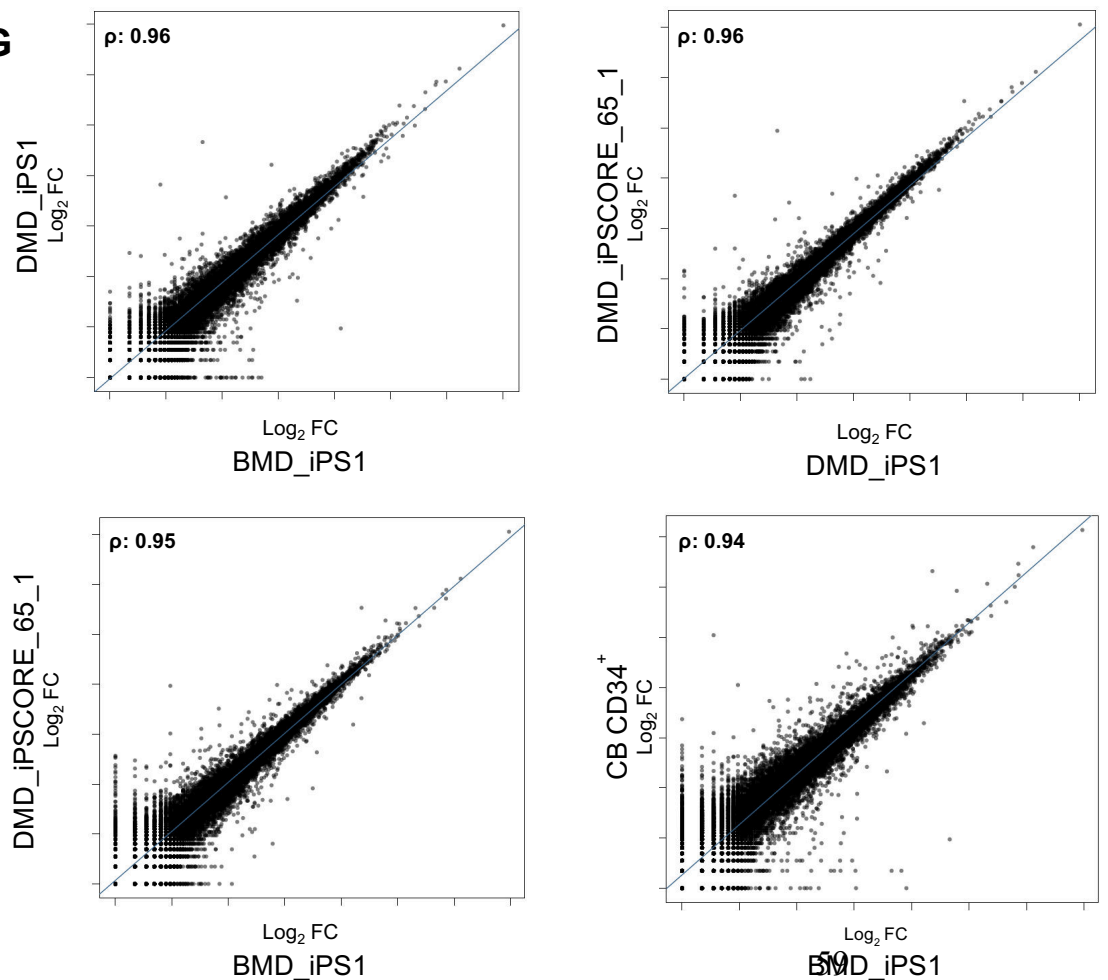

BNOD iPS1

F
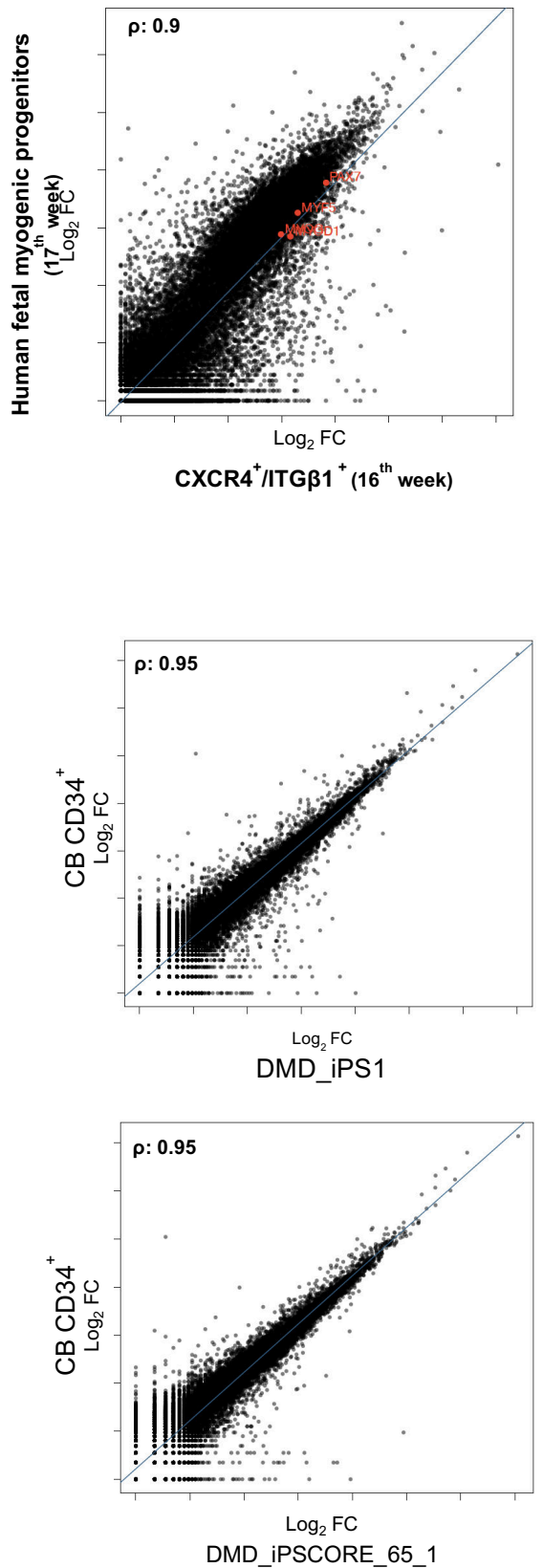
Figure 5 - figure supplement 3. Organoid derived myogenic progenitors and correlation to fetal muscle progenitors. (A) Gating strategy applied for FACS sorting CD29 ${ }^{+} / \mathrm{CXCR}^{+}$cells from 15 -16 w skeletal muscle organoids (B,C) Re-plating CD29 ${ }^{+}$/ CXCR4 ${ }^{+}$cells and culturing for 14 days highlights fetal myogenic potential, illustrated by brightfield and immunocytochemistry images for Fast $\mathrm{MyHC}^{+}, \mathrm{TITIN}^{+}$and PAX7 $7^{+}$populations (D) $t$-SNE feature plots for ITG $\beta 1$ and CXCR4 demarcate expression of FACS isolated calls into myogenic progenitor subcluster (E) Gating strategy from (A) together with unstained population (yellow), isotype control (red) and $\mathrm{CD}{ }^{+} / \mathrm{CXCR}^{+}{ }^{+}$(gray) population (F) Correlation coefficient plot for Log2 fold change (Log2 FC) values for isolated myogenic progenitors from human fetal tissue $(17 \mathrm{w})$ and FACS sorted CXCR4 ${ }^{+}$ / ITG $\beta 1^{+}$organoid derived myogenic progenitors (16w). PAX7, MYF5, MYOD1, MYOG are highlighted on the plot (G) Correlation coefficient plot for Log2 fold change (Log2 FC) values for FACS sorted CXCR4 ${ }^{+} / \mathrm{ITG}_{3} 1^{+}$organoid derived myogenic progenitors (16 w) from CB CD34 ${ }^{+}$, DMD_IPS1, BMD_iPS1 and iPSCORE_65_1 pluripotent lines. Scale bars, 200uM (B), 100uM (C). 
bioRxiv preprint doi: https://doi.org/10.1101/2020.0914 295832; this version posted January 8,2021 . The copyright holder for this preprint (which was not certified by peer review) is the author/funder, who has granted bioRxiv a license to display the preprint in perpetuity. It is made available under aCC-BY-NC-ND 4.0 International license.

A
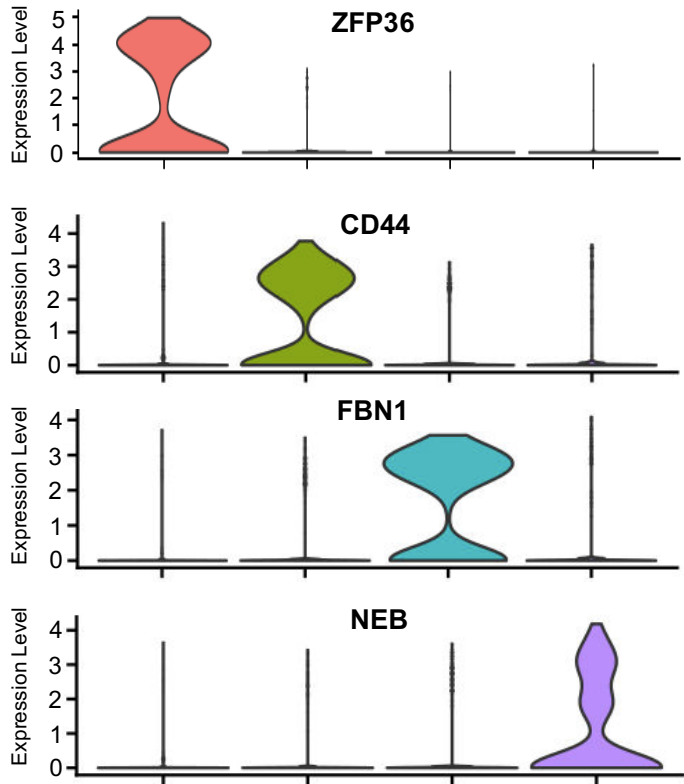

S 5 SPRY1

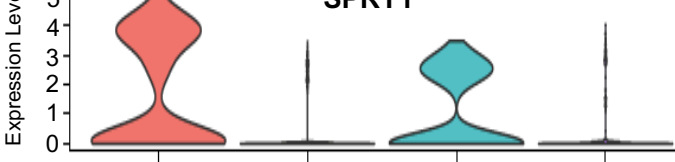

Identity

C

Satellite Cells

FOS ${ }^{\text {high }}$

JUN high

MYF5 ${ }^{\text {high }}$

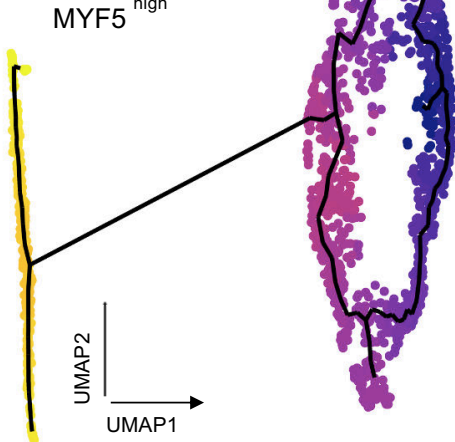

Pseudotime

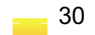

$-20$

10

0

Quiescent

Myogenic Progenitors $\mathrm{NOTCH} 3^{\text {high }}$ RBPJ ${ }^{\text {high }}$
PAX7 $7^{\text {high }}$
B

Satellite cells

Myogenic Progenitors (Organoid derived)

- Dormant state

Activated state

- Committed state

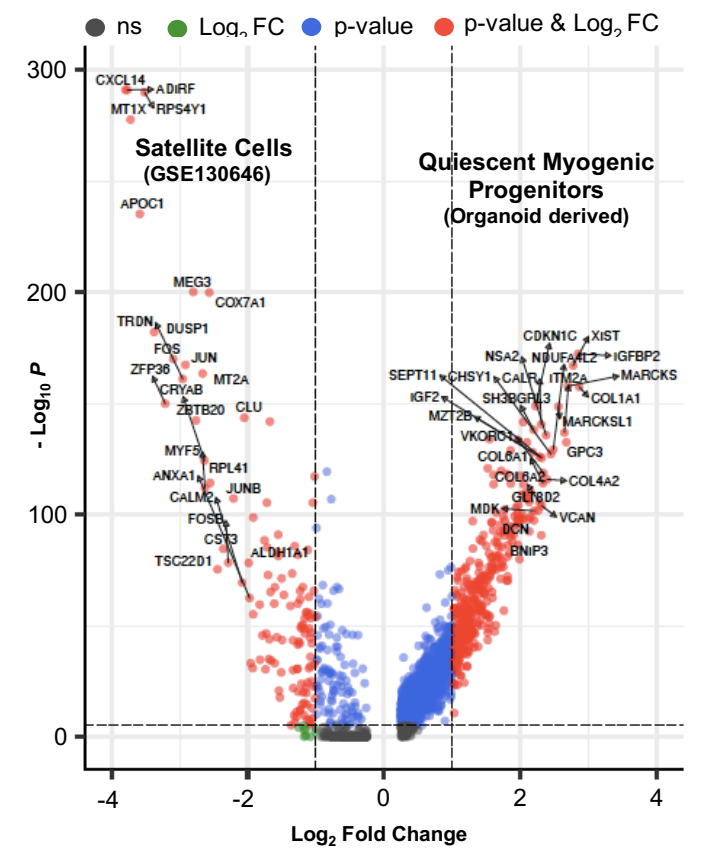

D

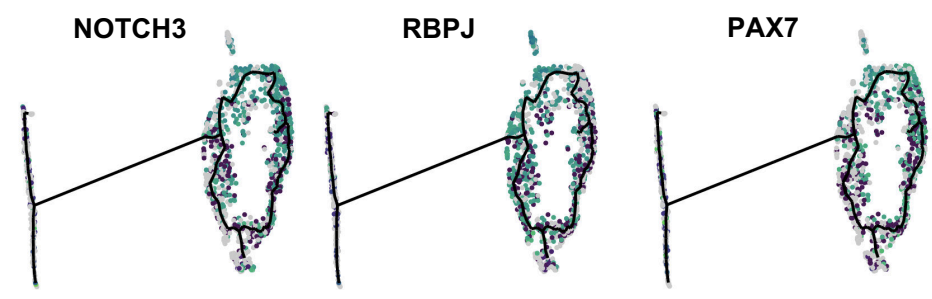

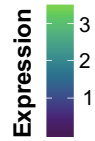

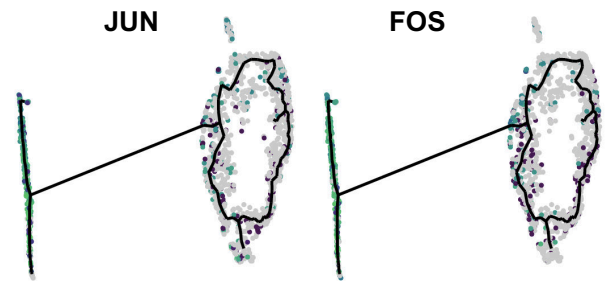

MYF5

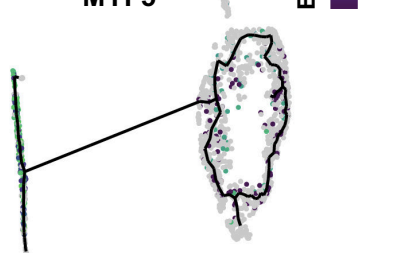


Figure 5 - figure supplement 4 . Organoid derived myogenic progenitors and correlation to adult human satellite cells. (A) Violin plots highlighting developmental status for organoid derived myogenic progenitors and satellite cells through relative expression of key signature markers ZFP36, CD44, FBN1 and NEB for each subcluster (B) Enhanced Volcano plot from comparing transcript levels between all adult satellite cells (GSE130646) and organoid derived myogenic progenitors. Log2 fold-change in normalized gene expression vs. - Log10 adjusted p-value is plotted. Differentially expressed genes: blue, adjusted $p$-value $<0.001$; green, adjusted p-value $>$ 0.001 and log2 fold-change $>1$; , red, log2 fold-change $>1$ and adjusted $p$ value $<0.001$; gray, no significance. (C) Pseudotime ordering for organoid derived myogenic progenitors and adult satellite cells together with expression of selected genes (D) Expression of genes selected for dormant myogenic progenitors (PAX7, NOTCH3, RBPJ) and activated satellite cells (MYF5, JUN, FOS). 
bioRxiv preprint doi: https://doi org/10.1101/2020.09.14 295832; this version posted January 8, 2021. The copyright holder for this preprint (which was not certified by peer review) is the author/funder, who has granted bioRxiv a license to display the preprint in perpetuity. It is made available under aCC-BY-NC-ND 4.0 International license.
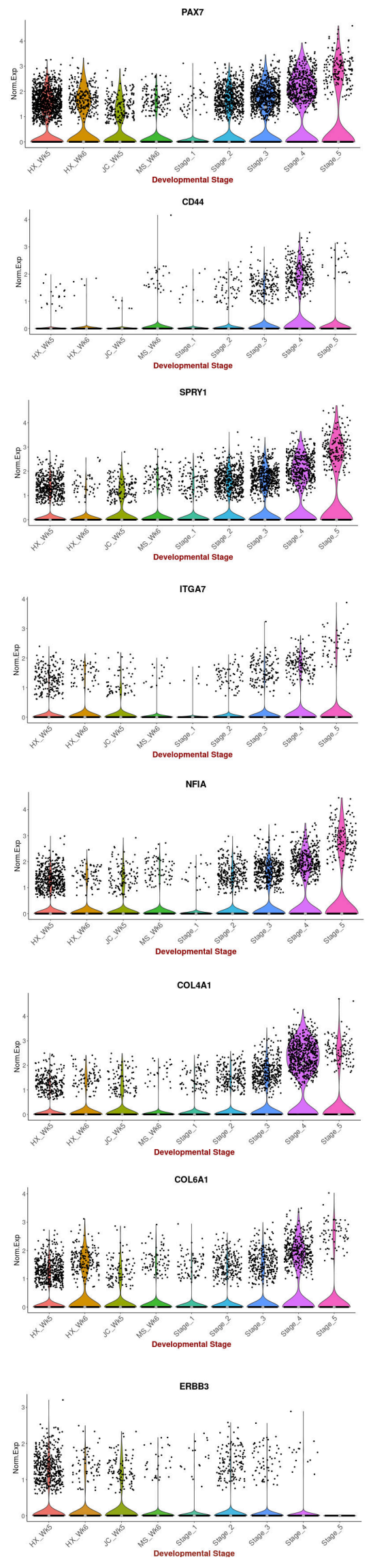
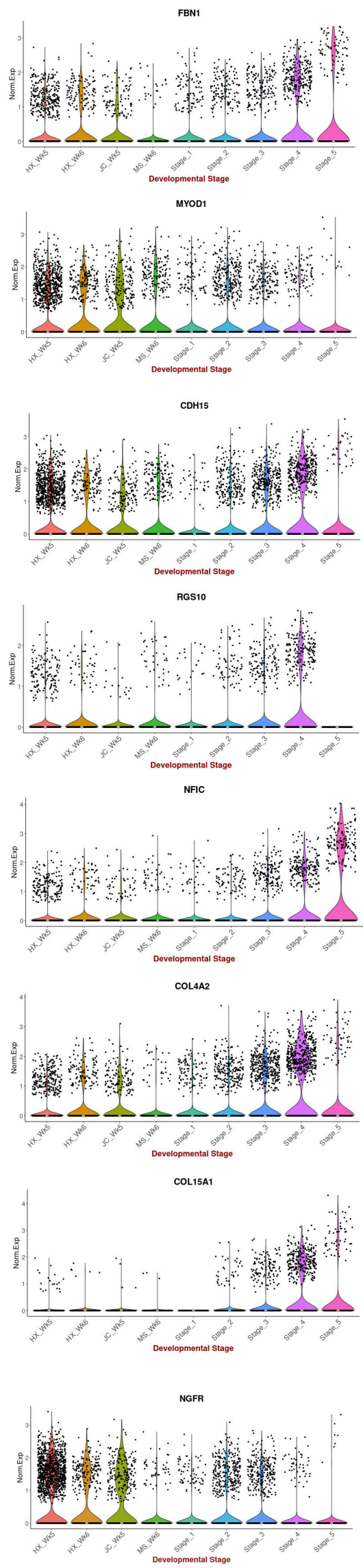
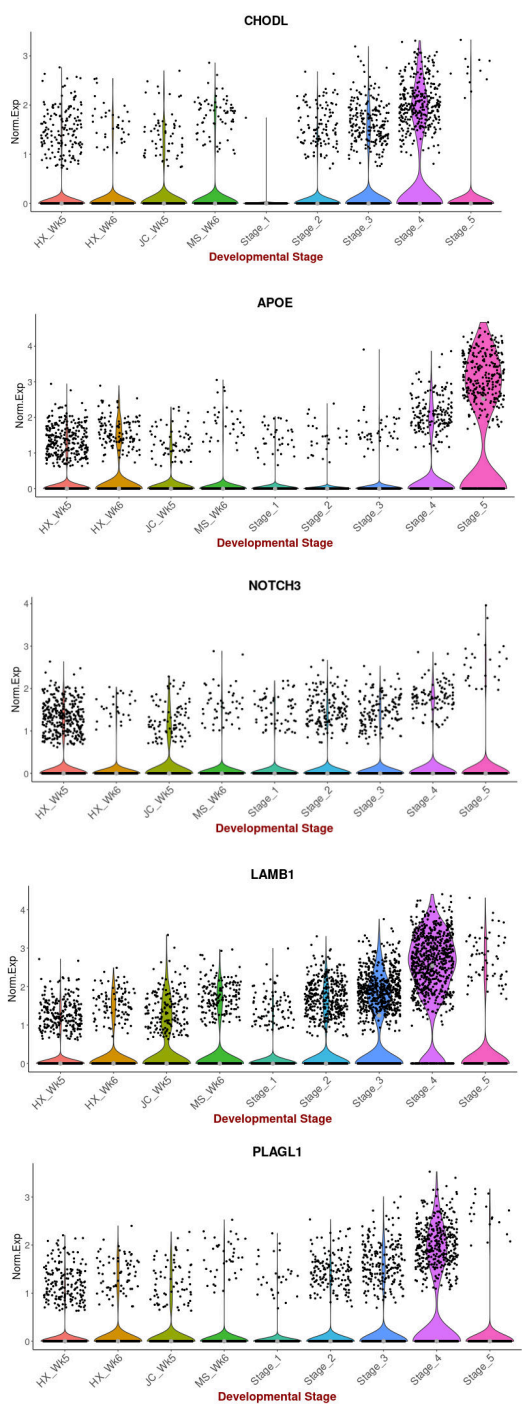

COL5A1
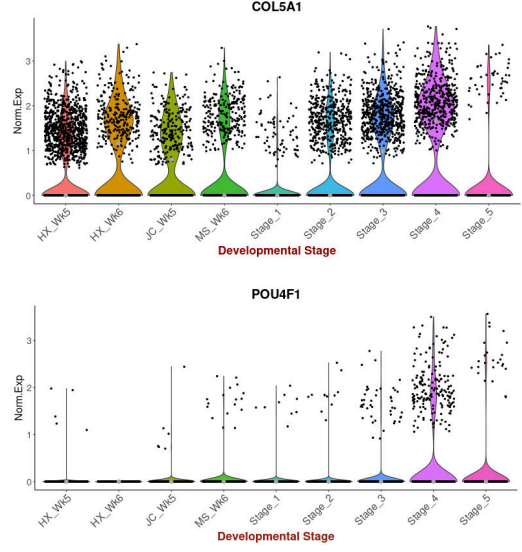

VEGFA

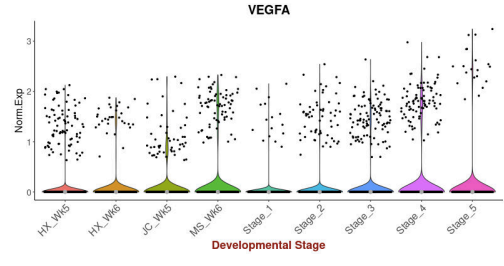


bioRxiv preprint doi: https://doi org/10.1101/2020.09.14 295832; this version posted January 8,2021 . The copyright holder for this preprint (which was not certified by peer review) is the author/funder, who has granted bioRxiv a license to display the preprint in perpetuity. It is made available under aCC-BY-NC-ND 4.0 International license.
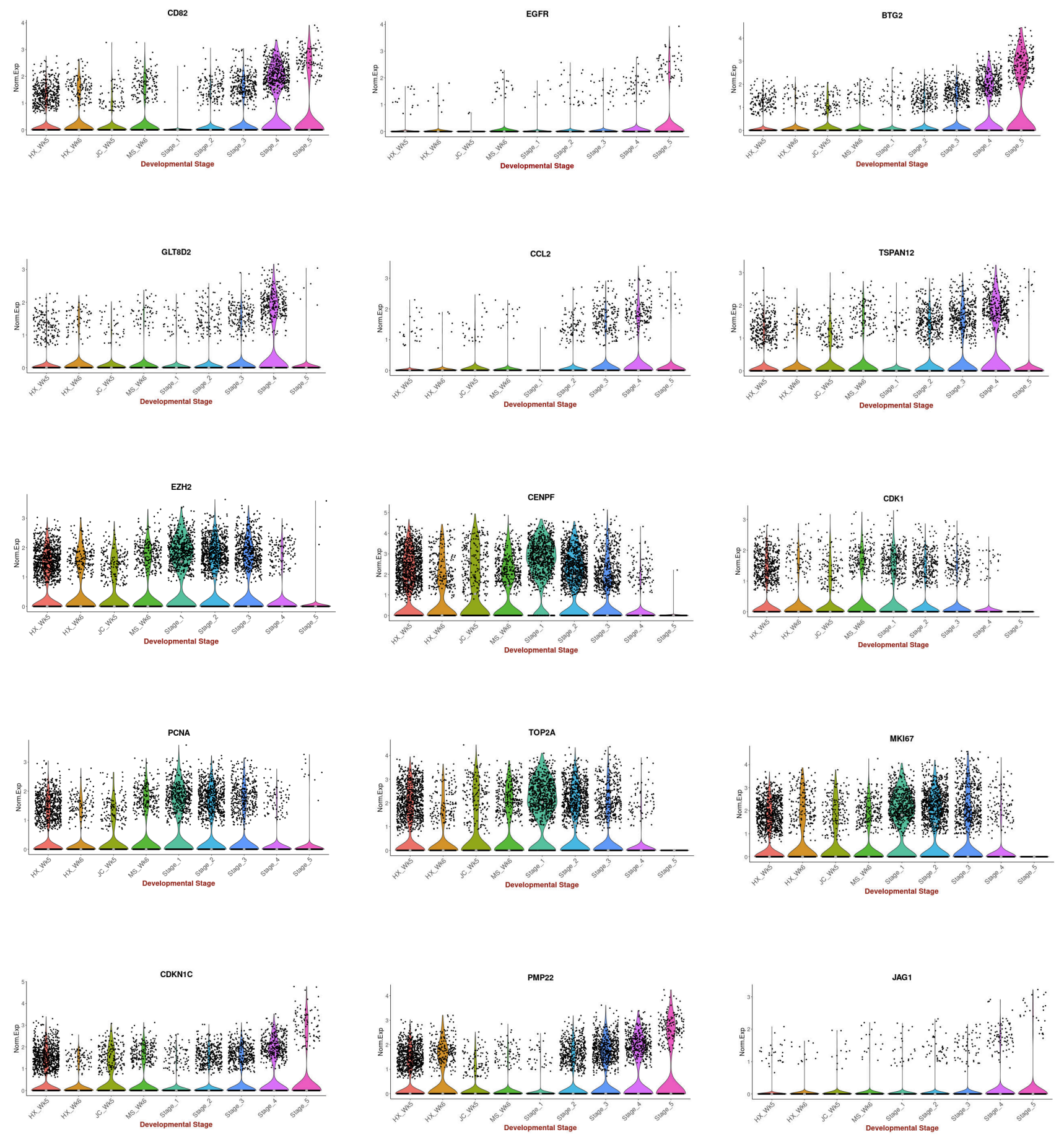
Figure 5 - figure supplement 5 . Comparison between 2D in vitro myogenic differentiation protocols and in vivo staging. Violin plots highlighting expression of key myogenesis markers: Comparison between myogenic progenitors derived in 2D differentiation protocols (HX protocol, Xi et al., 2017; JC protocol, Chal et al., 2015; MS protocol, Shelton et al., 2014) and in vivo myogenic progenitors (5 stages: 1,2: embryonic; 3,4: fetal; 5: postnatal). Data were acquired from Pyle's LAB UCLA website, (https://aprilpylelab.com/datasets/in-vivo-and-in-vitro-multipleprotocols-smpcs-and-scs/) and Xi et al. (2020). 
bioRxiv preprint doi: https://doi org/10.1101/2020.09.14.295832; this version posted January 8, 2021. The copyright holder for this preprint (which was not certified by peer review) is the author/funder, who has granted bioRxiv a license to display the preprint in perpetuity. It is made available under aCC-BY-NC-ND 4.0 International license.

\begin{tabular}{|c|c|c|c|c|c|c|c|c|}
\hline Off -Target Site & Off-Target Sequence & PAM & Strand & мм & Forward detection Primer & Reverse detection Primer & Gene & Position \\
\hline $\begin{array}{l}\text { Chromosome 15: } \\
42386225 \text { - } 42386247\end{array}$ & TTTGATCA [TGGGGTATGACT] & CGG & & 0 & ПТСTCCTTCCCTGGGTTGAC & CTCGGCTGGATTTTGCAACC & CAPN3 & Exonic \\
\hline $\begin{array}{c}\text { Chromosome 5: } \\
125465023 \text {-125465045 }\end{array}$ & CTGAGTCA [TGGGGTATGACT] & AGG & - & 4 & CCCCAAGGAGTGCCAGAGTAA & TGGAGAAGCACTACCTTATGGC & RP11-756H20.1 & Intergenic \\
\hline $\begin{array}{l}\text { Chromosome 14: } \\
66857796-66857818\end{array}$ & GTTGCTGC [TGGGGTATGACT] & GGG & - & 4 & СCTCTTCCTAAGCGAAACTGA & GTGGTTCCCCTCTGTGTAGGG & GPHN & Intronic \\
\hline $\begin{array}{c}\text { Chromosome 2: } \\
167762690 \text { - } 167762712\end{array}$ & TTAGAGTा [TGGGGTATGACT] & GGG & + & 4 & AGCAGGCCACTACTACCTCT & CAGGTCTATTCACCCTCTGGG & CTAGE14P & Intergenic \\
\hline $\begin{array}{c}\text { Chromosome 5: } \\
\text { 33894317 - } 33894339\end{array}$ & GTGGATCA [AAGGGTATGACT] & GGG & - & 4 & GTATTCTGCCAGCCCTTCCAA & TCTACGCTGAGGTAACTCCAAG & ADAMTS12 & Intergenic \\
\hline $\begin{array}{l}\text { Chromosome 6: } \\
87520187-87520209\end{array}$ & GAAGATCA [TGGGATATGACT] & GGG & & 4 & ACTAAGCCACTGAGAGCAGAT & TCCCTCCCTTGTAGAGCAGT & RARS2 & Exonic \\
\hline $\begin{array}{c}\text { Chromosome 14: } \\
57973592 \text { - } 57973614\end{array}$ & TTGCATTA [TGGGATATGACT] & TGG & + & 4 & CTGTGGTTCTGTTTTCCTGCTG & GCAGTTTGGGTTCAGGGAG & SLC35F4 & Intronic \\
\hline $\begin{array}{c}\text { Chromosome X: } \\
75062360-75062382\end{array}$ & СTTCATCA [TAGAGTATGACT] & GGG & + & 4 & TGGAAAAAGGGGGATAGGCAT & TCTTCCCACCTGCTATGAAGT & ABCB7 & Exonic \\
\hline $\begin{array}{c}\text { Chromosome 11: } \\
133745438-133745460\end{array}$ & TGTTCTCA [TGGGGAATGACT] & AGG & - & 4 & GGCAGGAGCAGGCAAGAATA & GTAGCAACCCAGGAGTACTGT & RP11-448P19.1 & Intergenic \\
\hline $\begin{array}{c}\text { Chromosome 10: } \\
105967626 \text { - 105967648 }\end{array}$ & TTTGATAT [AGAGGTATGACT] & TGG & + & 4 & AGTGGCCATGGGAGATTGTC & AGCACATAACGCATGCTCAG & $\mathrm{N} / \mathrm{A}$ & Intergenic \\
\hline $\begin{array}{l}\text { Chromosome 4: } \\
\text { 41570773 - 41570795 }\end{array}$ & ATTGGCCA [TGGGGTGTGACT] & TGG & + & 4 & ATCCTGGTTGGACCTGTGC & ACCCTAACGAACAGTCCTCCA & LIMCH1 & Intronic \\
\hline
\end{tabular}

Table S1. Predicted off-target effects of the 5'-TTTGATCATGGGGTATGACT -3 ' sgRNA sequence using ccTOP CRISPR/Cas9 target online predictor program. 


\begin{tabular}{|c|c|c|}
\hline Gene & Forward Primer Sequence & Reverse Primer Sequence \\
\hline OCT4 & AGTGAGAGGCAACCTGGAGA & ACACTCGGACCACATCCTTC \\
\hline sox2 & GCCCTGCAGTACAACTCCAT & GACTTGACCACCGAACCCAT \\
\hline NANOG & CTGAGATGCCTCACACGGAG & GTGGGTTGTTTGCCTTTGGG \\
\hline PAX6 & GTGAGAGTGGACAGACATCCG & CTGTTCTGCATGCTGGCTCT \\
\hline BRACHYURY & TTCATAGCGGTGACTGCTTATCA & CACCCCCATTGGGAGTACC \\
\hline MESOGENIN & CAGGATGAGGACCTTGGCAG & GGATCTTGGTGAGAGGCTGG \\
\hline TBX6 & СССTACTCGGCTGCATTTCT & GAGCCCACATCCAGATAGCC \\
\hline HES7 & GGAACCCGAAGCTGGAGAAA & CGGAAACCGGACAAGTAGCA \\
\hline UNCX & GGAGAAGGCGTTCAACGAGA & GGAACCAGACCTGAACTCGG \\
\hline TBX18 & CCACCCCGTGTGTACATTCA & TGGCCTTGGTCATCCAGTTC \\
\hline MEOX2 & СTCTGCAAACCAACTGGCAC & AAGAGTTGGAGCACAGGACG \\
\hline PAX3 & AGACTGGCTCCATACGTCCT & CATGCCCGGGTTCTCTCTTT \\
\hline PAX7 & AACCACATCCGCCACAAGAT & СTCCTGGTAGCGGCAAAGAA \\
\hline EN1 & CAGGAACTCAGCCTCAACGA & АCTCGCTCTCGTCTTTGTCC \\
\hline SIM1 & GAGTGGTGTTCCCAGAAGGG & ATCCAGGGTCTGGAGCAGAT \\
\hline LBX1 & GCGGAGAAGTTACTCGCTGT & CCTTAAACGTCTTGCTGGCG \\
\hline TFAP2A & CCAAGTCCAACAGCAATGCC & CGACCCGGAACTGAACAGAA \\
\hline sox10 & CCATCCAGGCCCACTACAAG & GCTCTGGCCTGAGGGGT \\
\hline $\begin{array}{l}\text { RPS16 } \\
\text { (Housekeeping) }\end{array}$ & GCTATCCGTCAGTCCATCTCCAA & CСTTCTTGGAAGCCTCATCCAC \\
\hline
\end{tabular}

Table S2. qPCR primer pairs applied to detect relative expression on key markers during skeletal muscle organoid development. 